\title{
The Sea Cucumber Holothuria (Halodeima) atra (Jager, 1833), in South Tarawa Lagoon (Republic of Kiribati): Environmental Variability, Population Biology and Fishing Pressure.
}

Teatim Tamaroa

A thesis submitted as partial fulfilment for the degree of Master of Science in Marine Biology

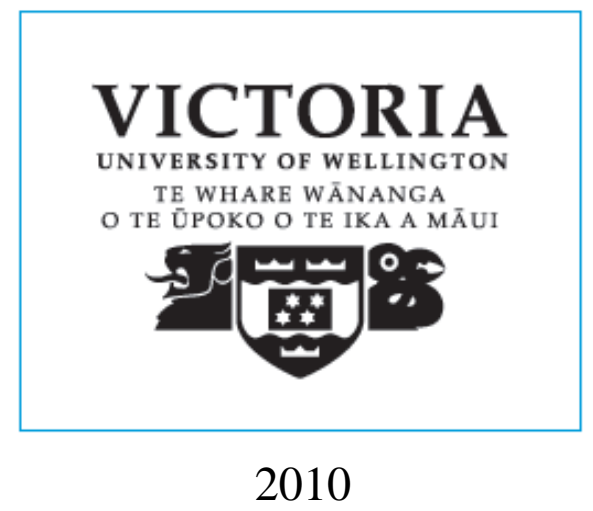




\begin{abstract}
Holothuria atra or lollyfish is the most common sea cucumber in the Pacific and Indian Oceans. The current status of Holothria atra at 13 sites of South Tarawa lagoon (Republic of Kiribati) was established by using biological surveys and fishers' questionnaires. A preliminary investigation was conducted in order to assess how and why environmental variability and fishing pressure have affected the spatial and temporal distribution, mean abundant and mean size of this species at the sites. The 13 sites were selected randomly, and marked with a GPS on the map of South Tarawa. Sedimentary characteristics were determined for each site, and a qualitative assessment of sites health was made. Lollyfish length, biomass and abundance and transect density were calculated for each site. The weight of organic matter content and size of sediment sample were determined. Data were analysed using KruskalWalis (KW) and Repeated measures (RM) ANOVA tests. This thesis shows that the environmental variability could not offer reasons as to why the biological data of lollyfish varied from one site to another. However, other factors that were tested may explain the variation in biological data. Fishing pressure is one of those parameters that can regulate the lollyfish distribution and density and responses from local fishers indicate that fishing pressure is high and that the lollyfish resource is under considerable harvest pressure. Dissolved oxygen concentration in the water column and in the sediment may be also involved in the variation in lollyfish distribution and density but this was not tested. The findings of this research lead to a number of recommendations for the sustainable harvest of lollyfish in Tarawa lagoon. These include consideration of gear restrictions, lollyfish size and number limits, and the establishment of marine protected areas under co-management arrangements.
\end{abstract}




\section{Acknowledgements}

I'd like to thank:

The New Zealand Government through New Zealand International Development Aid (NZAID) for financing this study. Without such assistance, it would have been impossible for me to complete this research.

My only great and admirable supervisor, Jonathan Gardner, for supporting my studies by providing sharp decisive advice and constructive feedback. To you, Jonathan, you are the greatest leader and supervisor!

My English tutor, Brie Jessen, who had been requested and appointed by my sponsor NZAID to help me throughout my studies. Without your commitment and time into my writing, this thesis would not come at the end. You are a great English teacher. To Sheree Christian, thank you for proof reading my first draft for chapter one, and suggesting ways for it's improvement. Without your wisdom and expertise, chapter one could not be a better chapter.

Staff at the Student Learning Support Services; Ema Sanga, Ruth-DavidsonToumu'a, Liz O'Connor, Debora Laurs, Mary Robert and Dennis Dawson, thank you all for your help in correcting my thesis, and encouraging me to write academically.

Liz Richardson for allowing me to use the whānau room for 24 hours. I would like to thank all my friends in the Āwhina whanau for their help, especially Alex Richardson, Ali Richardson, Natalie Stewart, and Emma Leigh for their spontaneous responses to my questions. To you all, you have taught me to help others. Vinaka vakalevu.

Kabunare's family for providing me with a shelter to rest. Thank you, Kabunare and your family for giving me more time to study. I would also like to thank Tebou, for sharing his room with me as a secondary place to sleep and relaxed. Thank you, Tebou, for your kindness.

Lastly, I would like to thank my brother-in-law Mautaake Tamoa and cousin Raratu Tebuka in Tarawa, who had tirelessly worked with me like remoras during data collecting. Big thank to you two, for your great assistance for without it, this thesis would not come this far. 


\section{CONTENTS}

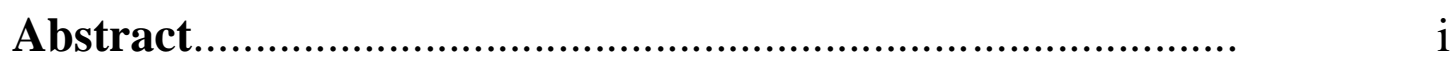

Acknowledgements.......................................................... ii

List of Tables................................................................. vi

List of Figures.................................................................... ix

\section{Chapter One - Introduction}

1.1 - Lollyfish biology .........................................................................

1.2 - Exploitation...............................................................................

1.3 - Socio - economic and ecological significance ……………….............

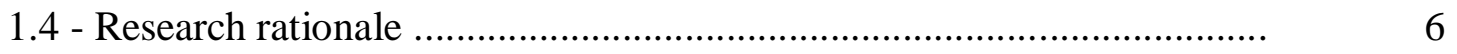

\section{Chapter Two - Material and methods}

2.1- Study site ...........................................................................................

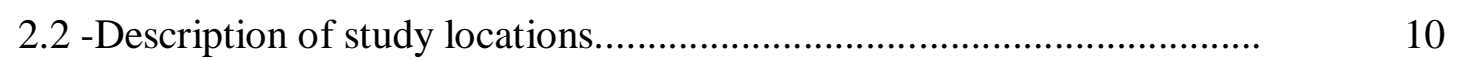

2.3- Biological survey............................................................................... 10

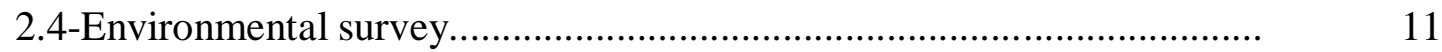

\section{Chapter Three - Results}

3.1 - Biological and Environmental survey.................................................... 16

3.1 .1 - Density.......................................................................... 16

3.1.1.1 - Non-parametric analysis............................ 16

3.1.1.2 - Parametric analysis.................................... 18

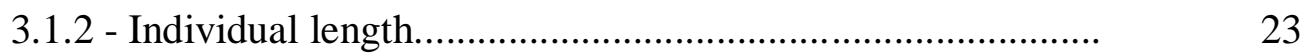

3.1.2.1 - Non-parametric analysis............................ 23

3.1.2.2 - Parametric analysis..................................... 25

3.1.2.3 - Length-frequency distribution.................... $\quad 30$

3.1.3 - Total lollyfish weight..........................................................

3.1.3.1 - Non-parametric analysis.................. 36

3.1.3.2 - Parametric analysis ....................... $\quad 39$ 
3.1.4 - Transect biomass.......................................................................

3.1.4.1 - Non-parametric........................................... 43

3.1.4.2 - Parametric analysis..................................... 46

3.2 - Bottom sediment......................................................................

3.2.1 - Organic matter...................................................................... 51

3.2.2 - Sediment grain size............................................................... 52

3.3 - Linking biological and environmental variables................................... 58

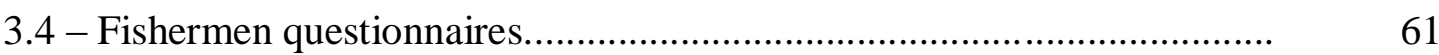

\section{Chapter Four - General discussion and conclusions}

4.1 Introduction.........................................................................................

4.2 Biological and Environmental Survey...................................................

4.2.1 Density distribution..................................................................

4.2.1.1 Non-parametric and parametric analyses...................... $\quad 73$

4.2.1.1.1 Actual mean density...................................... 73

4.2.1.1.1.1 Low - mean density.......................... 73

4.2.1.1.1.2 Medium-mean density..................... $\quad 74$

4.2.1.1.1.3 High-medium density...................... $\quad 76$

4.2.1.1.1.4 Variability in density........................ $\quad 81$

4.2.1.2 Parametric Analyses: Repeated Measures ANOVA ... $\quad 81$

4.2.2 Length distribution............................................................... 82

4.2.2.1 Non - parametric and parametric analyses................... $\quad 83$

4.2.2.1.1 Actual mean-ranked length.............................. 83

4.2.2.1.1.1 Small-mean ranked length............... $\quad 83$

4.2.2.1.1.2 Medium-mean ranked length........... $\quad 84$

4.2.2.1.1.3 Large-mean ranked length................. 84

4.2.2.1.1.4 Variability in length.......................... 84

4.2.2.2 Parametric analyses: Repeated Measures ANOVA.... $\quad 87$

4.2.2.3 Size-frequency distribution......................................... 87

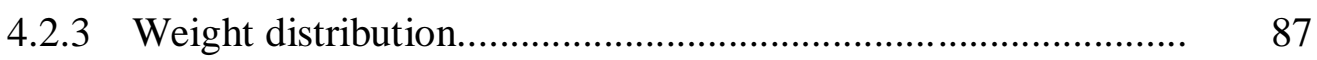

4.2.3.1 Non - parametric analyses............................................ 88 
4.2.3.1.1 Actual mean-weight.................................... 88

4.2.3.1.1.1 The lighter or (low) - weight........ 88

4.2.3.1.1.2 The medium-weight............... 89

4.2.3.1.1.3 Heavy-weight .............................. $\quad 90$

4.2.3.1.1.4 Variability in weight.................... 91

4.2.3.2 Parametric Analyses............................. 93

4.2.4 Biomass distribution......................................................... 95

4.2.4.1Non - parametric analyses........................................ $\quad 95$

4.2.4.1.1 Actual mean biomass................................. 95

4.2.4.1.1.1 Low-mean biomass...................... $\quad 95$

4.2.4.1.1.2 Medium-mean biomass................ 96

4.2.4.1.1.3 High-mean biomass...................... 97

4.2.4.1.1.4 Variability in biomass.................. 99

4.2.4.2 Parametric Analyses ........................... $\quad 99$

4.3. Environmental survey.......................................... 100

4.3.1 Organic matter contents................................................ 100

4.3.1.1 Density................................................................... 100

4.3.1.2 Length............................................................. 100

4.3.1.3 Weight.............................................................. 101

4.3.1.4 Biomass..................................................................... 101

4.3.2 Sizes of sediment..................................... 101

4.3.2.1 Density....................................... 102

4.3.2.2 Length......................................... $\quad 102$

4.3.2.3 Weight.......................................... 102

4.3.2.4 Biomass....................................... 102

$4.4 \quad$ Summary Paragraph........................................ 103

4.5 Fishing Pressure ............................................. 103

4.4.1 Variability in distribution and abundance ... .................... 103

4.6 Conclusions and Recommendations................................................. 105 
References.

CD

1. Abundance of Holothuria atra at South Tarawa during the three days surveys.

2. LS 13320 Software for the Laser particle sizer.

3. Fishermen questionnaires

4. Analysis of the Holothuria atra population density, length, weight and biomass

5. Sediment sizes obtained from South Tarawa (Republic of Kiribati).

6. Analysis of the questionnaires. 


\section{List of Tables}

Page

\section{Chapter Two}

Table 1. Names, position and health descriptions of the sites

in Tarawa lagoon

\section{Chapter Three}

Table 2. Lollyfish density - Kruskal-Wallis test for differences

amongst sites: multiple comparison (p-value) results.

Results in red are significant $(\mathrm{p}<0.05)$

Table 3. Lollyfish density - Repeated measures ANOVA of

differences amongst sites. Results in red are significant

Table 4. Lollyfish density - Mean. Standard error and 95\%

confidence intervals for site-specific values

Table 5. Lollyfish density - Bonferroni test for differences amongst sites: multiple comparison ( $\mathrm{p}$-values) results.

Results in red significant $(\mathrm{p}<0.05)$

Table 6. Lollyfish length - Kruskal-Wallis test for differences amongst sites : multiple comparison ( $\mathrm{p}$-values) results. Results in red are significant $(\mathrm{p}<0.05)$

Table 7. Lollyfish length - Repeated measures ANOVA on the effects of sites, week, and site by week interaction. Results in red are significant $(\mathrm{p}<0.05)$

Table 8. Lollyfish length - Mean, standard error and $95 \%$ confidence interval for site-specific values.

Table 9. Lollyfish length - Bonferroni test for differences amongst sites, weeks, and site by weeks : multiple comparison (p-value) results. Results in red are significant $(\mathrm{p}<0.05)$

Table 10. Lollyfish weight - Kruskal-Wallis test for differences amongst sites:multiple comparison (p-values) results. Results in red are significant $(\mathrm{p}<0.05$.

Table 11. Analysis of variance on the effect of site, week and week by site interaction. Results in red are significant $(\mathrm{p}<0.05)$ 
Table 12. Values of the least squares mean of the weight amongst the

13 sites .42

Table 13. Lollyfish total weight - Bonferroni test for differences amongst the sites: multiple comparison (p-values) results. Results in red are significantly different $(p<0.05$.

Table 14. Transect biomass - Kruskal-Wallis test for differences amongst sites: multiple comparison (p-values) results. Results in red are significantly different $(\mathrm{p}<0.05)$.

Table 15. Repeated measures ANOVA of mean transect biomass as function of site and time. Results in red are significant $(\mathrm{p}<0.05)$ 46

Table 16. Mean transect biomass, standard error and the $95 \%$ confidence interval.

Table 17. Transect biomas - Bonferroni test for differences amongst sites : multiple comparison results. Results in red are significantly different $(\mathrm{p}<0.05)$

Table 18. Ranking of sites according to the size of the sediment exists in each site

Table 19. Summary of dry, organic matter content and percentage organic matter content of sediment samples collected from each of the 13 sites.

Table 20. Details of the grain analysis of sediment from 13 sites in Tarawa lagoon 53

Table 21. Correlation between biological and environmental variability....... 59

Table 22. Comparative densities and biomas of lollyfish 72 


\section{List of Figures}

\section{Chapter One}

Figure 1 Photo of Holothuria atra on the seagrass bed

\section{Chapter Two}

Figure 2 Map of Tarawa Atoll and the locations of the 13 sites studied...

\section{Chapter Three}

Figure 3 Variation in mean density of lollyfish among the 13 sites ......

Figure 4 Variation in mean density of lollyfish among the 13 sites ......

Figure 5 Variation in mean density of lollyfish at the three weeks

Figure 6 Variation in mean density of lollyfish at week bweteen site interactions

Figure 7 Variation in mean length of lollyfish among the 13 site.

Figure 8 Variation in mean length of lollyfish among the 13 site........

Figure 9 Variation in mean length of lollyfish at the three weeks.......

Figure 10 Variation in mean length of lollyfish at week by site interactions

Figure 11 Variation in length-frequency plots of lollyfish among the 13 sites.

$30-36$

Figure 12 Variation in mean weight of lollyfish among the 13 sites ......

Figure 13 Variation in mean weight of lollyfish among the 13 sites.....

Figure 14 Variation in mean weight of lollyfish at the 3 week...............

Figure 15 Variation in mean weight of lollyfish at week by site interaction.

Figure 16 Variation in biomass of lollyfish among the 13 sites....

Figure 17 Variation in biomass of lollyfish among the 13 sites

Figure 18 Variation in biomass of lollyfish at the 3 weeks

Figure 19 Variation in biomass of lolyfish at week by site interaction

Figure 20 Relationship of percentage organic matter verses geography

Figure 21 Relationship of particle size verses differential volumes for the sites 
Figure 22 Projection of site groupings based on six environmental

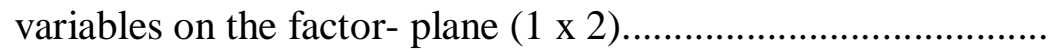

Figure 23 Projection of site groupings based on four biological variables on the factor-plane $(1 \times 2)$

Figure 24 Projection of the six environmental variables on

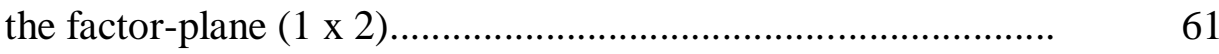

Figure 25 Sites use for collecting lollyfish................................................. 63

Figure 26 Responses to the question - How long have you been collecting lollyfish at this site $64-66$

Figure 27 Sites where collecting lollyfish used to occur. 


\section{CHAPTER ONE}

\section{INTRODUCTION}

\section{1 - Lollyfish biology}

Taxonomically, sea cucumbers belong to the phylum Echinodermata, class Holothuroidae, order Aspidochirotidae, family Holothuriida and the genera Holothurian. There are about 1250 species of sea cucumber in the world of which more than 36 species are extensively fished in the Pacific. Lollyfish or Holothuria (Halodeima) atra (Jäger 1833) is a tropical holothurian species, which is also heavily harvested and is the focus of this thesis (see Fig 1).

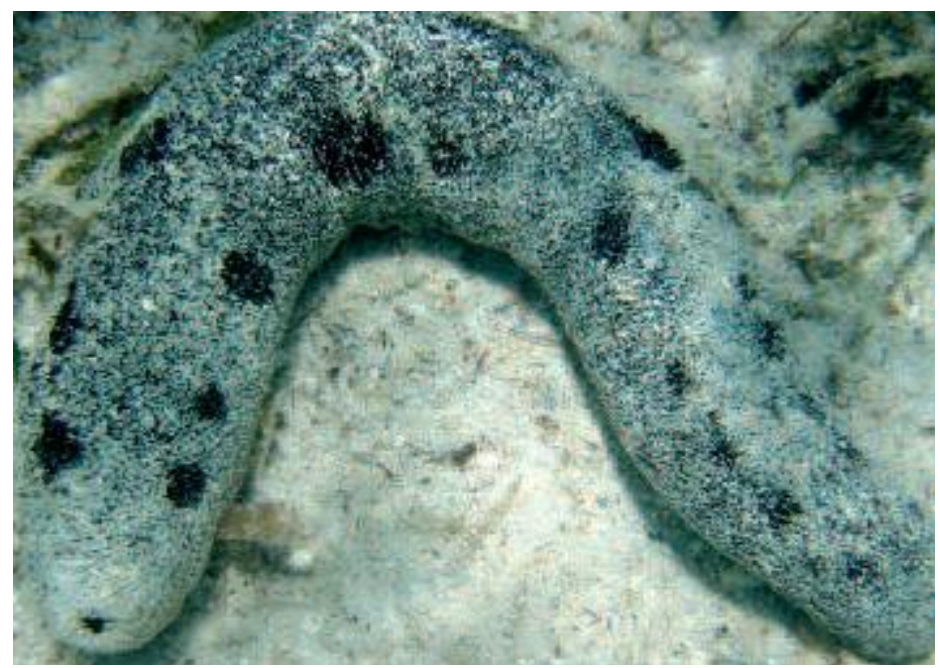

Figure 1. Holothuria atra or lollyfish is commonly found in sandy and rubble-filled habitats and even in seagrass beds in Tarawa's lagoon. Photo is modified from S. Purcell, WorldFish Center.

Lollyfish are widely distributed in the tropical Pacific and Indian Oceans, as far west as the Red Sea. This species is abundant in many places, including the Republic of Kiribati (Paulay 2000), Marshall Islands (Bakus 1968), Vanuatu (Baker 1929), New Caledonia (Conand 1993), Palau (Yamanouchi 1939), northern Australia (Stephenson, Endean et al. 1958; Lee, Byrne et al. 2008), Papua New Guinea (Massin and Doumen 1986), the Taiwan (Chao, Chen et al. 1992), New Reunion (Fabianek 2005) and Egypt (Abdel-Razek, Abdel-Rahman et al. 2005).

Density amongst sea cucumber species is variable from one site or place to another. Paulay (2000) described adults of Holothuria atra inhabiting the sand flat zone of 
South Tarawa lagoon (Kiribati) at a density of $0.83 \pm 0.34(\mathrm{std}=2.98)$ indicating that Holothuria atra are deposit-feeders. The feeding mode for most sea cucumbers involves use of the mouth with several short tentacles for foraging on debris, organic matter, bacteria and single-cell algae that have been deposited in the sand sediments (Conand 1998). Sea cucumbers employ two modes of reproduction - asexual and sexual reproduction (SPC 1994; Conand 1998).

Sea cucumbers exhibit species-specific variability in preferential sites (SPC 1994). Like other sea cucumbers, lollyfish (Holothuria atra) may be common and numerous on many reefs, their densities differing substantially from one site or country to another. For example, in the Marshall Islands the density may attain between 5 to 35 individuals $\mathrm{m}^{-2}$ (Bakus 1973), while in Reunion it is reported at 5.1 to 6.6 individuals $\mathrm{m}^{-2}$ (Fabianek 2005). Even amongst the Pacific Island nations the densities of lollyfish are highly variable (Uthicke, 2001). The variation in density was suggested to be the result of the reproductive strategy of the lollyfish, which may use either sexual (fusion) or asexual (fission) reproduction (Harriott 1985; Chao, Chen et al. 1992; Lee, Byrne et al. 2008). Small size sea cucumbers are normally produced asexually and found in the shallow tide-pools zone in great abundance (Harriott 1982; Chao, Chen et al. 1992). In contrast, large animals are produced sexually (fusion), and found mostly in deep waters at much lower abundance (Chao, Chen et al. 1992; Conand 1998; Lee, Byrne et al. 2008). According to Chao et al. (1992) small body size individuals (ca. $<250 \mathrm{~g}$ ) are found in shallow waters with the depth of less than $0.6 \mathrm{~m}$, while the large size lollyfishs (ca. > $300 \mathrm{~g}$ ) are found in subtidal zones (>0.6 $\mathrm{m})$. Extensive reviews of the reproductive biology of lollyfish have been carried out by researchers (e.g., Conand, 1993; Abdel-Rahman et al., 2005). One of the outcomes of these reviews is the finding of a clear link between reproductive strategy (asexual versus sexual) and the distribution of lollyfish.

\section{2 - Exploitation}

Although lollyfish (Holothuria atra) are widely distributed and are believed to be the most common sea cucumber species in many tropical Indo-Pacific countries (Clark and Rowe 1971; Ebert 1978; Harriott 1980) it is hardly been commercialised because it is a low-value species (Taddei, 2006). However, an unprecedented phase shift from high-value sea cucumber species like white teatfish (Holothuria fuscogilva) and sandfish (Holothuria scabra) to low-value sea cucumber species like Holothuria atra 
is occurring in many parts of the world due to overfishing. As a consequence, lollyfish stocks in many regions are now being exploited and are often marketed under the name bêche-de-mer which means "dried sea cucumbers" (Skewes, 1990; Joseph, 1992; Anon, 2008).

The sea cucumber fishery industry in the Indo-Pacific has existed since the sixteen century (Akamine 2004). It expanded and reached the Western Central Pacific around the seventeen century from Makassar in South Sulawest (Indonesia) (Fox and Sen 2002). Records show that sea cucumber fishers from Makassar have collected and prepared sea cucumbers on the northern shore of Australia in 1803 to the 1880's (Mulvaney 1975; Conand 1990; Purwati 2005). In the early nineteenth century, the sea cucumber trade further expanded from Australia to other Pacific regions mainly to Guam and Fiji (Ward, 1972). The expansion in fishery trade was enhanced with the new arrivals of Europeans and Japanese to the Central Pacific islands. By the early twentieth century, the fishery reached its highest peak and then slowly declined but again increased in the early 1980s (Preston, 1993). Around this time, harvesting of low value sea cucumber species was common in bêche-de-mer industries throughout the Pacific Island Nations. For example, the Solomon Islands (Alexandra 1994), Fiji (Anon. 2008), and Papua New Guinea (Friedman et al., 2008) have exported increasingly more low value sea cucumber species, predominantly the lollyfish Holothuria atra.

This shift from high to low value species reflects the fact that the high value sea cucumbers are currently over-fished and have declined in abundance, and that there is large and unsatisfied consumer demand for this product. Lollyfish are now fished in many islands in the Republic of Kiribati, and like most other nations during recent years, Kiribati has also experienced this same evolution in fishing history for sea cucumbers (Kinch, Purcell et al. 2008) . This fishery sector is currently expanding to all parts of Kiribati (the Line, Phoenix and Gilbert islands) which has resulted in over-fishing and the depletion of lollyfish in Kiribati's coastal waters.

Sea cucumbers are fished by hand collecting, gleaning, lead bomb, SCUBA diving, hookah and dredging (Toral-Granda, Lovatelli et al. 2008). Over-fishing of sea cucumbers has triggered the global community's concern for the preservation of several sea cucumber species before they are depleted. Expression of this concern has been highlighted by FAO (the Food and Agriculture Organisation of the United 
Nations - www.fao.org) through CITES (Convention on International Trade in Endanger Species of Wild Fauna and Flora) for both Stichopodidae and Holothuriidea families to be listed under Appendix II of the Convention in order to be sustainably conserved and managed (Choo, 2008). Because of this growing concern both the FAO and CITES mobilised resources and staged several international workshops related to sea cucumber management, aquaculture, and conservation. It was in the $22^{\text {nd }}$ meeting of the Animals Committee held on $7-13^{\text {th }}$ of July 2006, in Lima (Peru) that a completed summary of findings and conclusion from all FAO and CITES workshops on sea cucumbers were submitted to the Secretariat (Toral-Granda 2006). The full summary of the text can be cited at: (http://www.cites.org/common/com/AC/22/EFS-AC20-Inf01.pdf). This summary highlights how Holothuria atra or lollyfish (which belongs to the family Holothuriidae) is now being over-fished, becoming increasingly rare in the wild.

The depletion of stocks of lollyfish in the waters of any nation raises a numbers of concerns. The first is the loss of various important ecological roles and functions played by this species in ameliorating the conditions and processes of the benthic community. Similar to other benthic dwelling and deposit feeding taxa, lollyfish play vital roles in the recycling of nutrients, including reducing algal growth and biomass through their feeding and bioturbation activities (Moriarty, Pollard et al. 1985; Uthicke 1999). The faeces of these organisms are useful as fertilizers for the marine community (Uthicke, 2001a; Uthicke, 2001b), resulting in better community growth and development (Uthicke, 2001a). Even their slow motions when accompanied by bioturbation activity has been shown to be significant in improving oxygen content and softening of bottom sediments, which in turns makes the ecosystem more habitable for diverse organisms (Bruckner, Johnson et al. 2003; Kitano, Kurata et al. 2003). Finally, lollyfish are capable of improving water quality by removing organic matter from the sediment through ingestion process (Dilek and Denis 2007). The depletion of lollyfish therefore could lead to some profound negative effects on the marine ecology of many shallow tropical coastal environments. The ecological consequences (e.g., changes in biodiversity, tropic interactions, and ecosystem functioning) of lollyfish stock depletion are presently limited in literature, but need to be assessed.

Production and rearing of juvenile sea cucumbers in a hatchery is thought to be one of the best solutions for re-stocking depleted sea cucumber populations. Recently, the 
WorldFish Centre (previously ICLARM) in the Solomon Islands and now in New Caledonia has attempted to rear juveniles of Holothuria scabra (sandfish) in landbased hatchery system for the purpose of restocking the wild (Purcell et al., 2002). Currently, countries like Vietnam, Indonesia, New Caledonia, Solomons Islands, and Australia are using Indian technology to produce new juveniles of this species to rebuild their depleted wild stocks (Battaglene 1999). Holothuria fuscogilva (white teatfish) is another high value sea cucumber species that has been produced and reared in a hatchery in Kiribati (Sato 2000). Unfortunately, the technology in mass producing juveniles of this species is now at its worst state since ten years ago. Difficulties in acquiring broodstock and the lack of technicality were the two reasons for the setback in the technology. High mortality of larvae is the most frequent problem in teatfish production because they are very susceptible to bacteria attacks (Battaglene 1999). At the present time, there is no readily available technology to produce lollyfish in a hatchery, suggesting that lollyfish availability in the wild will continue to decline as a consequence of over-fishing, resulting in associated ecological and socio-economical problems.

\section{3 - Socio-economic and ecological significance}

The importance and benefits of a lollyfish fishery to the people of South Pacific countries are fully integrated in the sustenance of the coastal people (Kinch, James et al. 2007; Kinch, Purcell et al. 2008). In many countries such as the Solomon Islands (Ramofafia, 2004), Papua New Guinea (Kinch, James et al. 2007), and Samoa (Eriksson 2006), the lollyfish fishery is a vital component for the development and improvement in lifestyle and well-being of local people. Monetary values earned by sea cucumber fishers from Asia and Pacific countries are well documented. In a recent socio-economic survey of the sea cucumber fisheries in certain Provinces of Papua New Guinea, Kinch et al. (2007), showed that on average, a fisher could earn between US\$1000-3000 annually from the sale of lollyfish. A fisher from Buton in Southwest Sulawesi could receive between US\$164-3058 per kilogramme as their annual income, once bêche-de-mer are sold on the international market (Asmedi 2009). In contrast, a diver in Vietnam could earn between US\$130-134 per month (Otero-Villanueva and Ut 2007). Reports from the Philippines show that a fisher (middleman) may earn US\$118.43 per month for their dried sea cucumber (Schoppe 2000). Monetary values earned from the fishery of these countries are indicative of variability in financial benefits among their societies that are heterogeneous from one 
country to another. Because of the profound socio-economic and environmental importance of sea cucumbers, it is necessary to manage the resource in a sustainable manner in order to maintain the well-being of the people of the South Pacific.

The depletion of lollyfish from the wild means the loss of economic opportunities and social benefits for the people living close to the coasts of many Pacific Islands (Conand and Byrne 1993; Eriksson 2006). People may become more vulnerable to socio-economical instabilities in many aspects of life because of no means to support them socially and financially. In addition, others may experience destituteness, social and economical insecurity without a sense of belonging. Furthermore, more social and economical problems could be emerging in the near future due to the loss of lollyfish.

In spite of the fact that Aspidochirote sea cucumbers like Holothuria atra are an integral member of the epibenthic community of the flat coastal lagoon of Tarawa (Paulay 2000), they have diverse ecological importance (Dilek and Denis 2007) and financial benefits to lollyfish fishers (Conand and Byrne 1993; Conand 1997). None of them offers scientific data for their current status along the coastal lagoon of South Tarawa. The only available comprehensive data on benthic ecology and biota of Tarawa coastal lagoon has been compiled by Paulay (2000).

\section{4 - Research rationale}

This thesis first establishes the current status of Holothuria atra in South Tarawa Lagoon (Republic of Kiribati) by using biological surveys and fisher's questionnaires to analyze the population density, size, weight and biomass distribution. Information obtained from these two surveys is analysed quantitatively in order to understand the status of Holothuria atra in South Tarawa. In addition, the distribution patterns of lollyfish are quantified in order to determine some of the factors explaining the distribution of this species at the thirteen coastal sites. The general purpose of this research is to investigate the environmental and socio-economic aspects of lollyfish occurrence and exploitation in the lagoon at Tarawa, Republic of Kiribati. New data on sea cucumber population biology and fishing activity are collected and analysed to (1) better understand the population of lollyfish, (2) better understand the exploitation of lollyfish, and (3) to make recommendations to ensure the sustainability of this resource. 
The specific aims of this study can be summarized in three questions:

1. What is the current distribution of Holothuria atra at 13 sites in South Tarawa and how does this relate to environmental variability?

2 How and why does the mean abundance and mean size of this species vary among the sites?

3 Presently and in the recent past, what are the histories of fishing activities of local fishermen, and how might these affect the lollyfish population in the lagoon? 


\section{CHAPTER TWO}

\section{MATERIALS AND METHODS}

\section{1 - Study site}

Tarawa Atoll is in the Gilbert Island group ( $\left.1^{\circ} 30^{\prime} \mathrm{N}, 173^{\circ} 00^{\prime} \mathrm{E}\right)$, in the central Pacific Ocean (Figure 2). The land part is represented by the dark colours, while the clear part represents the sea part. It is the capital of the Republic of Kiribati, and is shaped like a sail of the Kiribati racing canoe. It is divided into two parts: a) the upper part is called north Tarawa or Tarawa Teinaieta and b) the lower part is called the south Tarawa or Tarawa Teinainano, but excludes the island of Betio. The current human population on South Tarawa is approximately 40,331 (43.6\%), of which 12,509 are living on Betio (Kiribati National Statistic Office 2005). This makes Tarawa the most densely populated island of the Republic when considering the 110,000 inhabitants, and also one of the most densely populated pieces of land anywhere in Pacific (Paulay and Alexander 2001).

The effects of high human population density on the environment of South Tarawa are numerous and evident around the island. High population density tends to exert extra pressures on many common vital resources and it may create more environmental problems in the future for the society. Scarcity of basic resources such as potable water, housing, land and food for the people of South Tarawa are a common phenomenon (UNDP 1999). Pollution and littering of marine and land ecosystems and the use of the lagoon for human defecation are common environmental issues encountered in South Tarawa (Thistlewaite and Davis 1996). Human defecation has altered the nutrient balance of the Tarawa lagoon, resulting in an increase in dissolved nutrients such as phosphorus, carbon and nitrogen. Nutrients originating from human waste and equatorial upwelling waters are two sources of nutrients for the biota in Tarawa's lagoon, making it the richest in benthos (diversity and biomass) in the South Pacific (Paulay and Alexander 2001). The lagoon bottom is mostly flat, the substrate is mainly sand to mud, and the lagoon is reasonably shallow: wading through much of it is possible when the tide is low (Paulay 2000). This project consists of two parts: (1) a biological and environmental survey and (2) a fishermen survey. The biological survey addresses the population biology of Holothuria atra, its density, size, biomass and spatial distribution. 


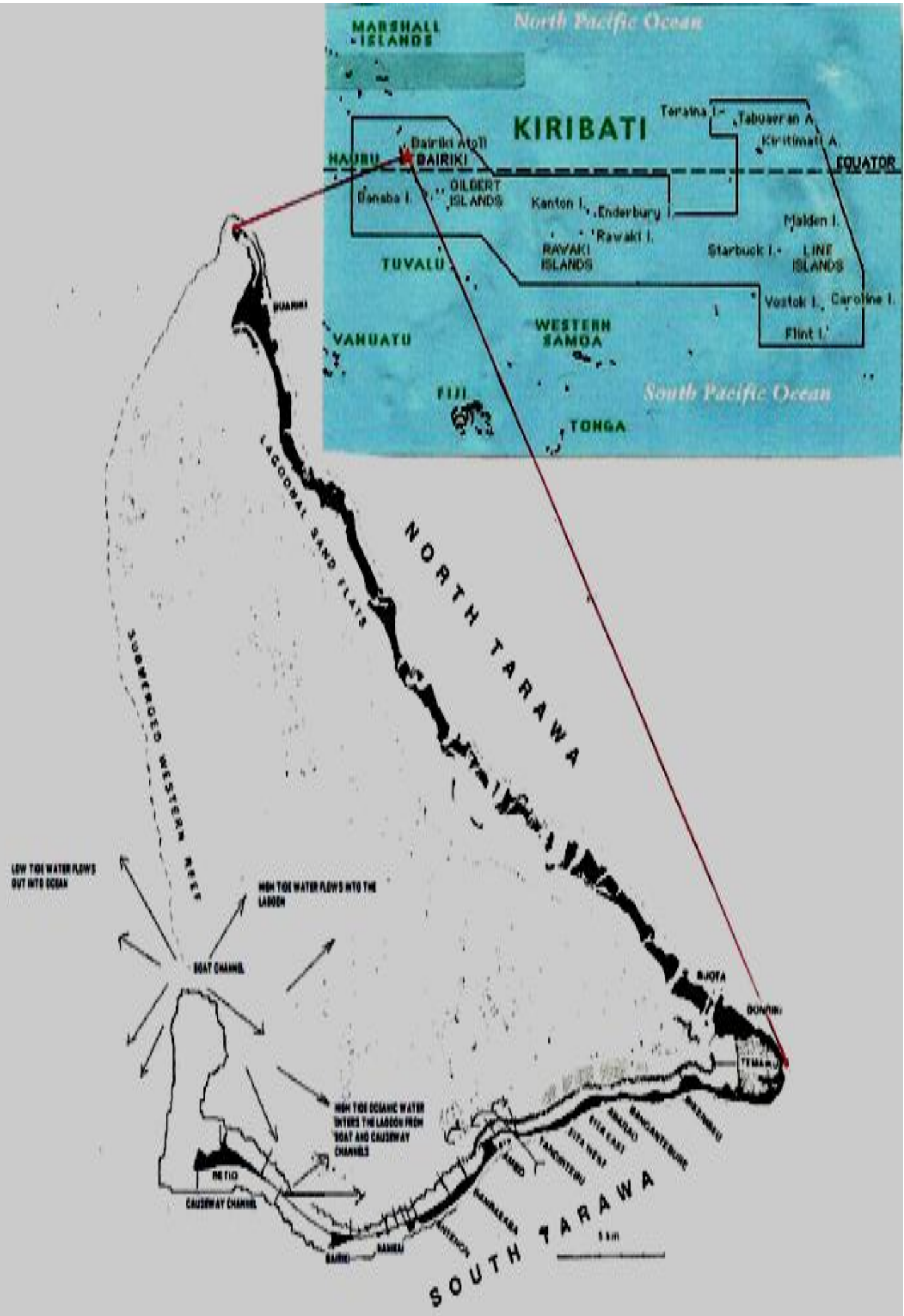

Flgure 2. Map of Tarawa Atoll indicating the locations of the 13 sites studied which are clearly marked by transects (long lines) lagoon. The 13 sand-flat transects are named by the adjacent islets name (see Table I for coordinates of the sites). Thin lines joining islets represent causeways. True North is towards the top of the page. Figure is modified from Pauley (2000). 
The environmental survey deals with sediment samples collection, organic matter determinations, and particle analyses. The second major part of the research is the fishermen survey which involved interviewing the lollyfish fishers about the history of their fishing activities. These fishermen were recruited by "word of mouth". They have provided new information about the sustainability of the sea cucumber Holothuria atra or lollyfish (Figure 1) fishery in South Tarawa. These two separate aspects of my research are brought together to better understand the biology and exploitation of the lollyfish in Tarawa's lagoon, as well as possible environmental impacts of the lagoon's health on the stock of lollyfish.

\section{2 - Description of study locations}

A qualitative survey was carried out at thirteen different sites in South Tarawa's lagoon (Figure 2). After preliminary dive survey work, before data analysis commenced, the sites were categorized according to their perceived environmental health (one of four categories - clean, partially polluted, polluted, and heavily polluted) based on local knowledge of anthropogenic inputs, presence and status of coral colonies and or seagrass beds, and proximity to human habitation (Table 1). Subsequently, these sites were surveyed fortnightly on three occasions $-9^{\text {th }}$ April, $24^{\text {th }}$ April and $8^{\text {th }}$ May 2009. Surveys were mainly carried out during low tides when walking was easier on the mud flats.

\section{3 - Biological survey}

The primary purpose of my research was to investigate the environmental and socioeconomic aspects of the occurrence and exploitation of lollyfish along the shoreline in South Tarawa. Thirteen coastal lagoon sites (polluted or clean - Table 1) were surveyed and evaluated for density, size and blotted wet weight (biomass) of lollyfish. Individuals were measured and studied through quantitative surveys; qualitative examinations of site-specific habitats were also considered.

At each site, the latitude and longitude was recorded on a GPS (Table 1). On the $9^{\text {th }}$ April 2009 (the first survey), a $50 \mathrm{~m}$ transect line was set perpendicular to the shoreline (following the long lines and coordinates in Figure 2). This transect line must be placed at the end of the long line in each site which was close in proximity to first cluster of sea cucumbers. Both ends of the line were held in place with $0.5 \mathrm{~m}$ wooden pegs. On either side of this line, another transect line was set running parallel 
to it at a distance of $1 \mathrm{~m}$ to give a $100 \mathrm{~m}^{2}$ transect (50 $\mathrm{m} \times 2 \mathrm{~m}$ ). Sea cucumbers found inside the $100 \mathrm{~m}^{2}$ were collected and counted. Their individual length was recorded to the nearest centimetre using vernier callipers and the combined weight (blotted wet weight) was measured to the nearest $1 \mathrm{~g}$ on the sand flat (Sewell 1991). Animals were returned to their habitats after measurements had been recorded. In addition to the first transect, three more transects of the same area were carried out (total of 4 replicate transects per site). These transects were spaced out between 5 to $10 \mathrm{~m}$ away from, and were parallel to, the first transect at each site (Figure 2). Lollyfish found in these transects were treated according to the method used in transect one. Similar steps were taken during the second and third surveys which were held on the $24^{\text {th }}$ April and the $8^{\text {th }}$ May 2009, respectively.

Biological data (density, size, individual weight and transect biomass) were analysed by using both non-parametric and parametric approaches. The non-parametric Kruskal-Wallis test $(\mathrm{KW})$ is a distribution-free test based on the testing of ranks, but it does not account for the repeated measures form of the data (i.e., week 1, week 3 , week 5). This is why parametric analysis was also employed. A parametric repeated measures analysis of variance (RM ANOVA) which requires normality and equality of variances (these assumptions were not allows met) has been employed to account for the repeated measures form of the biological data. The Bonferroni test was employed to identify the location of significant differences between sites.

\section{4 - Environmental survey}

\subsection{1 - Sediment}

For sediment organic matter and sediment grain size determinations, a sediment sample at each site was excavated to $3 \mathrm{~cm}$ depth and placed in a plastic bottle. Samples were preserved in a seawater solution of $10 \%$ of formaldehyde. Sediment samples were collected on the $9^{\text {th }}$ April 2009 at the end of transect 1 in each set of transect replicates (biological survey - above). Preserved sediment samples were analysed in New Zealand. These sample sediments were taken from 0.5 to 1 metre depths.

At Victoria University of Wellington (VUW), the sediment samples were divided into two parts for two different analyses in order to determine the content of the organic matter and grain size fractions. First, organic matter content was classified 
qualitatively at the VUW marine laboratory at Island Bay. Each sample was described according to the observed size and nature of particles (fine sand, coral rubble, large pebbles, etc) that it contained. Samples were qualitatively ranked from 1 to 13 according to their perceived sediment homogeneity (1 - most homogeneous fine sand; 13 - most heterogeneous, including material ranging from fine sand, through coral rubble, to large pebbles) on page 51 (Table 18). Quantitative grain size analyses were also conducted on sediment in the range $0-1.4 \mathrm{~mm}$ diameter at the soil laboratory of the Antarctic Research Centre at VUW. This qualitative and quantitative information provides data for categorisation of substrate type and habitat suitability for lollyfish at each site, and may contribute to explaining site-specific differences in lollyfish density, length and biomass. 
Table 1. Names, positions and health descriptions of the 13 sites surveyed in Tarawa lagoon

\begin{tabular}{|c|c|c|c|}
\hline Site & Name & Position & Health description of the 13 sites \\
\hline 1 & Taborio & $\mathrm{N} 01^{\circ} 21.472^{\prime} ; \mathrm{E} 173^{\circ} 03.057^{\prime}$ & $\begin{array}{l}\text { Clean: Only one house exists here. Water renewed from the water bore } \\
\text { originates from the ocean side seeping under causeway. Many live corals } \\
\text { and much rubble exist here. }\end{array}$ \\
\hline 2 & Ambo & $\mathrm{N} \mathrm{01}{ }^{\circ} 21.445^{\prime} ;$ E $173^{\circ} 02.679^{\prime}$ & $\begin{array}{l}\text { Clean: Close to the causeway so receives adequate amount of good water } \\
\text { from the bore water. Plenty of seagrass, little litter and few houses. }\end{array}$ \\
\hline 3 & Banraeaba & 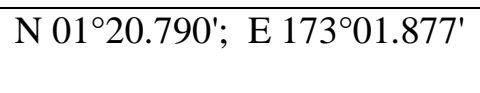 & $\begin{array}{l}\text { Partially polluted: Beach is littered with human faeces and rubbish. } \\
\text { Seagrass beds are well established but further from the shoreline. }\end{array}$ \\
\hline 4 & Tengaruru & N 01²0. 630'; E 17301.729' & $\begin{array}{l}\text { Polluted: Lagoon is littered with rubbish, car bodies and faeces. It is close } \\
\text { to } 2 \text { car companies (Lagoon Motors and Tarawa Motors) but water } \\
\text { become clear further from the shore. Seagrass beds are found close from } \\
\text { shoreline. }\end{array}$ \\
\hline 5 & Teaoraereke 3 & 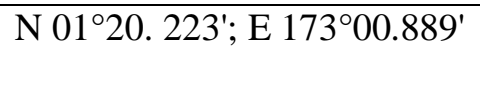 & $\begin{array}{l}\text { Partially-polluted: Lagoon is heavily littered with rubbish and has a high } \\
\text { population density along its shore. Seagrass beds are closer to shoreline }\end{array}$ \\
\hline 6 & Teaoraereke 2 & 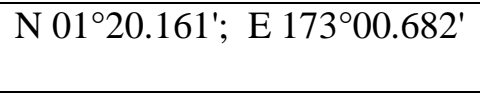 & $\begin{array}{l}\text { Partially polluted: Due to high human habitation, marine litter is } \\
\text { everywhere along the beach. Seagrass beds are close to shoreline. }\end{array}$ \\
\hline 7 & Teaoraereke 1 & $\mathrm{~N} 01^{\circ} 20.037^{\prime} ; \mathrm{E} 173^{\circ} 00.346^{\prime}$ & $\begin{array}{l}\text { Partially polluted: Due to dumping of rubbish in the main channel of } \\
\text { Catholic dock and close to } 2 \text { national landfills. Seagrass beds are close to } \\
\text { shoreline. }\end{array}$ \\
\hline 8 & Nanikai 2 & N 01⒛ 017'; E $173^{\circ} 00.123^{\prime}$ & $\begin{array}{l}\text { Highly polluted: Due to effluent and leachates from the landfill leaching } \\
\text { to the lagoon where sea grass is covered with live and dead brown algae. } \\
\text { Anadara uropigimelana is abundant in the soft sand. Dumping ground } \\
\text { during colonial times and is close to national } 2 \text { landfills. }\end{array}$ \\
\hline 9 & Nanikai 1 & N 01⒚969'; E 17259.991' & $\begin{array}{l}\text { Clean: Dense sea grass mats covered with brown algae. Nanikai used to } \\
\text { be a national landfill and dumping ground during Colonial times. }\end{array}$ \\
\hline 10 & Bairiki & 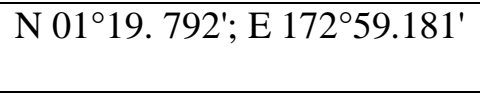 & $\begin{array}{l}\text { Clean: Bottom sediment full with dead brown algae. Bottom sediment is } \\
\text { muddy. }\end{array}$ \\
\hline 11 & Taiwan Park & 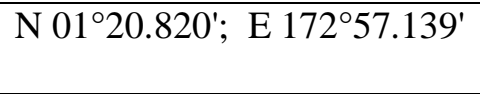 & $\begin{array}{l}\text { Clean: Water renewed daily from the channel, plenty of rubbles and } \\
\text { coarse sands are white. Water is flowing fast during high and low tide. }\end{array}$ \\
\hline 12 & Terawabono & $\mathrm{N} 01^{\circ} 21.820^{\prime} ;$ E $172^{\circ} 55.776^{\prime}$ & $\begin{array}{l}\text { Highly polluted: High concentration of leachates such as TBT from } \\
\text { landfill, and from the Shipyard company. Relics from WW II are visible at } \\
\text { low tide. }\end{array}$ \\
\hline 13 & Temakin & N 0121. 208'; E 17255.091' & Highly polluted: High concentration of effluents from public sewage. \\
\hline
\end{tabular}




\subsection{2 - Organic matter content}

Determination of weight of sediment organic matter (and thereafter percent organic matter - POM) was determined by the weight loss on ignition method. At the marine laboratory at Island Bay, initial weights of 13 aluminium trays were measured to four decimal places using an electronic balance. A small subsample of wet sediment from each sample was placed on the preweighed aluminium trays and placed inside the oven at a temperature of $60^{\circ} \mathrm{C}$ for $48 \mathrm{~h}$ to dry. Samples were fully dried after $48 \mathrm{~h}$. The dried samples were weighed. They were then transferred into the muffle oven where organic materials burned off at $450-500^{\circ} \mathrm{C}$ for $24 \mathrm{~h}$, leaving only ash (inorganic material) in the trays. Trays containing ash were weighed to four decimal places. The weight loss on ignition or AFDW (ash free dry weight) is then calculated using the following formula:

$$
\mathrm{LOI}_{500}=\left[\left(\mathrm{DW}_{60}-\mathrm{DW}_{500}\right) / \mathrm{DW}\right] \times 100
$$

where $\mathrm{LOI}_{500}$ represents the loss on ignition at 500 (as a percentage), $\mathrm{DW}_{60}$ is the dry weight of the sample before combustion and $\mathrm{DW}_{500}$ represents the dry weight of the sample after heating to $500^{\circ} \mathrm{C}$ (both in $\mathrm{g}$ ). The weight loss then should be equivalent to the amount of organic matter present in the sample (Dean 1974).

\subsection{3 - Particle size analysis}

Particle sizing of sediments from the thirteen sites was conducted using a Beckman Coulter LS 13320 Laser Diffraction Particle Size Analyser. Sediment samples were first sieved through a $1.4 \mathrm{~mm}$ sieve into a $100 \mathrm{ml}$ beaker. A spray of distilled water from the wash bottle was added to speed up the sieving process. Approximately three teaspoons of each sediment sample was sieved and delivered into the sample delivery tube of the Laser machine to be analysed. A graphical representation of each of the analysed samples was computed indicating the mean, median, standard deviation, $10^{\text {th }}$ percentile $\left(\mathrm{d}_{10}\right)$ and $90^{\text {th }}$ percentile $\left(\mathrm{d}_{90}\right)$.

This Laser Particle Sizer measures the particle size using the technique of laser diffraction. This technique relies on the behaviour of particles as they disperse in a multi-directional path with variable intensity. This behaviour is a function of particle size, assuming that the material has a spherical shape. By focusing a laser beam at the measured material, the dispersal of the cluster of particles is limited and equal to the sum of the individual scattering patterns of all particles that exist. By using an optical 
model to compute scattering patterns for unit volumes of particles in selected size classes, a volumetric particle size distribution can be calculated.

\section{4 - Fishermen questionnaire}

Tarawa fishermen of the lollyfish who live at or near to the thirteen sites were interviewed in order to gather information about the past history and present status of their fishing activities. A total of twenty fishermen, predominantly males of ages 30 to 50 , responded to the questionnaire. These fishermen were recruited by "word of mouth”. Each questionnaire of 19 questions (see CD- Fishermen's questionnaire) lasted about twenty minutes. Questions were answered individually with oral responses which were written down by me and volunteer helpers that were recruited specifically for the task.

During this interview, the fishermen were asked to respond to 19 questions concerning information about their fishing sites (old and new), fishing times (month of high and low catches), water depths (mean, minimum and maximum), sizes of sea cucumber (mean, maximum and minimum), frequency of their fishing, reason for their fishing and their opinion about the cause for the decrease in lollyfish stocks.

The focus of these questions was to gather information to determine if fishing activities had had an influence on the present distribution patterns, density, biomass, stock and status of lollyfish at these coastal sites of Tarawa's lagoon. The results of this survey should point out to whether the lollyfish fishery is sustainable or not. If the fishery is not sustainable then recommendations will be stated in this project in a measure to maintain the lollyfish sustainability. 


\section{CHAPTER THREE}

\section{RESULTS}

\section{1 - Biological and Environmental Survey}

\subsection{1 - Density}

\subsubsection{1 - Non-parametric analysis}

The Kruskal-Wallis test revealed that there were significant differences in density (numbers of lollyfish $\mathrm{m}^{-2}$ ) amongst the 13 sites $(\mathrm{p}<0.0001)$ and the location of differences is given in Table 2. The mean ranked densities of lollyfish were highest at Taiwan Park (Rank - 139.25; Number - 1824), and lowest at Terawabono (Rank 8.71; Number - 4) (see CD 4- Analysed biological data).

Based on variation in the actual mean density amongst the 13 sites, Figure 3 reveals the existence of three different groupings of populations: low density (Temakin, Terawabono, Bairiki, and Nanikai 1, Nanikai 2, Teaoraereke 1), (b) medium density (Teaoraereke 2, Teaoraereke 3, Banraeaba), and (c) high density (Ambo, Taborio, and Taiwan Park). These variations in the actual densities differed according to their mean values, with $<0.3 \mathrm{~m}^{-2}$ for low, $0.3-1.0 \mathrm{~m}^{-2}$ for medium and $>1.0 \mathrm{~m}^{-2}$ for high. Figure 3 also highlights three different groupings of populations existed based on the variability of the density among transects and/or samples. This variability in density is categorized into three groups: (a) low (Temakin, Terawabono, Bairiki and Nanikai 1), (b) medium (Nanikai 2, Teaoraereke 1, Teaoraereke 2, Teaoraereke 3, Tengaruru, Ambo and Taborio), (c) high (Taiwan Park and Banraeaba). 
Table 2. Lollyfish density - Kruskal-Wallis test for differences amongst sites: multiple comparison (p values) results. Results in red are significant $(\mathrm{p}<0.05)$

\begin{tabular}{|c|c|c|c|c|c|c|c|c|c|c|c|c|c|}
\hline $\begin{array}{l}\text { Depend } \\
\text { Density }(N m-2)\end{array}$ & $\begin{array}{l}\text { Temakin } \\
\text { R:20.333 }\end{array}$ & $\begin{array}{c}\text { Terawabono } \\
\text { R:8.7083 }\end{array}$ & $\begin{array}{c}\text { Taiwan } \\
\text { Park } \\
\text { R:139.25 } \\
\end{array}$ & $\begin{array}{c}\text { Bainiki } \\
\text { R:47.958 }\end{array}$ & $\begin{array}{l}\text { Nanikai 1 } \\
\text { R:35.833 }\end{array}$ & $\begin{array}{l}\text { Nanikai 2 } \\
\text { R:45.000 }\end{array}$ & $\begin{array}{c}\text { Teacraereke } \\
1 \\
\text { R:66.167 } \\
\end{array}$ & $\begin{array}{c}\text { Teaoraereke } \\
2 \\
\text { R:89.333 } \\
\end{array}$ & $\begin{array}{c}\text { Teaoraereke } \\
3 \\
\text { R: } 85.583 \\
\end{array}$ & $\begin{array}{l}\text { Tengaruru } \\
\mathrm{R}: 137.33\end{array}$ & $\begin{array}{c}\text { Banraeaba } \\
\text { R:92.375 }\end{array}$ & $\begin{array}{c}\text { Ambo } \\
\text { R:129.33 }\end{array}$ & $\begin{array}{l}\text { Taborio } \\
\text { R:123.29 }\end{array}$ \\
\hline Temakin & & 1.000000 & 0.000000 & 1.000000 & 1.000000 & 1.000000 & 1.000000 & 0.014289 & 0.031470 & 0.000000 & 0.007318 & 0.000000 & 0.000002 \\
\hline Terawabono & 1.000000 & & 0.000000 & 1.000000 & 1.000000 & 1.000000 & 0.143306 & 0.000963 & 0.002396 & 0.000000 & 0.000446 & 0.000000 & 0.000000 \\
\hline Taiwan Park & 0.000000 & 0.000000 & & 0.000058 & 0.000002 & 0.000025 & 0.005784 & 0.530456 & 0.282121 & 1.000000 & 0.860872 & 1.000000 & 1.000000 \\
\hline Bainiki & 1.000000 & 1.000000 & 0.000058 & & 1.000000 & 1.000000 & 1.000000 & 1.000000 & 1.000000 & 0.000098 & 1.000000 & 0.000799 & 0.003445 \\
\hline Nanikai 1 & 1.000000 & 1.000000 & 0.000002 & 1.000000 & & 1.000000 & 1.000000 & 0.290386 & 0.545071 & 0.00 & 0.169413 & 0.000031 & 0.000165 \\
\hline Nanikai 2 & 1.000000 & 1.000000 & 0.000025 & 1.000000 & 1.000000 & & 1.000000 & 1.000000 & 1.000000 & 0.0 & 6367 & 0.000376 & 0.001706 \\
\hline Teaoraereke 1 & 1.000000 & 0.143306 & 0.005784 & 1.000000 & 1.000000 & 1.000000 & & 1.000000 & 1.000000 & 0.008895 & 1.000000 & 0.047980 & 0.152339 \\
\hline Teaoraereke 2 & 0.014289 & 0.000963 & 0.530456 & 1.000000 & 0.290386 & 1.000000 & 1.000000 & & 1.000000 & 0.721807 & 1.000000 & 1.000000 & 1.000000 \\
\hline Teaoraereke 3 & 0.031470 & 0.002396 & 0.282121 & 1.000000 & 0.545071 & 1.000000 & 1.000000 & 1.000000 & & 0.391435 & 1.000000 & 1.000000 & 1.000000 \\
\hline Tengarunu & 0.000000 & 0.000000 & 1.000000 & 0.000098 & 0.000003 & 0.000043 & 0.008895 & 0.721807 & 0.3 & & 1.000000 & 1.000000 & 1.000000 \\
\hline Banraeaba & 0.007318 & 0.000446 & 0.860872 & 1.000000 & 0.169413 & 0.796367 & 1.000000 & 1.000000 & & & & 1.000000 & 1.000000 \\
\hline Ambo & 0.000000 & 0.000000 & 1.000000 & 0.000799 & 0.000031 & 0.000376 & 0.047980 & 1.000000 & 1.000000 & 1.000000 & 1.000000 & & 1.000000 \\
\hline Taborio & 0.000002 & 0.000000 & 1.000000 & 0.003445 & 0.000165 & 0.001706 & 0.152339 & 1.000000 & 1.000000 & 1.000000 & 1.000000 & 1.000000 & \\
\hline
\end{tabular}




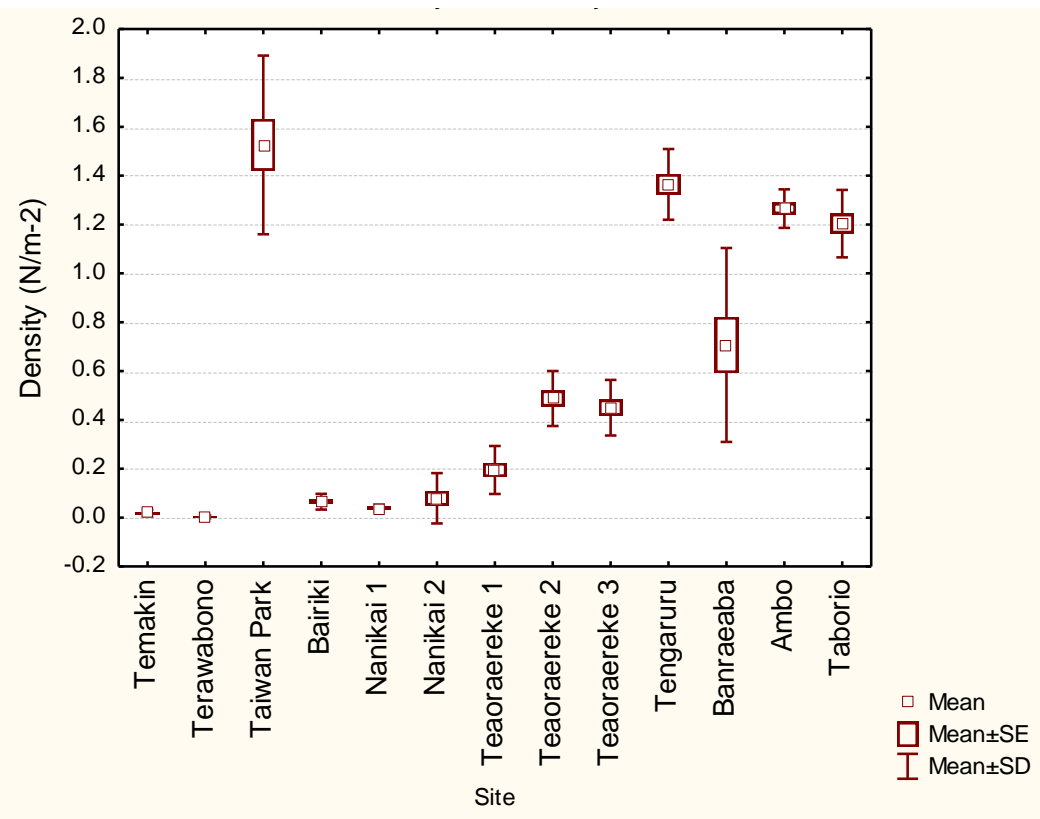

Figure 3. Variation in the actual mean density and standard deviation of lollyfish observed amongst the 13 sites at Tarawa's lagoon.

\subsubsection{2 - Parametric analysis}

The repeated measures ANOVA reveals that there are differences in density of lollyfish amongst 13 sites, amongst the three weeks, and between the week by site interactions (Table 3).

Table 3. Lollyfish density - Repeated measures ANOVA of differences among sites

\begin{tabular}{|l|l|l|l|l|l|}
\hline Effect & SS & $\begin{array}{l}\text { Degree of } \\
\text { freedom }\end{array}$ & MS & F & P \\
\hline Intercept & 501727.0 & 1 & 501727.0 & 1230.554 & 0.000000 \\
\hline Site & 485085.4 & 12 & 40423.8 & 99.145 & 0.000000 \\
\hline Error & 15901.3 & 39 & 407 & & \\
\hline WEEK & 650 & 2 & 325.2 & 7.183 & 0.001370 \\
\hline WEEK*SITE & 21161.4 & 24 & 881.7 & 19.475 & 0.000000 \\
\hline Error & 3531.5 & 78 & 45.3 & & \\
\hline
\end{tabular}


From Table 3, the p-value for repeated measures in the average density of lollyfish amongst the sites is 0.000001 which is less than $5 \%$ and thus the variation in average density among the sites is highly significantly different. Figure 4, Figure 5 and Figure 6 show similar trends in the variation in the mean density amongst 13 sites, among the three weeks, and at week by site interactions, respectively.

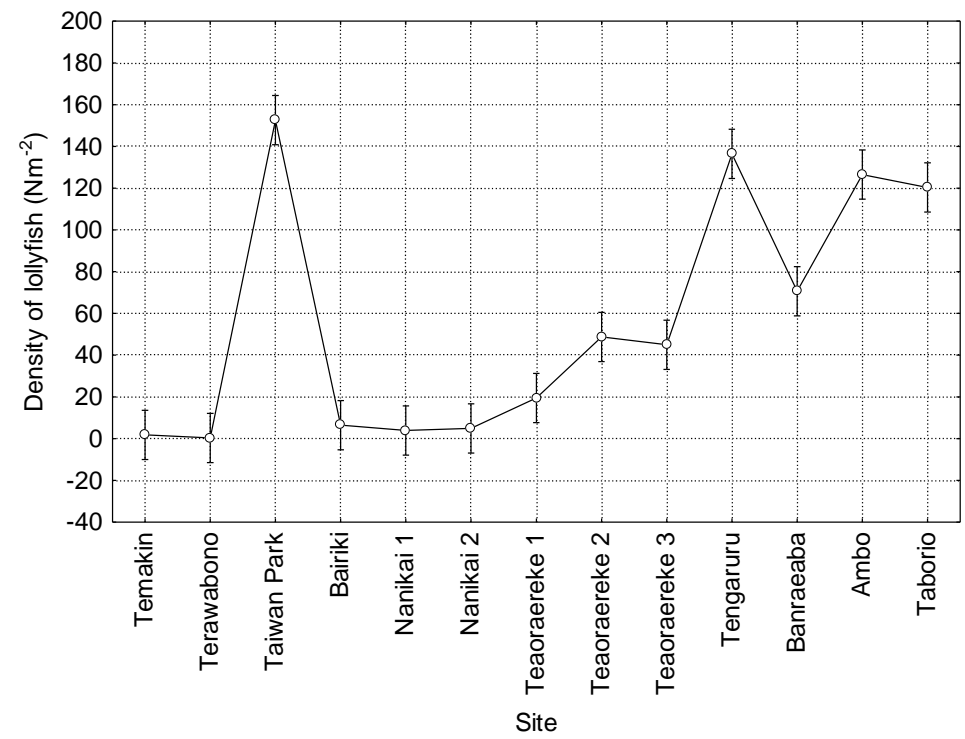

Figure 4. Variation in mean-density of lollyfish amongst the 13 sites with vertical bars denoting 0.95 confidence intervals. 


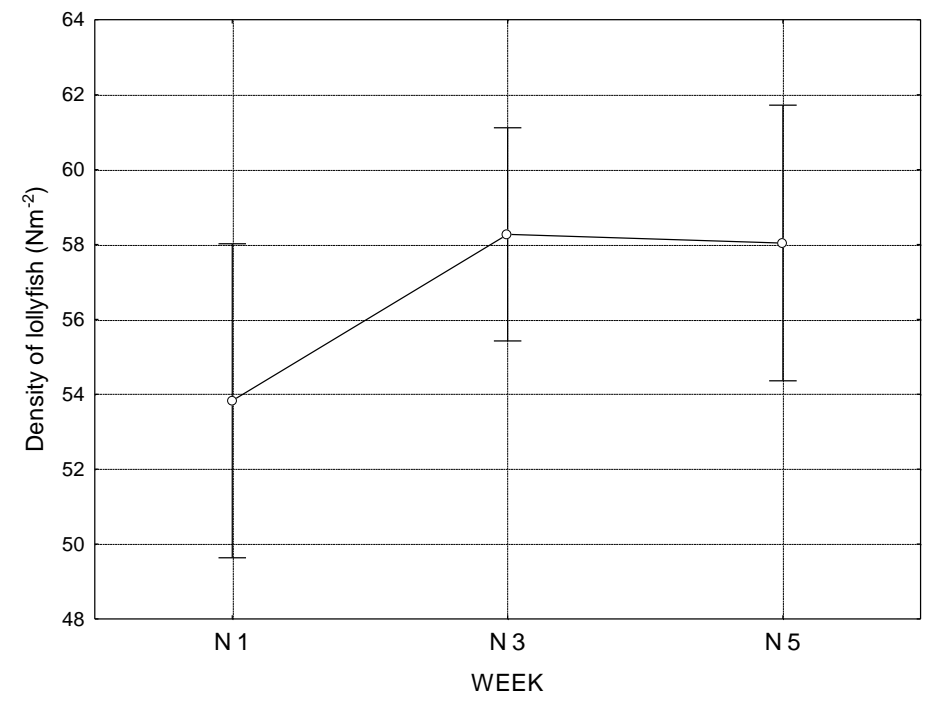

Figure 5. Variation in mean density of lollyfish among the three weeks with vertical bars denoting 0.95 confidence intervals.

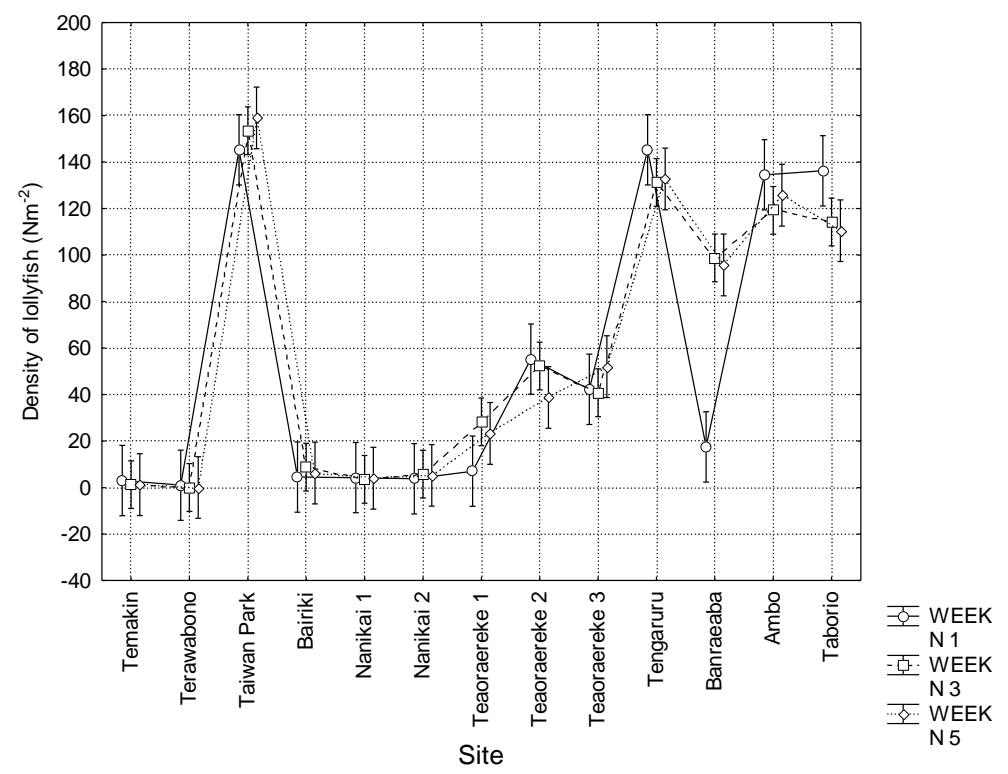

Figure 6. Variation in mean density of lollyfish at week-by-site interactions with vertical bars denoting 0.95 confidence intervals.

The relationship in the mean density of lollyfish among 13 sites, 3 weeks and week by site interaction are strongly significantly different. The main contributing difference here appears to be the low density of lollyfish at Banraeaba in week one. 
Table 4. Lollyfish density - Mean, standard error and 95\% confidence intervals for site-specific values

\begin{tabular}{|c|c|c|c|c|c|c|}
\hline Cell No. & Site & $\begin{array}{l}\text { DV_1 } \\
\text { Mean }\end{array}$ & $\begin{array}{c}\text { DV_1 } \\
\text { Std.Err. }\end{array}$ & \begin{tabular}{c|} 
DV_1 \\
$-95.00 \%$ \\
\end{tabular} & $\begin{array}{c}\text { DV_1 } \\
+95.00 \% \\
\end{array}$ & $\mathrm{~N}$ \\
\hline 1 & Temakin & 1.8333 & 5.828982 & -9.9569 & 13.6236 & 4 \\
\hline 2 & Terawabond & 0.3333 & 5.828982 & -11.4569 & 12.1236 & 4 \\
\hline 3 & Taiwan Park & 152.5833 & 5.828982 & 140.7931 & 164.3736 & 4 \\
\hline 4 & Bairiki & 6.5000 & 5.828982 & -5.2902 & 18.2902 & 4 \\
\hline 5 & Nanikai 1| & 3.9167 & 5.828982 & -7.8736 & $15.706 \mathrm{~g}$ & 4 \\
\hline 6 & Nanikai 2 & 4.9167 & 5.828982 & -6.8736 & $16.706 \mathrm{~g}$ & 4 \\
\hline 7 & Teaoraereke $1 \mid$ & 19.5000 & 5.828982 & 7.7098 & 31.2902 & 4 \\
\hline 8 & Teaoraereke 2 & 48.7500 & 5.828982 & 36.9598 & 60.5402 & 4 \\
\hline 9 & Teaoraereke 3 & 45.0000 & 5.828982 & 33.2098 & 56.7902 & 4 \\
\hline 10 & Tengaruru| & 136.4167 & 5.828982 & 124.6264 & 148.2069 & 4 \\
\hline 11 & Banraeaba & 70.6667 & 5.828982 & 58.8764 & 82.4569 & 4 \\
\hline 12 & Ambo & 126.5000 & 5.828982 & 114.7098 & 138.2902 & 4 \\
\hline 13 & Taborid & 120.3333 & 5.828982 & 108.5431 & 132.1236 & 4 \\
\hline
\end{tabular}

Table 4 shows significantly different values of the least squares means for the average density of lollyfish among the 13 sites. Table 4 shows six sites having a low average density (Temakin, Terawabono, Bairiki, Nanikai 1, Nanikai 2, and Teaoraereke 1). Secondly, it shows three sites having a medium average density (Teaoraereke 2, Teaoraereke 3 and Banraeaba). Finally, Table 4 reveals four sites having large average density (Taiwan Park, Tengaruru, Ambo and Taborio).

The locations of significant site-specific differences are shown in Table 5, which reveals that Terawabono has the least mean density of 0.33 , while Taiwan Park with the largest mean density of 152.58 are shown to be really different. The mean values for the other eleven sites will be found in between these two values. 
Table 5. Lollyfish density - Bonferroni test for differences amongst sites: multiple comparison (p values) results. Results in red are significant $(\mathrm{p}<0.05)$

\begin{tabular}{|c|c|c|c|c|c|c|c|c|c|c|c|c|c|c|}
\hline Cell No. & Site & $\begin{array}{c}\{1\} \\
1.8333\end{array}$ & $\begin{array}{c}\{2\} \\
.33333\end{array}$ & $\begin{array}{c}\{3\} \\
152.58\end{array}$ & $\begin{array}{c}\{4\} \\
6.5000\end{array}$ & $\begin{array}{c}\{5\} \\
3.9167\end{array}$ & $\begin{array}{c}{[6\}} \\
4.9167\end{array}$ & $\begin{array}{c}\{7\} \\
19.500\end{array}$ & $\begin{array}{c}{[8\}} \\
48.750\end{array}$ & $\begin{array}{c}\{9\} \\
45.000\end{array}$ & $\begin{array}{c}\{10\} \\
136.42\end{array}$ & $\begin{array}{c}\{11\} \\
70.667\end{array}$ & $\begin{array}{c}\{12\} \\
126.50\end{array}$ & $\begin{array}{c}13\}\} \\
120.33\end{array}$ \\
\hline 1 & Temakin & & 1.000000 & 0.000000 & 1.000000 & 1.000000 & 1.000000 & 1.000000 & 0.000108 & 0.000462 & 0.000000 & 0.000000 & 0.000000 & 0.000000 \\
\hline 2 & Terawabono & 1.000000 & & 0.000000 & 1.000000 & 1.000000 & 1.000000 & 1.000000 & 0.000061 & 0.000259 & 0.000000 & 0.000000 & 0.000000 & 0.000000 \\
\hline 3 & Taiwan Park & 0.000000 & 0.000000 & & 0.000000 & 0.000000 & 0.000000 & 0.000000 & 0.000000 & 0.000000 & 1.000000 & 0.000000 & 0.234945 & 0.027746 \\
\hline 4 & Bairiki & 1.000000 & 1.000000 & 0.000000 & & 1.000000 & 1.000000 & 1.000000 & 0.000657 & 0.002748 & 0.000000 & 0.000000 & 0.000000 & 0.000000 \\
\hline 5 & Nanikai 1 & 1.000000 & 1.000000 & 0.000000 & 1.000000 & & 1.000000 & 1.000000 & 0.000243 & 0.001028 & 0.000000 & 0.000000 & 0.000000 & 0.000000 \\
\hline 6 & Nanikai 2 & 1.000000 & 1.000000 & 0.000000 & 1.000000 & 1.000000 & & 1.000000 & 0.000357 & 0.001506 & 0.000000 & 0.000000 & 0.000000 & 0.000000 \\
\hline 7 & Teaoraereke 1 & 1.000000 & 1.000000 & 0.000000 & 1.000000 & 1.000000 & 1.000000 & & 0.080230 & 0284655 & 0.000000 & 0.000021 & 0.000000 & 0.000000 \\
\hline 8 & Teaoraereke 2 & 0.000108 & 0.000061 & 0.000000 & 0.000657 & 0.000243 & 0.000357 & 0.080230 & & 1.000000 & 0.000000 & 0.882829 & 0.000000 & 0.000000 \\
\hline 9 & Teaoraereke 3 & 0.000462 & 0.000259 & 0.000000 & 0.002748 & 0.001028 & 0.001506 & 0.284655 & 1.000000 & & 0.000000 & 0.269521 & 0.000000 & 0.000000 \\
\hline 10 & Tengaruru & 0.000000 & 0.000000 & 1.000000 & 0.000000 & 0.000000 & 0.000000 & 0.000000 & 0.000000 & 0.000000 & & 0.000000 & 1.000000 & 1000000 \\
\hline 11 & Banraeaba & 0.000000 & 0.000000 & 0.000000 & 0.000000 & 0.000000 & 0.000000 & 0.000021 & 0.882829 & 0.269521 & 0.000000 & & 0.000003 & 0.000037 \\
\hline 12 & Ambo & 0.000000 & 0.000000 & 0.234945 & 0.000000 & 0.000000 & 0.000000 & 0.000000 & 0.000000 & 0.000000 & 1.000000 & 0.000003 & & 1000000 \\
\hline 13 & Taborio & 0.000000 & 0.000000 & 0.027746 & 0.000000 & 0.000000 & 0.000000 & 0.000000 & 0.000000 & 0.000000 & 1.000000 & 0.000037 & 1.000000 & \\
\hline
\end{tabular}




\subsection{2 - Individual length}

\subsubsection{1 - Non-parametric analysis}

The Kruskal-Wallis test revealed that there were significant differences in the mean ranked lengths of lollyfish among the 13 sites as shown in Table 6. It shows that $H$. atra mean ranked lengths are statistically significantly different amongst the 13 sites $(\mathrm{H}=156, \mathrm{p}<0.0001)$.

Table 6 also reveals that Taiwan Park has the smallest mean ranked length amongst the 13 sites, while lollyfish at Nanikai 2 show the highest ranked length. The rest of the values for the ranked values fall in between $R=20.75$ and $R=124$.

Figure 7 shows variations in the mean ranked length of the $H$. atra among the 13 sites. Based on variation in the ranked length amongst the 13 sites, three different groupings of populations were found: 1) small (Terawabono), 2) medium (Temakin, Taiwan Park, Teaoraereke 1, Teaoraereke 2, Teaoraereke 3, Tengaruru, Banraeaba, Ambo, and Taborio) and 3) large (Bairiki, Nanikai 1 and Nanikai 2). These variations in ranked length differed according to their values, with $<6 \mathrm{~cm}$ for small, $6-14 \mathrm{~cm}$ for medium and $>14 \mathrm{~cm}$ for large.

In addition, Figure 7 reveals that three different groupings of populations existed based on the extent of variability observed among the transects. This variability is grouped into three categories: a) low (Taiwan Park, Teaoraereke 1, Teaoraereke 2, Teaoraereke 3, Tengaruru, Banreaba, Ambo and Taborio), b) moderate (Bairiki, Nanikai 1, and Nanikai 2), and c) large (Temakin and Terawabono). 
Table 6. Lollyfish length - Kruskal-Wallis test for differences amongst sites: Bonferroni multiple comparison (p values) results. Results in red are significant $(\mathrm{p}<0.05)$

\begin{tabular}{|c|c|c|c|c|c|c|c|c|c|c|c|c|c|}
\hline $\begin{array}{l}\text { Depend.: } \\
\text { Av.length }\end{array}$ & $\begin{array}{l}\text { Temakin } \\
\text { R-104.88 }\end{array}$ & $\begin{array}{c}\text { Terawabono } \\
\text { R29250 }\end{array}$ & $\begin{array}{c}\text { Taiwan Park } \\
\text { R20.750 }\end{array}$ & $\begin{array}{c}\text { Bairiki } \\
\text { R:108.33 }\end{array}$ & $\begin{array}{l}\text { Nanikai } 1 \\
\text { R-109.33 }\end{array}$ & $\begin{array}{l}\text { Nanikai } 2 \\
\text { R:124.00 }\end{array}$ & $\begin{array}{c}\text { Teaoraereke } \\
1 \\
\text { R.64208 }\end{array}$ & $\begin{array}{c}\text { Teaoraereke } \\
2 \\
\text { R } 88.375\end{array}$ & $\begin{array}{c}\text { Teaoraereke } \\
3 \\
\text { R.94708 }\end{array}$ & $\begin{array}{r}\text { Tengaruru } \\
\text { R:39.958 }\end{array}$ & $\begin{array}{c}\text { Banraeaba } \\
\text { R.59.375 }\end{array}$ & $\begin{array}{c}\text { Ambo } \\
\mathrm{R} 84.875\end{array}$ & $\begin{array}{l}\text { Taborio } \\
\text { R:92.458 }\end{array}$ \\
\hline Temakin & & 0.003218 & 0.000397 & 1.000000 & 1.000000 & 1000000 & 1000000 & 1.000000 & 1.000000 & 0.033694 & 1.000000 & 1.000000 & 1.000000 \\
\hline Terawabono & 0.003218 & & 1.000000 & 0.001407 & 0.001101 & 0.000022 & 1000000 & 0.105086 & 0.030150 & 1.000000 & 1.000000 & 0.199817 & 0.047583 \\
\hline Taiwan Park & 0.000397 & 1.000000 & & 0.000160 & 0.000122 & 0.000002 & 1000000 & 0.019174 & 0.004737 & 1.000000 & 1.000000 & 0.039578 & 0.007884 \\
\hline Bairiki & 1.000000 & 0.001407 & 0.000160 & & 1.000000 & 1.000000 & 1000000 & 1.000000 & 1.000000 & 0.016343 & 0.619545 & 1.000000 & 1.000000 \\
\hline Nanikai 1 & 1.000000 & 0.001101 & 0.000122 & 1.000000 & & 1.000000 & 1000000 & 1.000000 & 1.000000 & 0.013176 & 0.526858 & 1.000000 & 1.000000 \\
\hline Nanikai 2 & 1.000000 & 0.000022 & 0.000002 & 1.000000 & 1.000000 & & 0.092626 & 1.000000 & 1.000000 & 0.000405 & 0.035760 & 1.000000 & 1.000000 \\
\hline Teaoraereke 1 & 1.000000 & 1.000000 & 1.000000 & 1.000000 & 1.000000 & 0.092626 & & 1.000000 & 1.000000 & 1.000000 & 1.000000 & 1.000000 & 1.000000 \\
\hline Teaoraereke 2 & 1.000000 & 0.105086 & 0.019174 & 1.000000 & 1.000000 & 1.000000 & 1000000 & & 1.000000 & 0.675626 & 1.000000 & 1.000000 & 1.000000 \\
\hline Teaoraereke 3 & 1.000000 & 0.030150 & 0.004737 & 1.000000 & 1.000000 & 1.000000 & 1000000 & 1.000000 & & 0.233414 & 1.000000 & 1.000000 & 1.000000 \\
\hline Tengaruru & 0.033694 & 1.000000 & 1.000000 & 0.016343 & 0.013176 & 0.000405 & 1000000 & 0.675626 & 0233414 & & 1.000000 & 1.000000 & 0.344765 \\
\hline Banraeaba & 1.000000 & 1.000000 & 1.000000 & 0.619545 & 0.526858 & 0.035760 & 1000000 & 1.000000 & 1.000000 & 1.000000 & & 1.000000 & 1.000000 \\
\hline Ambo & 1.000000 & 0.199817 & 0.039578 & 1.000000 & 1.000000 & 1.000000 & 1000000 & 1.000000 & 1.000000 & 1.000000 & 1.000000 & & 1.000000 \\
\hline Taborio & 1.000000 & 0.047583 & 0.007884 & 1.000000 & 1.000000 & 1.000000 & 1000000 & 1.000000 & 1.000000 & 0.344765 & 1.000000 & 1.000000 & \\
\hline
\end{tabular}




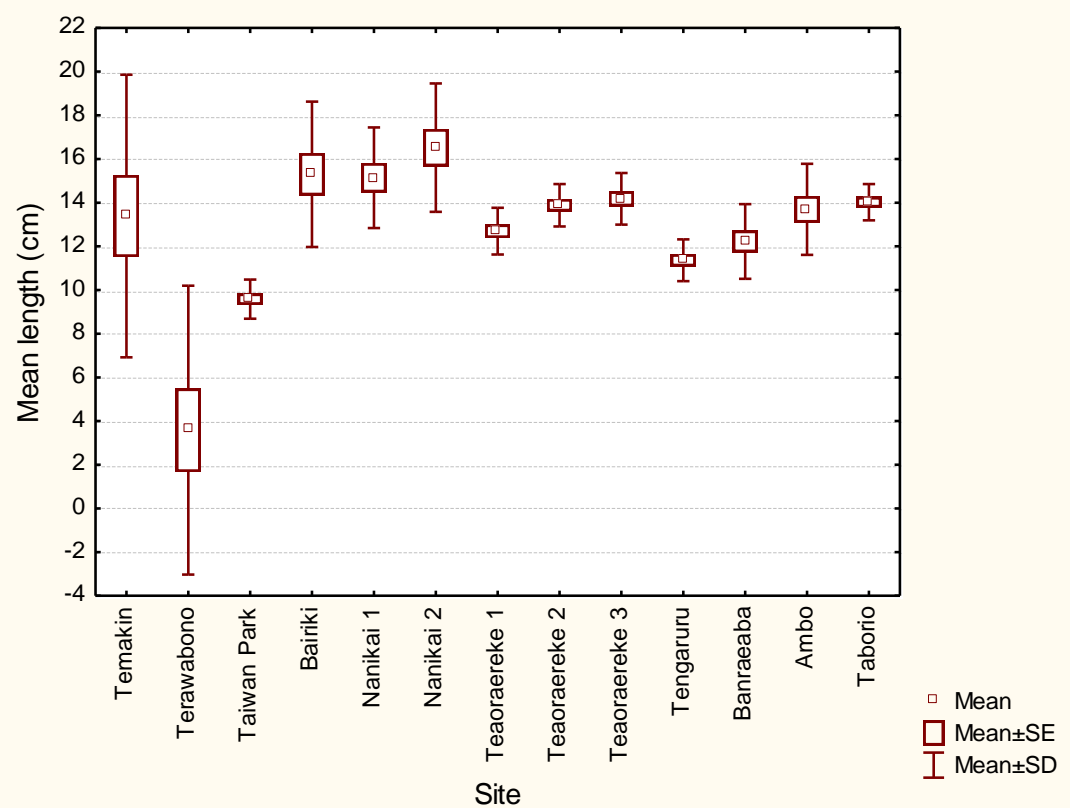

Figure 7. Variation in mean length of lollyfish amongst the 13 sites.

\subsubsection{2 - Parametric analysis}

A repeated measures ANOVA test showed that mean length of lollyfish among sites and site by week interactions were significantly different, while the mean length amongst the site by week interactions were not significantly different. These differences are illustrated below.

Table 7. Lollyfish length - Repeated measures ANOVA on the Effects of Site, Week, and Site by Week interaction.

\begin{tabular}{|l|l|l|l|l|l|}
\hline Effect & SS & Dof & MS & F & P \\
\hline Intercept & 25304.45 & 1 & 25304.45 & 2025.951 & 0.000000 \\
\hline Site & 1547.08 & 12 & 128.92 & 10.322 & 0.000000 \\
\hline Error & 487.12 & 39 & 12.49 & & \\
\hline WEEK & 5.49 & 2 & 2.74 & 0.611 & 0.545520 \\
\hline WEEK*SITE & 518.53 & 24 & 21.61 & 4.811 & 0.000000 \\
\hline Error & 350.27 & 78 & 4.49 & & \\
\hline
\end{tabular}


From Table 7, the p-value for repeated measures for the actual length of lollyfish among sites is 0.000001 , which is less than $5 \%$ and thus the variation in the actual length among the 13 sites is significantly different in figure 8 . Figure 9 shows the pvalue for the repeated measures ANOVA for the actual length of lollyfish among the three weeks is 0.545520 which is greater than $5 \%$ and thus the variation is not significantly different. This must be noted that the variation is not significantly different at among the three weeks. Lastly, figure 10 shows a similar pattern where the variation is highly significantly different at the week by site interaction shows the p-value for repeated measures for the actual length of lollyfish among week by site interaction is 0.000001 .

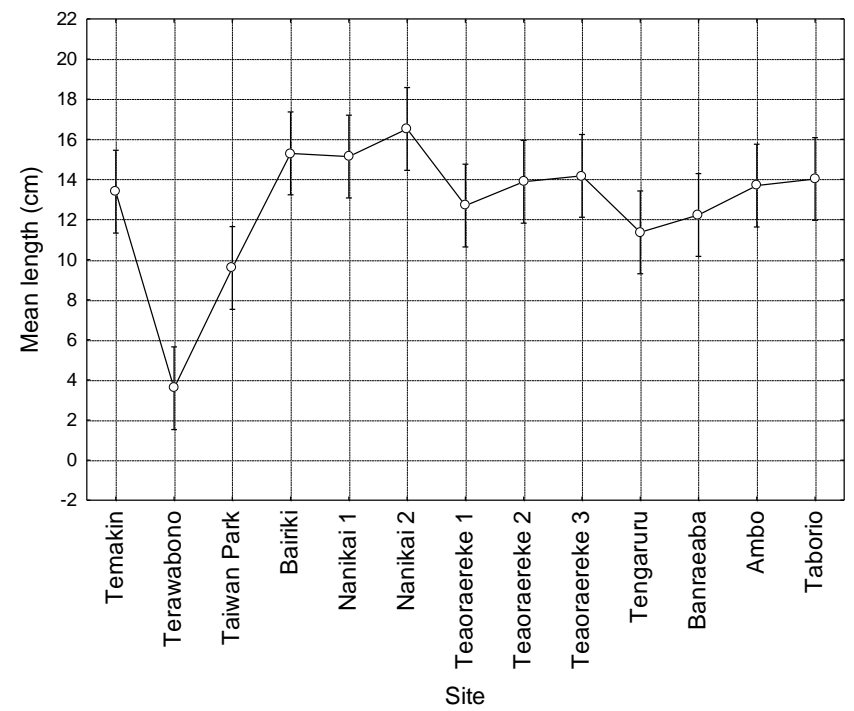

Figure 8. Variation in mean length of lollyfish among the 13 sites with vertical bars denoting 0.95 confidence intervals. 


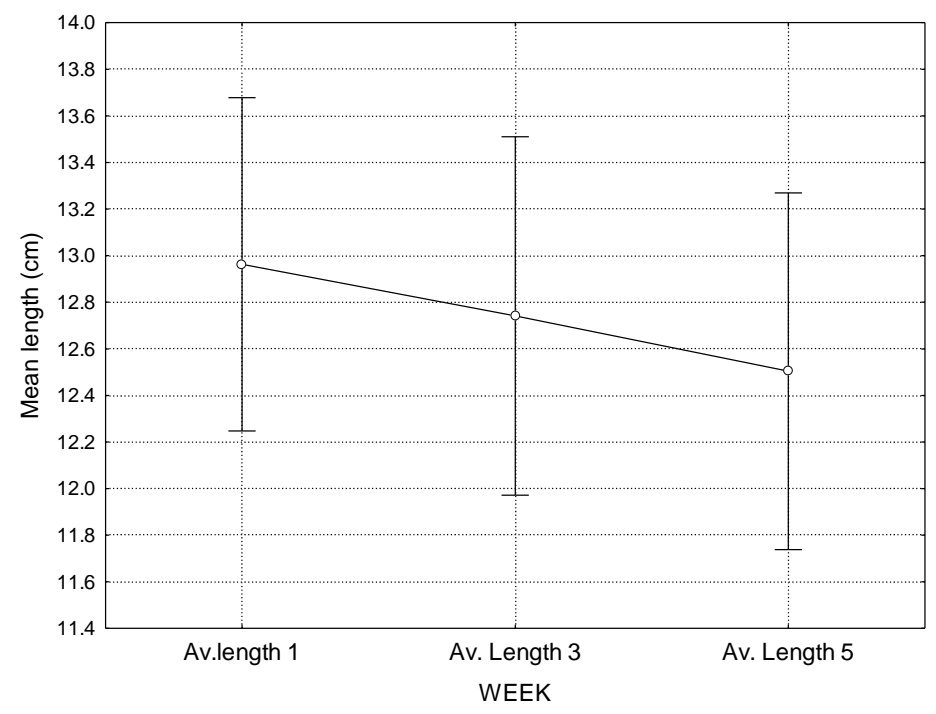

Figure 9. Variation in mean length of lollyfish among the three weeks with vertical bars denoting 0.95 confidence intervals.

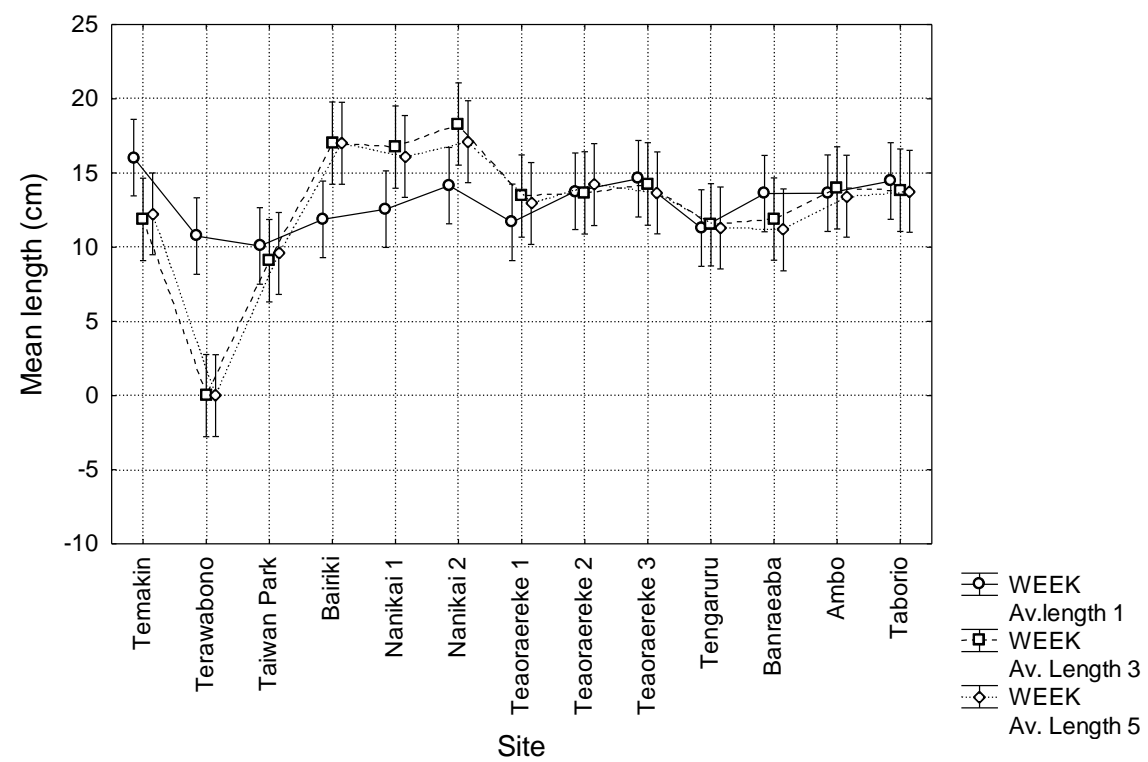

Figure 10. Variation in mean length of lollyfish at week by site interaction with vertical bars denoting 0.95 confidence intervals.

The relationship in mean length of lollyfish among sites, and week by site interactions differ significantly, but these differences are not shown between weeks. Inspection of Figure 10 suggests that the significant site by week interaction occurs because difference in lollyfish mean length values in week one versus weeks three and five at Terawabono. 
Table 8. Lollyfish length - Mean, standard error and 95\% confidence intervals for site-specific values

\begin{tabular}{|c|c|c|c|c|c|c|}
\hline Cell No. & Site & $\begin{array}{l}\text { DV_1 } \\
\text { Mean }\end{array}$ & $\begin{array}{c}\text { DV_1 } \\
\text { Std.Err. }\end{array}$ & \begin{tabular}{c|} 
DV_1 \\
$-95.00 \%$ \\
\end{tabular} & \begin{tabular}{c|} 
DV_1 \\
$+95.00 \%$ \\
\end{tabular} & N \\
\hline 1 & Temakin & 13.38750 & 1.020219 & 11.32391 & 15.45109 & 4 \\
\hline 2 & Terawabond & 3.58333 & 1.020219 & 1.51975 & 5.64692 & 4 \\
\hline 3 & Taiwan Park & 9.58333 & 1.020219 & 7.51975 & 11.64692 & 4 \\
\hline 4 & Bairiki & 15.30000 & 1.020219 & 13.23641 & 17.36359 & 4 \\
\hline 5 & Nanikai 1 & 15.14333 & 1.020219 & 13.07975 & 17.20692 & 4 \\
\hline 6 & Nanikai 2 & 16.51917 & 1.020219 & 14.45558 & 18.58275 & 4 \\
\hline 7 & Teaoraereke & 12.69333 & 1.020219 & 10.62975 & 14.75692 & 4 \\
\hline 8 & Teaoraereke 2 & 13.88167 & 1.020219 & 11.81808 & 15.94525 & 4 \\
\hline 9 & Teaoraereke 3 & 14.17750 & 1.020219 & 12.11391 & 16.24109 & 4 \\
\hline 10 & Tengarury & 11.36250 & 1.020219 & 9.29891 & 13.42609 & 4 \\
\hline 11 & Banraeaba & 12.22417 & 1.020219 & 10.16058 & 14.28775 & 4 \\
\hline 12 & Ambo & 13.69250 & 1.020219 & 11.62891 & 15.75609 & 4 \\
\hline 13 & Taborid & 14.02083 & 1.020219 & 11.95725 & 16.08442 & 4 \\
\hline
\end{tabular}

Table 8 shows the mean lollyfish lengths at the 13 sites. These lengths are categorized into three groups: 1) small (1-6); 2) medium (7-14); and 3) large (15-18). Table 8 shows only one site (Terawabono) as having particularly small lollyfish. It shows nine sites (Temakin, Taiwan Park, Teaoraereke 1, Teaoraereke 2, Teaoraereke 3, Tengaruru, Banraeaba, Ambo and Taborio) as having medium lollyfish. Then lastly, it shows three sites (Bairiki, Nanikai 1, and Nanikai 2) for having longer lollyfish. Table 8 behaves similarly to Figure 7 by showing three levels of significances in lollyfish length mainly associated with site, week and site by week interaction. 
Table 9. Lollyfish length - Bonferroni test for differences amongst sites, weeks, and site by weeks: multiple comparison

( $\mathrm{p}$ values) results. Results in red are significant $(\mathrm{p}<0.05)$

\begin{tabular}{|c|c|c|c|c|c|c|c|c|c|c|c|c|c|c|}
\hline $\mathrm{N}$ & Site & $\begin{array}{c}\{1\} \\
13.387\end{array}$ & $\begin{array}{c}\{2\} \\
3.5833\end{array}$ & $\begin{array}{c}3\} \\
9.5833\end{array}$ & $\begin{array}{c}\{4\} \\
15.300\end{array}$ & $\begin{array}{c}\{5\} \\
15.143\end{array}$ & $\begin{array}{c}\{6\} \\
16.519\end{array}$ & $\begin{array}{c}\{7\} \\
12.693\end{array}$ & $\begin{array}{c}\{8\} \\
13.882\end{array}$ & $\begin{array}{c}\{9\} \\
14.178\end{array}$ & $\begin{array}{c}\{10\} \\
11.363\end{array}$ & $\begin{array}{c}\{11\} \\
12.224\end{array}$ & $\begin{array}{c}12\} \\
13.692\end{array}$ & $\begin{array}{c}\{13\} \\
14.021\end{array}$ \\
\hline 1 & Temakin & & 0.000003 & 0.932806 & 1.000000 & 1.000000 & 1.000000 & 1.000000 & 1.000000 & 1.000000 & 1.000000 & 1.000000 & 1.000000 & 1.000000 \\
\hline 2 & Terawabond & 0.000003 & & 0.013257 & 0.000000 & 0.000000 & 0.000000 & 0.000015 & 0.00000 & 0.000001 & 0.000282 & 0.000042 & 0.000002 & 0.000001 \\
\hline 3 & Taiwan Park & 0.932806 & 0.013257 & & 0.023914 & 0.033004 & 0.001 & 1.000 & 0.386 & 0.222430 & 1.000000 & 1.000000 & & 0.298618 \\
\hline 4 & Bairiki & 1.000000 & 0.000000 & 0.023914 & & 1.000000 & 1.000000 & 1.000 & 1.000000 & 1.000000 & 0.73 & 1.000000 & 1.00 & 1.000000 \\
\hline 5 & Nanikai 1 & 1.000000 & 0.000000 & 0.033004 & 1.000000 & & 1.000000 & 1.000 & 1.000000 & 1.000 & 0.97 & 1.000 & 1.0 & 1.000000 \\
\hline 6 & Nanikai 2 & $\mid 1.000000$ & 0.000000 & 1792 & 1.000000 & 1.000000 & & $0.8 \mathrm{~s}$ & 1.0 & 1.0 & 0 & 0 & 1.000000 & 0000 \\
\hline 7 & aoraereke 1 & 1.000000 & 0.000015 & 1.000000 & 1.000000 & 1.000000 & 0.898482 & & 1.000000 & 1.000000 & 1.0 & 1.0 & 1.0 & 1.000000 \\
\hline 8 & Teaoraereke 2 & 1.000000 & 0.000001 & 0.386362 & 1.000000 & 1.000000 & 1.000000 & 1.000000 & & 1.000000 & 1.000000 & 1.00 & 1.0 & 1.000000 \\
\hline 9 & Teaoraereke 3 & 1.000000 & 0.000001 & 0.222430 & 1.000000 & 1.000000 & 1.000000 & 1.000000 & 1.000000 & & 1.000000 & 1.000000 & 1.000000 & 1.000000 \\
\hline 10 & engarury & 1.000000 & 0.000282 & 1.000000 & 0.739336 & 0.971116 & 0.074515 & 1.000000 & 1.000000 & 1.000000 & & 1.000000 & 1.00 & 1.000000 \\
\hline 11 & anraeaba & 1.000000 & 0.000042 & 1.000000 & 1.000000 & 1.000000 & 0.388734 & 1.000000 & 1.000000 & 1.000000 & 1.000000 & & 1.000000 & 1.000000 \\
\hline 12 & Ambo & 1.000000 & & & 1.000000 & & & & & 1.000000 & 1.000000 & 000 & & 1.000000 \\
\hline 13 & hari & .000000 & 0.000001 & 0.298618 & 1.000000 & 1.0 & 000 & & 10 & 40 & 1.000000 & 1.00 & 0000 & \\
\hline
\end{tabular}




\subsubsection{3 - Length-frequency distribution}

The differences in age classes can be compared to the length-frequency distributions shown in figure 11 below. Figure 11 represents overall thirteen variations in the age class distribution patterns of $H$. atra along the 13 sites in Tarawa lagoon. First, the results show two length-frequencies such as F11a and b that have a uniform normal distribution. Secondly, figure 11 reveals two length-frequencies plots such as F11d and $\mathrm{Fe}$ that show a bimodal distribution. Thirdly, this figure portrays three lengthfrequencies such as F11f, Fh and Fk that show a skewed positive asymmetrical unimodal distribution. Finally, figure 11 depicts six length-frequencies such as F11c, $\mathrm{g}, \mathrm{i}, \mathrm{j}, 1$ and $\mathrm{m}$ that show a symmetrical unimodal distribution.

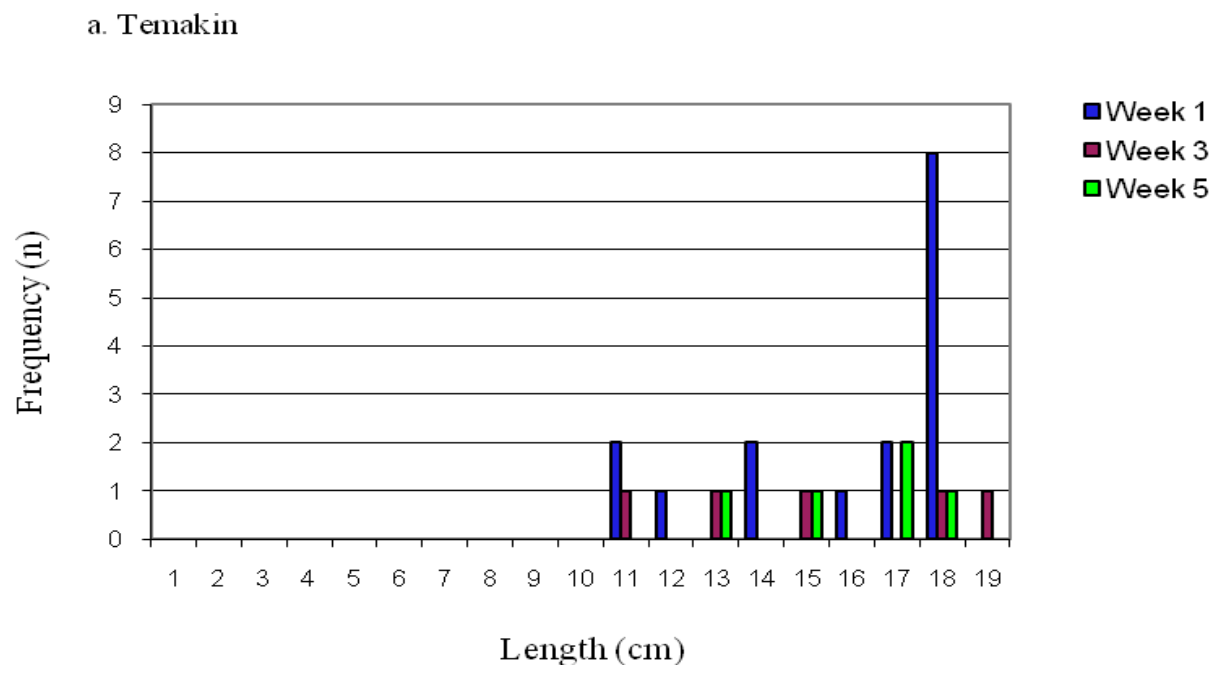

b. Terawabono

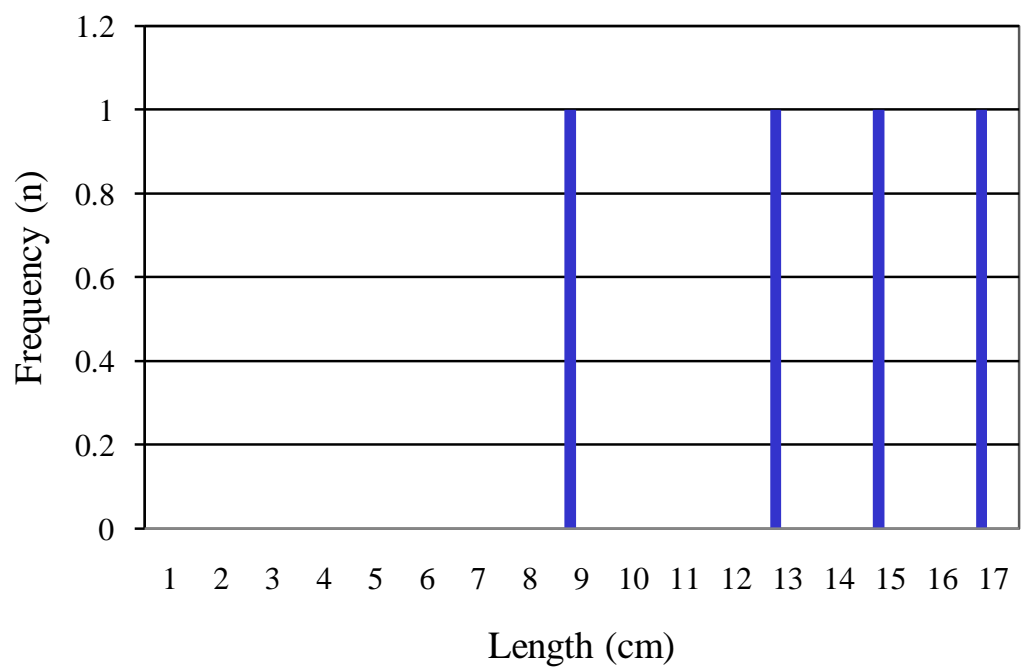

- Week 1

- Week 3

- Week 5 
c. Taiwan Park

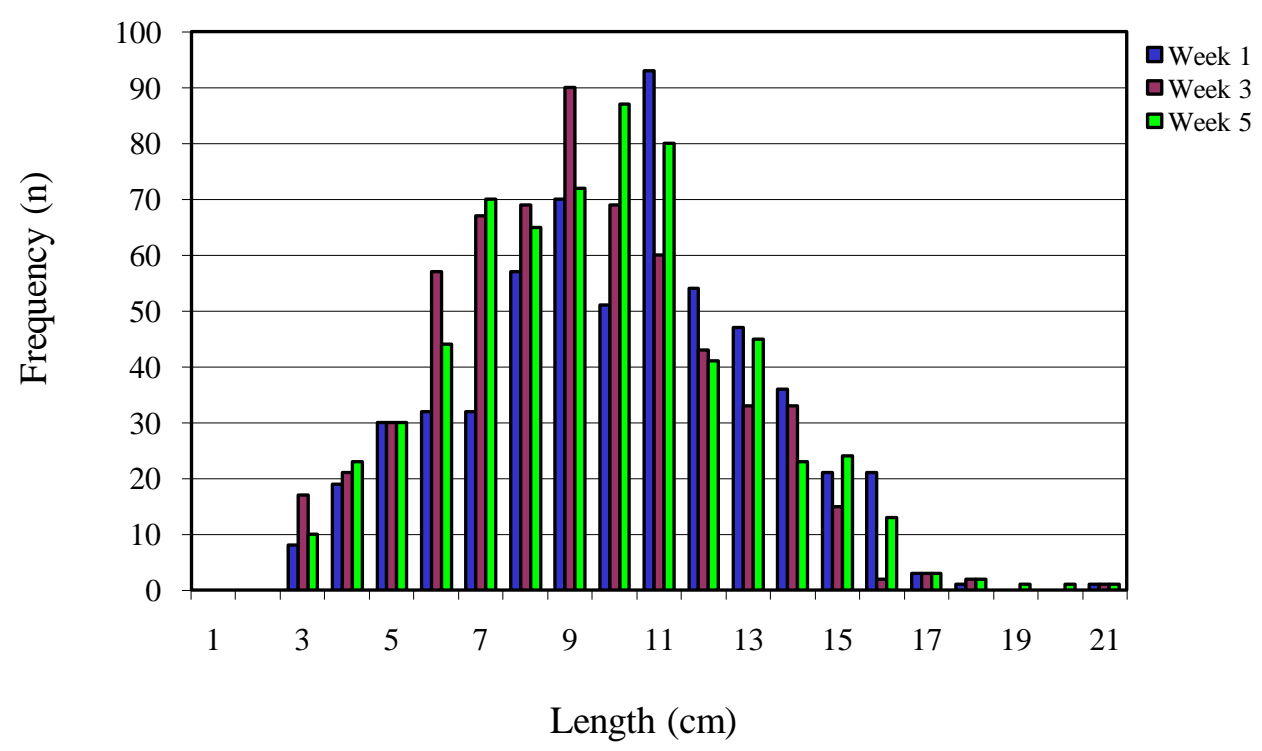

d. Bairiki

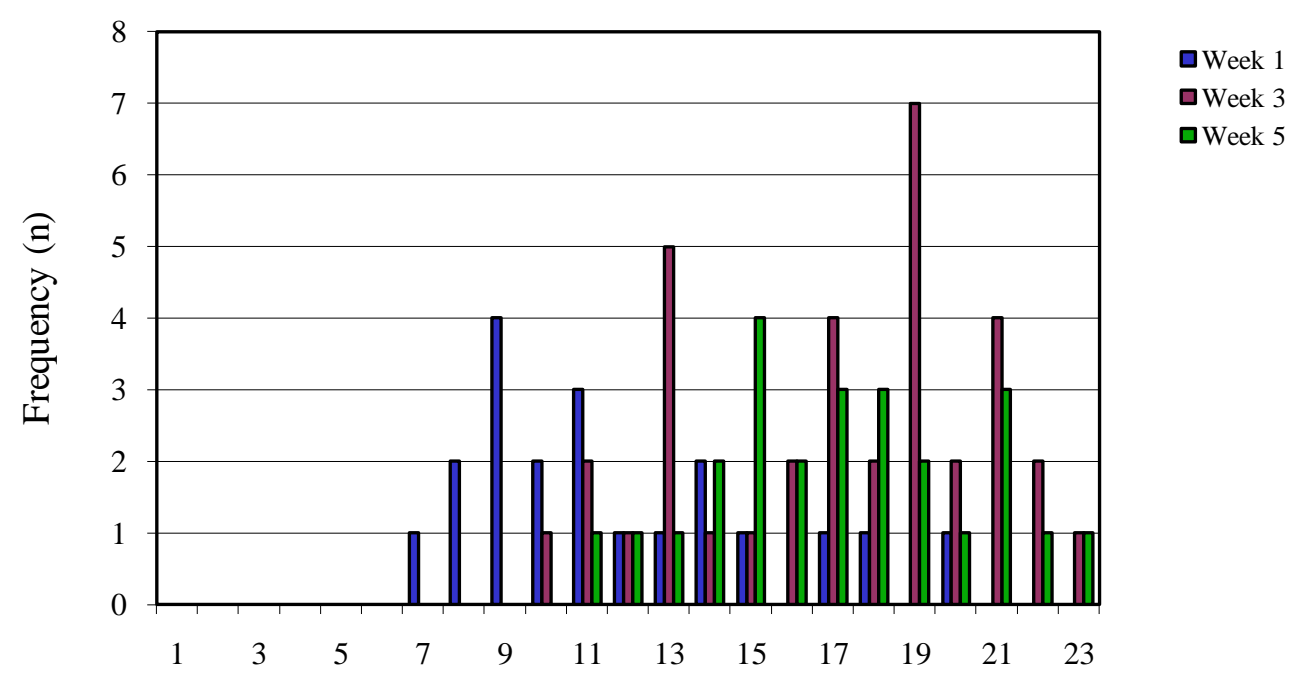

Length $(\mathrm{cm})$ 


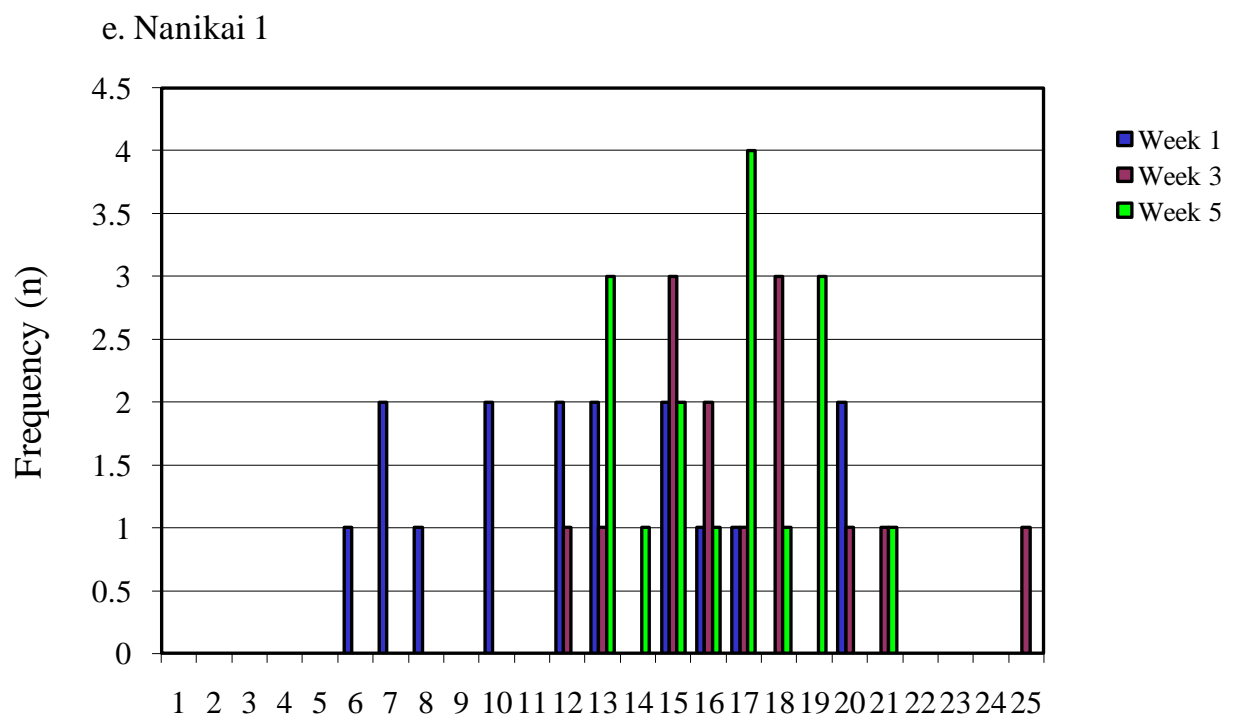

Length $(\mathrm{cm})$

f. Nanikai 2

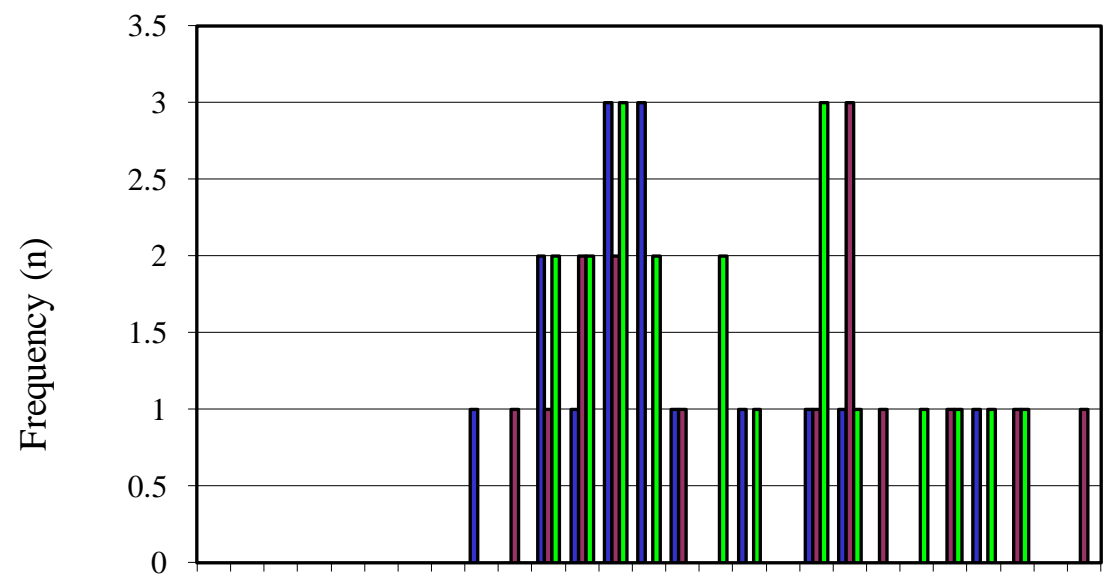

口Week 1

口Week 3

口Week 5

122345667899101112131415161718192021222324252627

Length $(\mathrm{cm})$ 
g. Teaoraereke 1

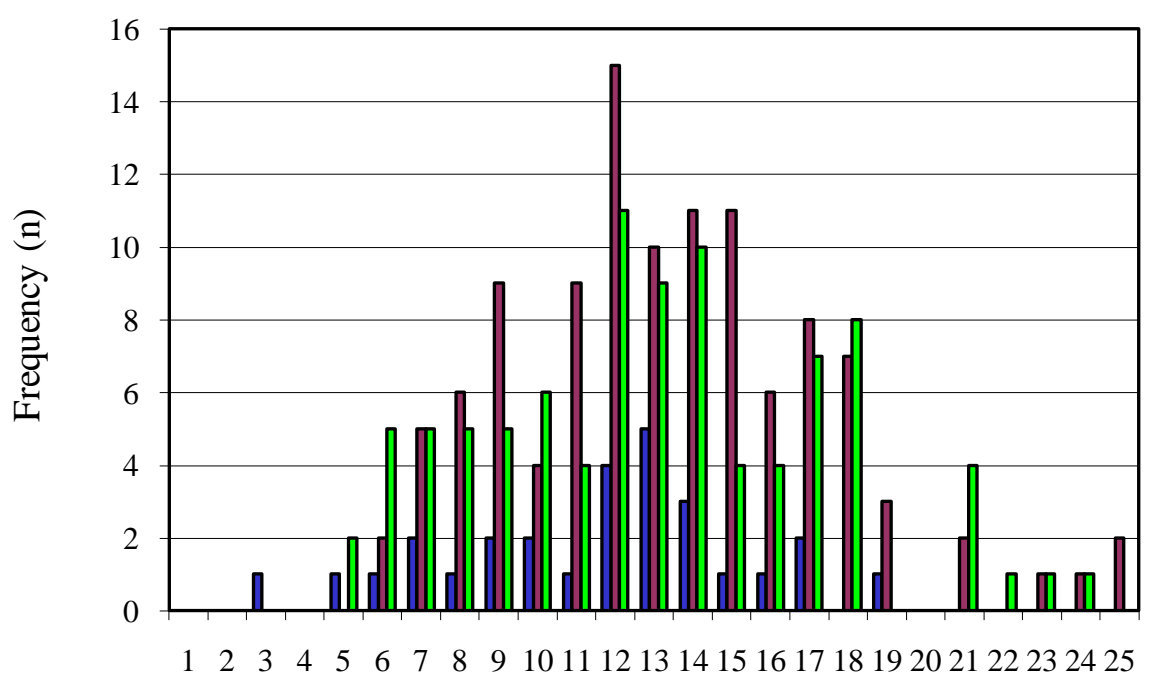

口Week 1

口Week 3

口Week 5

Length $(\mathrm{cm})$

h. Teaoraereke 2

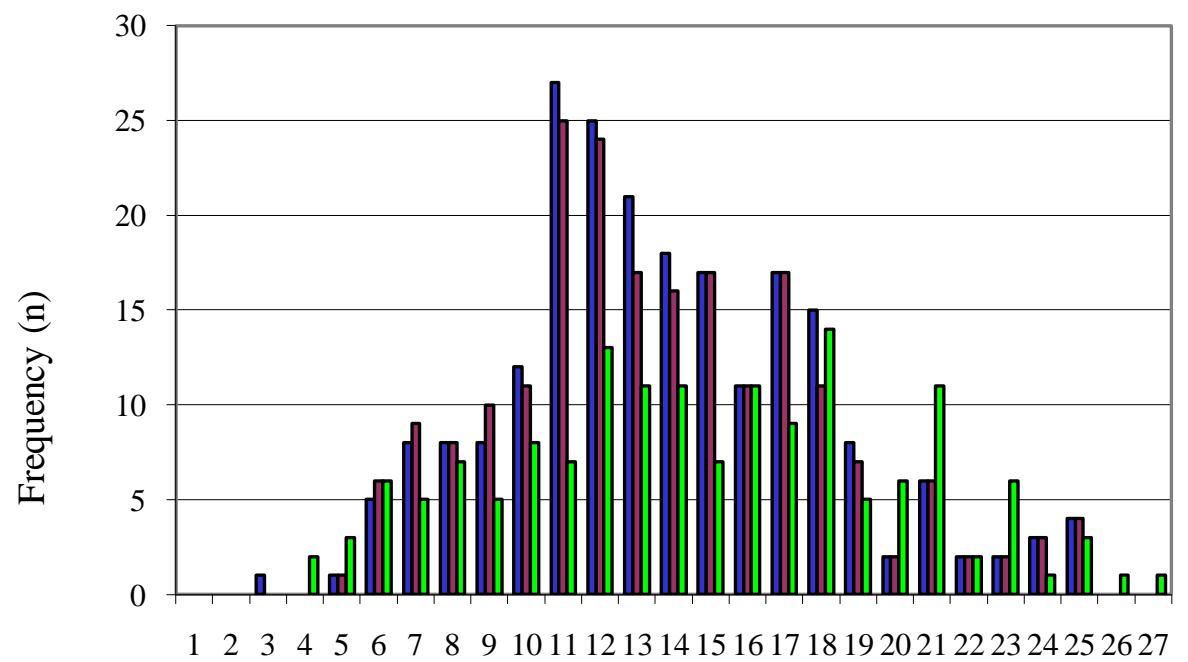

口Week 1

口Week 3

口Week 5

Length $(\mathrm{cm})$ 
i. Teaoraereke 3

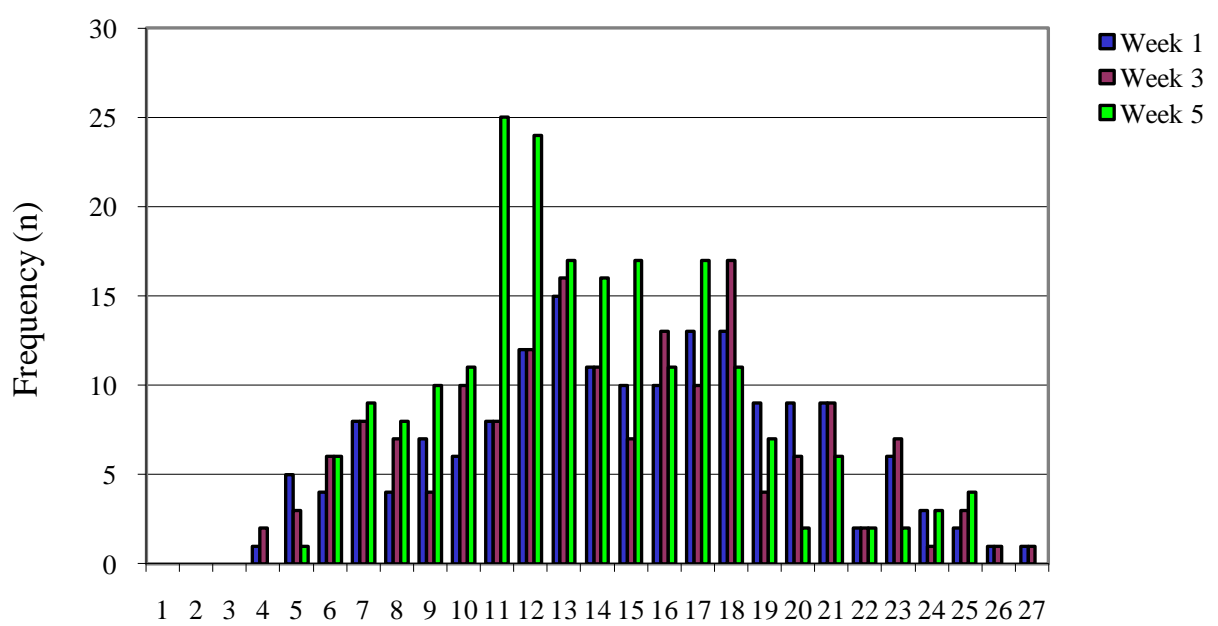

Length $(\mathrm{cm})$

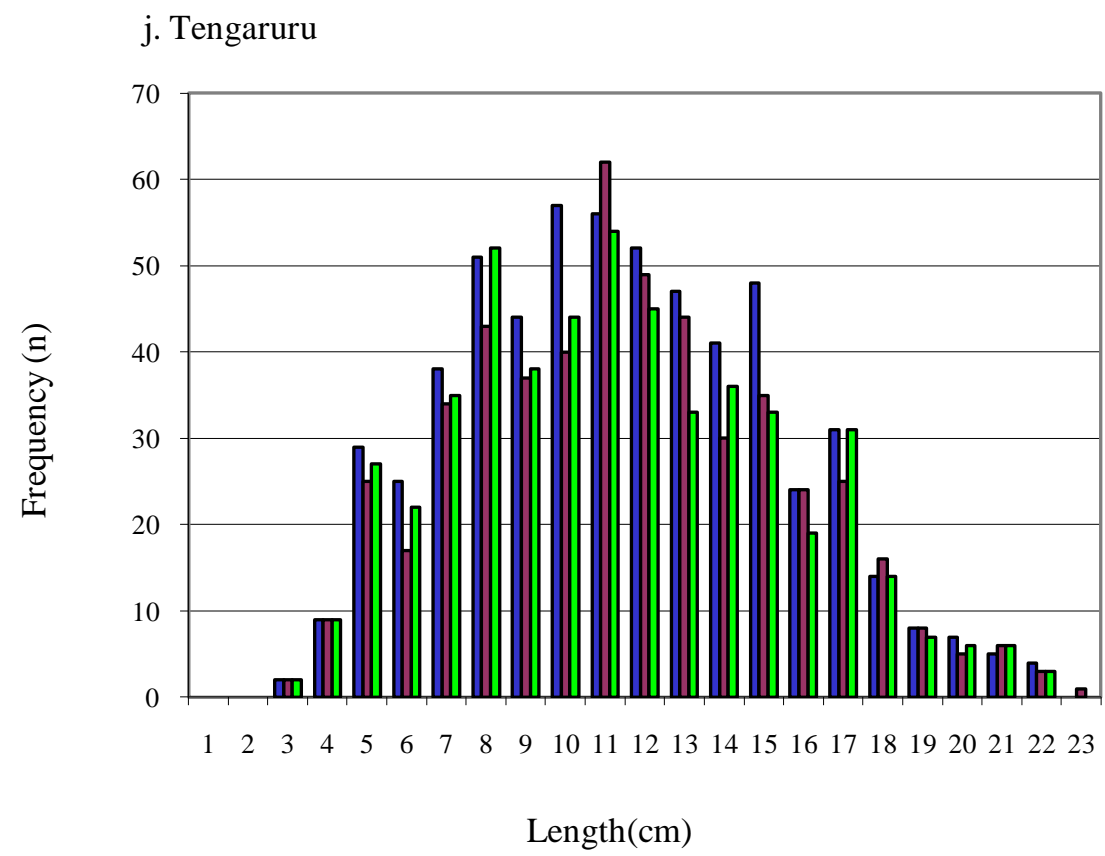

口Week

口Week 
k. Banraeaba

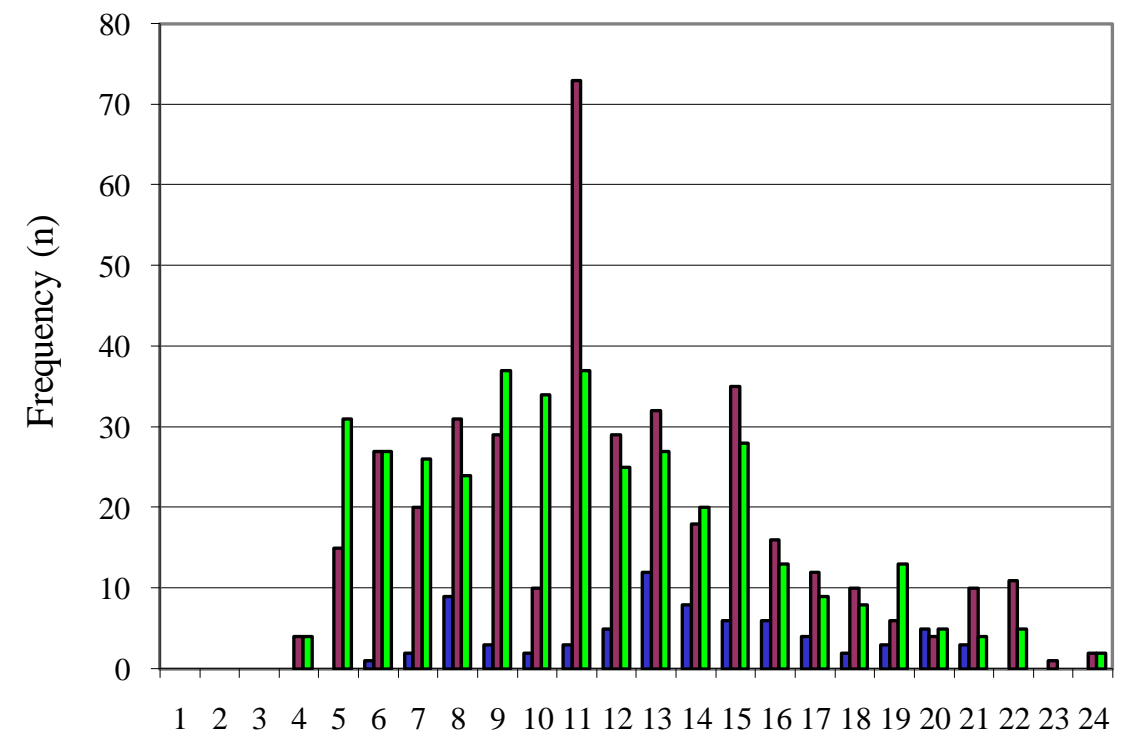

Length $(\mathrm{cm})$

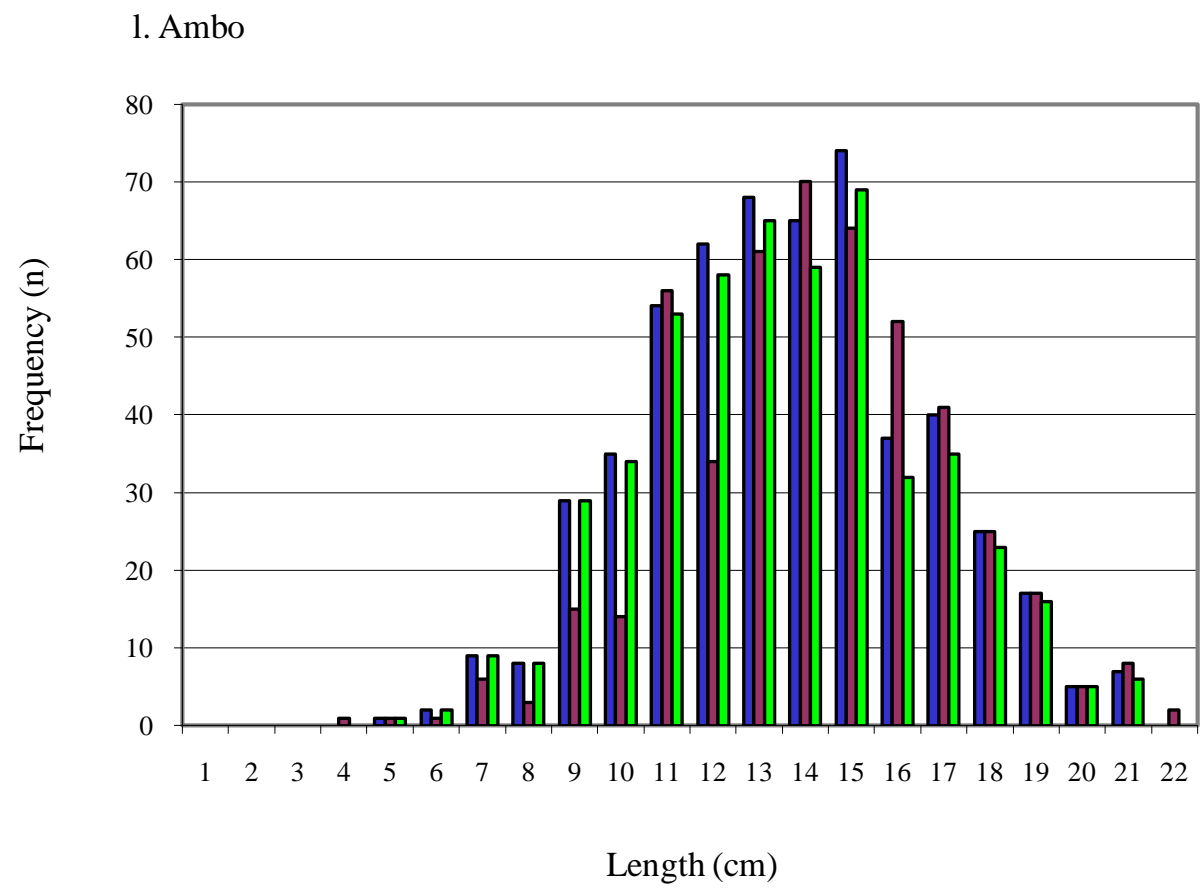

口Week 1

口Week 3

口Week 5 


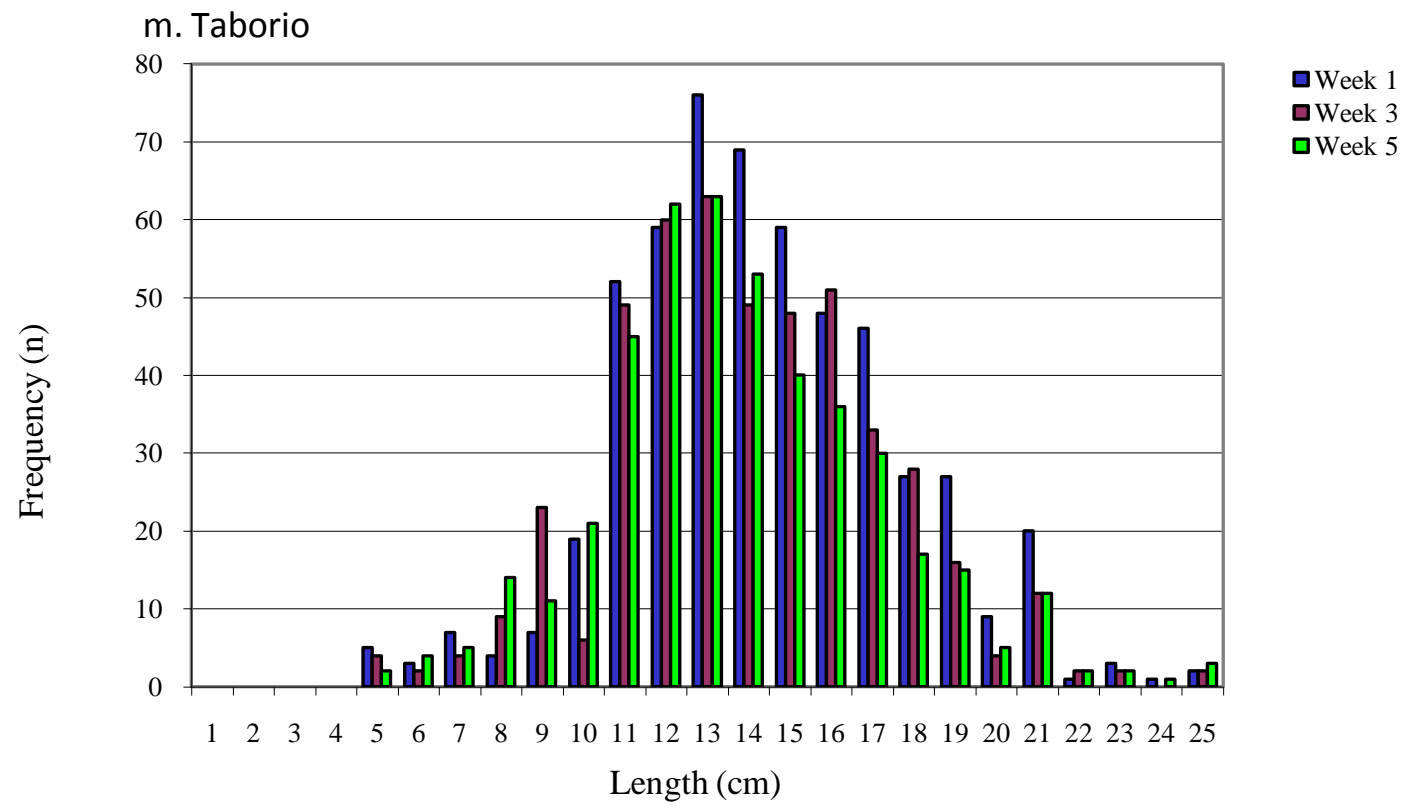

Figure 11. Combined length-frequency distribution of lollyfish in weeks 1,3 and 5 at 13 sites.

\subsection{3 - Total lollyfish weight}

\subsubsection{1 - Non-parametric analysis}

Results of the test show that $H$. atra are statistically significantly different in individual weight amongst the 13 sites $(\mathrm{N}=156, \mathrm{p}<0.0001)$.

Table 10 shows the maximum mean weight (R:143.71) occurred in Nanikai 2 and the minimum weight (R:9.16) observed in Terawabono. The weights of $H$. atra in the other eleven sites are fall in between these two values. Thus, the weight of $H$. atra amongst the 13 sites differs statistically.

Figure 12 summarises variability trends in average ranked weight amongst the 13 sites and reveals three different groups of populations based on variation in individual lollyfish weight amongst the 13 sites: a) low i.e., <60 g (Terawabono, Taiwan Park, Tengaruru and Taborio), b) medium i.e., 60-120 g (Temakin, Nanikai 1, Teaoraereke 1, Teaoraereke 2, Teaoraereke 3, Banraeaba and Ambo), and c) high i.e., $>120 \mathrm{~g}$ (Bairiki and 
Nainikai 1). Figure 12 also reveals that three different groupings of populations exist based on the variation in the size of standard deviation (variability) of lollyfish ranked biomasses. This variability is categorized into three groups: 1) low (Terawabono, Taiwan Park, Tengaruru, Banraeaba, Ambo and Taborio), 2) medium (Nanikai 1, Teaoraereke 2, and Teaoraereke 3), and 3) large (Temakin, Bairiki, Nanikai 2 and Teaoraereke 1).

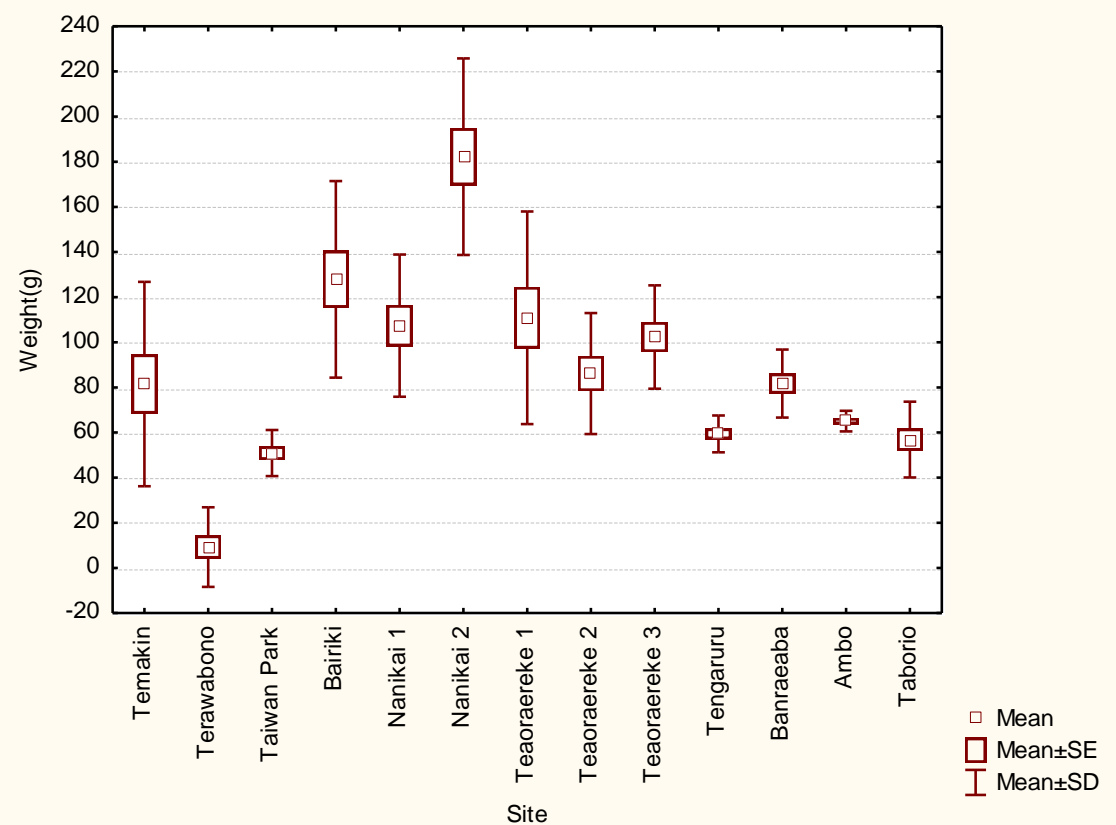

Figure 12. Variation in mean weight of lollyfish amongst 13 sites. 
Table 10. Lollyfish total weigth - Kruskal-Wallis test for differences amongst sites: multiple comparison (p values) results. Results in red are significant $(\mathrm{p}<0.05)$

\begin{tabular}{|c|c|c|c|c|c|c|c|c|c|c|c|c|c|}
\hline $\begin{array}{l}\text { Depend.: } \\
\text { Av.weight }\end{array}$ & $\begin{array}{l}\text { Temakin } \\
\text { R:82083 }\end{array}$ & $\begin{array}{r}\text { Terawabono } \\
\text { R:9.1667 }\end{array}$ & $\begin{array}{c}\text { Taiwan } \\
\text { Park } \\
\text { R:31.833 }\end{array}$ & $\begin{array}{c}\text { Barik } \\
\text { R:118.50 }\end{array}$ & \begin{tabular}{|l|} 
Nanikai 1 \\
R:109.92
\end{tabular} & $\begin{array}{c}\text { Nanikai } 2 \\
\text { R:143.71 }\end{array}$ & $\begin{array}{c}\text { Teaorareke } \\
1 \\
\text { R: } 103.38\end{array}$ & $\begin{array}{c}\text { Tearoreke } \\
2 \\
\text { R:83.958 }\end{array}$ & $\begin{array}{c}\text { Teaoraereke } \\
3 \\
\text { R: } 104.08\end{array}$ & $\begin{array}{c}\text { Tengaruru } \\
\text { R:45.250 }\end{array}$ & $\begin{array}{c}\text { Barraeaba } \\
\text { R:84.833 }\end{array}$ & $\begin{array}{c}\text { Anbo } \\
\text { R:56.458 }\end{array}$ & \begin{tabular}{|l|} 
Taborio \\
R:47.333
\end{tabular} \\
\hline Temakin & & 0.006007 & 0.502279 & 1.000000 & 1.000000 & 0.065050 & 1.000000 & 1.000000 & 1.000000 & 1.000000 & 1.000000 & 1.000000 & 1.000000 \\
\hline Terawabono & 0.006007 & & 1.000000 & 0.000000 & 0.000004 & 0.000000 & 0.000025 & 0.003908 & 0.000021 & 1.000000 & 0.003187 & 0.806809 & 1.000000 \\
\hline Tawan Park & 0.502279 & 1.000000 & & 0.000204 & 0.001794 & 0.000000 & 0.008183 & 0.367430 & 0.006983 & 1.000000 & 0.316517 & 1.000000 & 1.000000 \\
\hline Barik & 1.000000 & 0.000000 & 0.000204 & & 1.000000 & 1.000000 & 1.000000 & 1.000000 & 1.000000 & 0.005569 & 1.000000 & 0.059952 & 0.008995 \\
\hline Nanikai 1 & 1.000000 & 0.000004 & 0.001794 & 1.000000 & & 1.000000 & 1.000000 & 1.000000 & 1.000000 & 0.035457 & 1.000000 & 0.292486 & 0.053878 \\
\hline Nanikai 2 & 0.065050 & 0.000000 & 0.000000 & 1.000000 & 1.000000 & & 1.000000 & 0.093362 & 1.000000 & 0.000007 & 0.110145 & 0.000175 & 0.000014 \\
\hline Teaoraereke 1 & 1.000000 & 0.000025 & 0.008183 & 1.000000 & 1.000000 & 1.000000 & & 1.000000 & 1.000000 & 0.126699 & 1.000000 & 0.855324 & 0.185427 \\
\hline Teaoraereke 2 & 1.000000 & 0.003908 & 0.367430 & 1.000000 & 1.000000 & 0.093362 & 1.000000 & & 1.000000 & 1.000000 & 1.000000 & 1.000000 & 1.000000 \\
\hline Teaoraereke 3 & 1.000000 & 0.000021 & 0.006983 & 1.000000 & 1.000000 & 1.000000 & 1.000000 & 1.000000 & & 0.111010 & 1.000000 & 0.765757 & 0.163123 \\
\hline Tengaruru & 1.000000 & 1.000000 & 1.000000 & 0.005669 & 0.035457 & 0.000007 & 0.126699 & 1.000000 & 0.111010 & & 1.000000 & 1.000000 & 1.000000 \\
\hline Barraeaba & 1.000000 & 0.003187 & 0.316517 & 1.000000 & 1.000000 & 0.110145 & 1.000000 & 1.000000 & 1.000000 & 1.000000 & & 1.000000 & 1.000000 \\
\hline Annbo & 1.000000 & 0.806809 & 1.000000 & 0.059952 & 0.292486 & 0.000175 & 0.855324 & 1.000000 & 0.765757 & 1.000000 & 1.000000 & & 1.000000 \\
\hline Taborio & 1.000000 & 1.000000 & 1.000000 & 0.008895 & 0.053878 & 0.000014 & 0.185427 & 1.000000 & 0.163123 & 1.000000 & 1.000000 & 1.000000 & \\
\hline
\end{tabular}




\subsubsection{2 - Parametric analysis}

A repeated measures ANOVA showed that the average weight of individual lollyfish among 13 sites and among sites by week interactions were significantly different, but not the weight among weeks (Table 11).

Table 11. Analysis of variance on the effects of site, week and week by site interactions

\begin{tabular}{|l|l|l|l|l|l|}
\hline Effect & SS & DF & MS & F & P \\
\hline Intercept & 1160875 & 1 & 1160875 & 1612.019 & 0.000000 \\
\hline Site & 258129 & 12 & 21511 & 29.8670 & 0.000000 \\
\hline Error & 28085 & 39 & 720 & & \\
\hline WEEK & 57 & 2 & 28 & 0.037 & 0.963775 \\
\hline WEEK*Site & 36135 & 24 & 1506 & 1.952 & 0.014507 \\
\hline Error & 60148 & 78 & 771 & & \\
\hline
\end{tabular}

From Table 11, the p-value for repeated measures is 0.00001 which is less than $5 \%$ and thus the variation in site is significantly different. This shows that there are significant differences in average individual weight of lollyfish among sites, regardless of week. Figure 13 shows a similar trend where the variation is statically different at 13 sites. Secondly, Table 11 also shows the p-value of weight for repeated measures is 0.963775 which is greater than $5 \%$ and thus not significantly different. This implies that there is no significant difference in average individual weight of lollyfish among weeks. This variation is similar in trend to Figure 14. Variation in average weight of lollyfish in week by site interaction has the least significant difference by p-value of 0.014507 . Figure 15 shows a similar pattern where the variation is less significantly different at week by site interaction. 


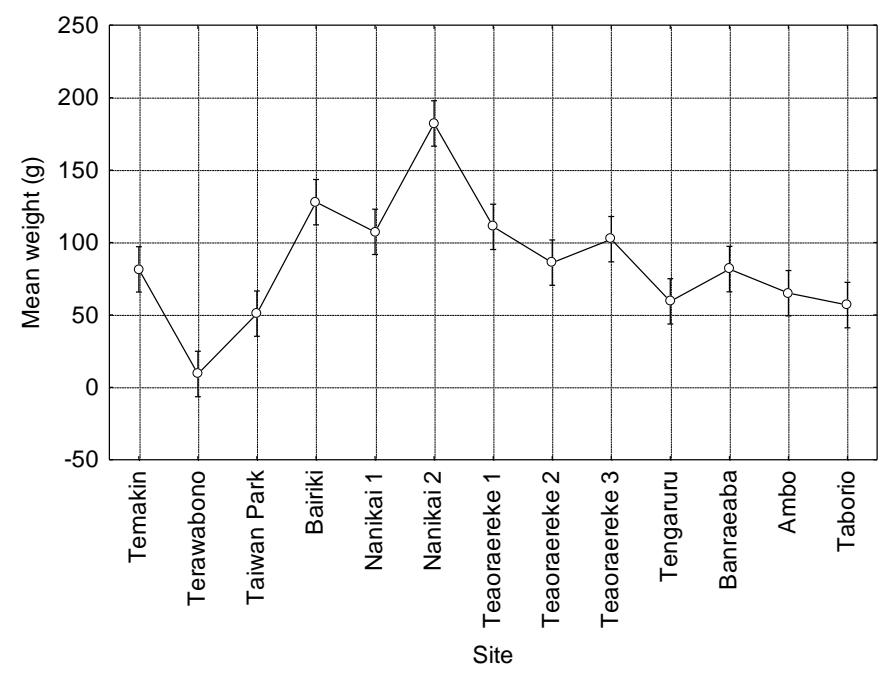

Figure 13. Variation in mean weight of lollyfish among the 13 sites with vertical bars denoting 0.95 confidence intervals.

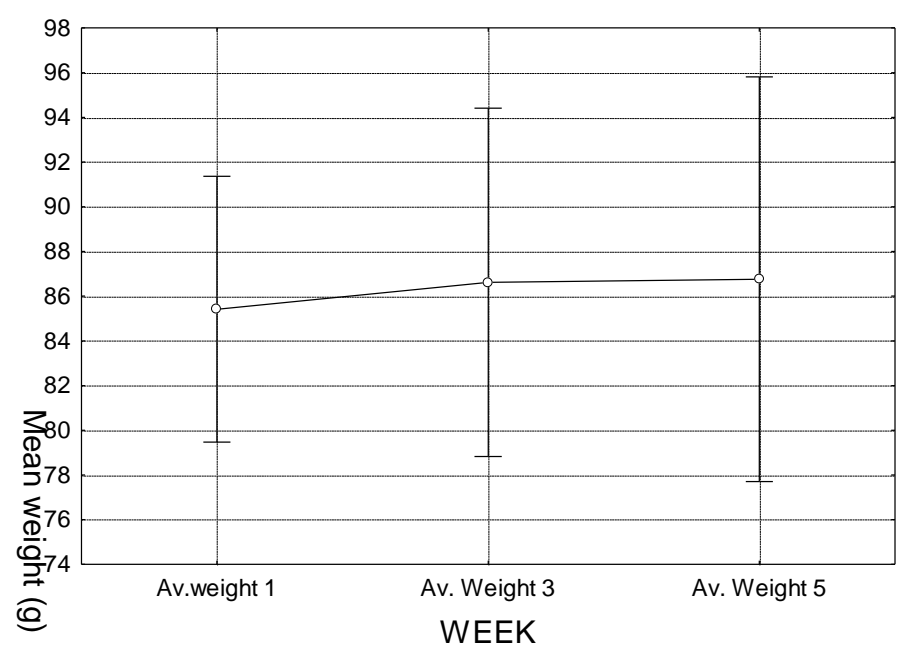

Figure 14. Variation in mean weight of lollyfish among the 3 weeks with vertical bars denoting 0.95 confidence intervals. 


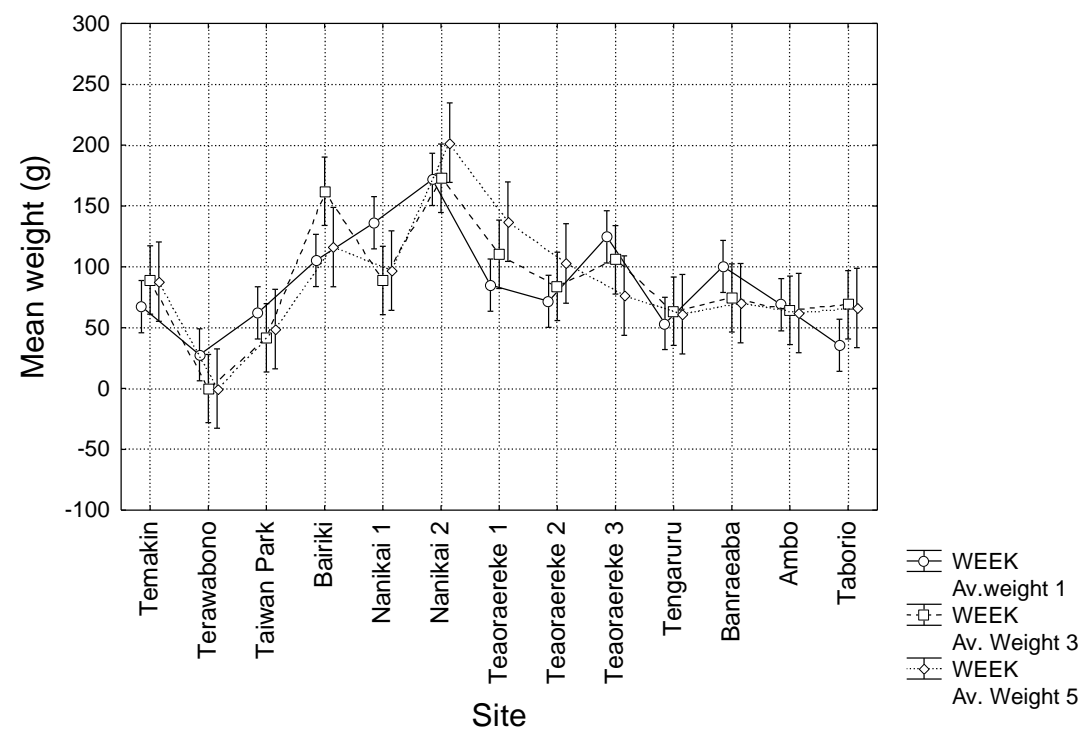

Figure 15. Variation in mean weight of lollyfish at week by site interaction with vertical bars denoting 0.95 confidence intervals.

The relationship between the mean weight of individual lollyfish among 13 sites and week by site interaction show a significant difference. However, the mean weights of lollyfish among the three weeks were not significantly different. Table 17 illustrates these differences.

Table 12 summarises the site-specific mean individual weight values, plus their standard errors, and the $95 \%$ confidence interval. These values of average weight are categorized into three groups: 1) low (0-60), 2) medium (61-100), and 3) large (101190). The sites that have low average weight are Terawabono, Taiwan Park, Tengaruru. Sites with medium average weights are Temakin, Teaoraereke 2, Banraeaba, Ambo, and Taborio. Lastly, the sites with large average weight are Bairiki, Nanikai 1, Nanikai 2, Teaoraereke 2, and Tearaereke 3. 
Table 12. Values of the least squares means of the weight amongst the 13 sites

\begin{tabular}{|c|c|c|c|c|c|}
\hline Cell No. & Site & $\begin{array}{l}\text { DV_1 } \\
\text { Mean }\end{array}$ & $\begin{array}{c}\text { DV_1 } \\
\text { Std.Err. }\end{array}$ & $\begin{array}{c}\text { DV_1 } \\
-95.00 \%\end{array}$ & $\begin{array}{c}\text { DV_1 } \\
+95.00 \%\end{array}$ \\
\hline 1 & Temakin & 81.4958 & 7.746705 & 65.8266 & 97.1650 \\
\hline 2 & Terawabond & 9.2500 & 7.746705 & -6.4192 & 24.9192 \\
\hline 3 & Taiwan Park & 50.9033 & 7.746705 & 35.2341 & 66.5725 \\
\hline 4 & Bairiki & 127.8842 & 7.746705 & 112.2150 & 143.5534 \\
\hline 5 & Nanikai 1 & 107.3533 & 7.746705 & 91.6841 & 123.0225 \\
\hline 6 & Nanikai 2 & 182.2375 & 7.746705 & 166.5683 & 197.9067 \\
\hline 7 & Teaoraereke & 110.8492 & 7.746705 & 95.1800 & 126.5184 \\
\hline 8 & Teaoraereke 2 & 86.1417 & 7.746705 & 70.4725 & 101.8109 \\
\hline 9 & Teaoraereke 3 & 102.3092 & 7.746705 & 86.6400 & 117.9784 \\
\hline 10 & Tengarury & 59.3983 & 7.746705 & 43.7291 & 75.0675 \\
\hline 11 & Banraeaba & 81.6850 & 7.746705 & 66.0158 & 97.3542 \\
\hline 12 & Ambo & 65.0683 & 7.746705 & 49.3991 & 80.7375 \\
\hline 13 & Taborid & 56.8583 & 7.746705 & 41.1891 & 72.5275 \\
\hline
\end{tabular}

Table 13 shows the results of the Bonferroni tests of location of significant differences among 13 sites. It shows $54 \%$ significances among sites. 
Table 13. Lollyfish total weight - Bonferroni test for differences amongst sites: multiple comparison ( $\mathrm{p}$ values) results. Results in red are significantly different $(\mathrm{p}<0.05)$

\begin{tabular}{|c|c|c|c|c|c|c|c|c|c|c|c|c|c|c|}
\hline Cell No. & Site & $\begin{array}{c}\{1\} \\
81.496\end{array}$ & $\begin{array}{c}\{2\} \\
9.2500\end{array}$ & $\begin{array}{c}\{3\} \\
50.903\end{array}$ & $\begin{array}{c}\{4\} \\
127.88\end{array}$ & $\begin{array}{c}\{5\} \\
107.35\end{array}$ & $\begin{array}{c}6\} \\
182.24\end{array}$ & $\begin{array}{c}\{7\} \\
110.85\end{array}$ & $\begin{array}{c}\{8\} \\
86.142\end{array}$ & $\begin{array}{c}9\} \\
102.31 \\
\end{array}$ & $\begin{array}{c}\{10\} \\
59.398 \\
\end{array}$ & $\begin{array}{c}\{11\} \\
81.685 \\
\end{array}$ & $\begin{array}{c}\{12\} \\
65.068 \\
\end{array}$ & $\begin{array}{c}\{13\} \\
56.858 \\
\end{array}$ \\
\hline 1 & Temakin & & 0.000006 & 0.628905 & 0.010537 & 1.000000 & 0.000000 & 0.838279 & 1.000000 & 1.000000 & 1.000000 & 1.000000 & 1.000000 & 1.000000 \\
\hline 2 & Terawabond & 0.000006 & & 0.038416 & 0.000000 & 0.000000 & 0.000000 & 0.000000 & 0.000002 & 0.000000 & 0.003668 & 0.000006 & 0.000724 & 0.007500 \\
\hline 3 & Taiwan Park & 0.628905 & 0.038416 & & 0.000002 & 0.000603 & 0.000000 & 0.000219 & 0.203581 & 0.002567 & 1.000000 & 0.601594 & 1.000000 & 1.000000 \\
\hline 4 & Bairiki & 0.010537 & 0.000000 & 0.000002 & & 1.000000 & 0.001104 & 1.000000 & 0.037508 & 1.000000 & 0.000018 & 0.011105 & 0.000095 & 0.000009 \\
\hline 5 & Nanikai 1 & 1.000000 & 0.000000 & 0.000603 & 1.000000 & & 0.000003 & 1.000000 & 1.000000 & 1.000000 & 0.006806 & 1.000000 & 0.032414 & 0.003325 \\
\hline 6 & Nanikai 2 & 0.000000 & 0.000000 & 0.000000 & 0.001104 & 0.000003 & & 0.000008 & 0.000000 & 0.000001 & 0.000000 & 0.000000 & 0.000000 & 0.000000 \\
\hline 7 & Teaoraereke 1 & 0.838279 & 0.000000 & 0.000219 & 1.000000 & 1.000000 & 0.000008 & & 1.000000 & 1.000000 & 0.002534 & 0.875401 & 0.01246 & 0.001225 \\
\hline 8 & Teaoraereke 2 & 1.000000 & 0.000002 & 0.203581 & 0.037508 & 1.000000 & 0.000000 & 1.000000 & & 1.000000 & 1.000000 & 1.000000 & 1.0 & 0.851843 \\
\hline 9 & Teaoraereke 3 & 1.000000 & 0.000000 & 0.002567 & 1.000000 & 1.000000 & 0.000001 & 1.000000 & 1.000000 & & 0.027368 & 1.00 & 0.1 & 0.013659 \\
\hline 10 & Tengarury & 1.000000 & 0.003668 & 1.000000 & 0.000018 & 0.006806 & 0.000000 & 0.002534 & 1.000000 & 0.027368 & & 1.000000 & 1.000000 & 1.000000 \\
\hline 11 & Banraeaba & 1.000000 & 0.000006 & 0.601594 & 0.011105 & 1.000000 & 0.000000 & 0.875401 & 1.000000 & 1.000000 & 1.000000 & & 1.000000 & 1.000000 \\
\hline 12 & Ambo & 1.000000 & 0.000724 & 1.000000 & 0.000095 & 0.032414 & 0.000000 & 0.012469 & 1.000000 & 0.122467 & 1.000000 & 1.000000 & & 1.000000 \\
\hline 13 & Taborio & & & & & & & & & & & 1.00000 & 000 & \\
\hline
\end{tabular}




\subsection{4 - Transect biomass}

\subsubsection{1 - Non-parametric approach}

Transect biomass of Holothuria atra was statistically significantly different among the 13 sites $(\mathrm{N}=156, \mathrm{p}<0.0001)$.

In addition, Table 14 shows that the least ranked mean biomass (R:7.75) occurred at Terawabono and the highest biomass (R:126.50) was observed in Taiwan Park. The ranked biomasses of $H$. atra in the other eleven sites all fall in between these two values.

Based on variation in the ranked average biomass amongst the 13 sites, Figure 16 reveals three different groupings of populations: (a) low biomass per transect (Temakin, Terawabono, Bairiki, Nanikai 1 and Nanikai 2.), (b) medium biomass per transect (Teaoraereke 1, Teaoraereke 2, and Teaoraereke 3 ), (c) high biomass per transect (Taiwan Park, Tengaruru, Banraeaba, Ambo and Taborio). Values for these differences in biomass are given as follows: low biomas $(<2000 \mathrm{~g})$, medium biomass (2001-6000 g), large biomass (>6001 g).

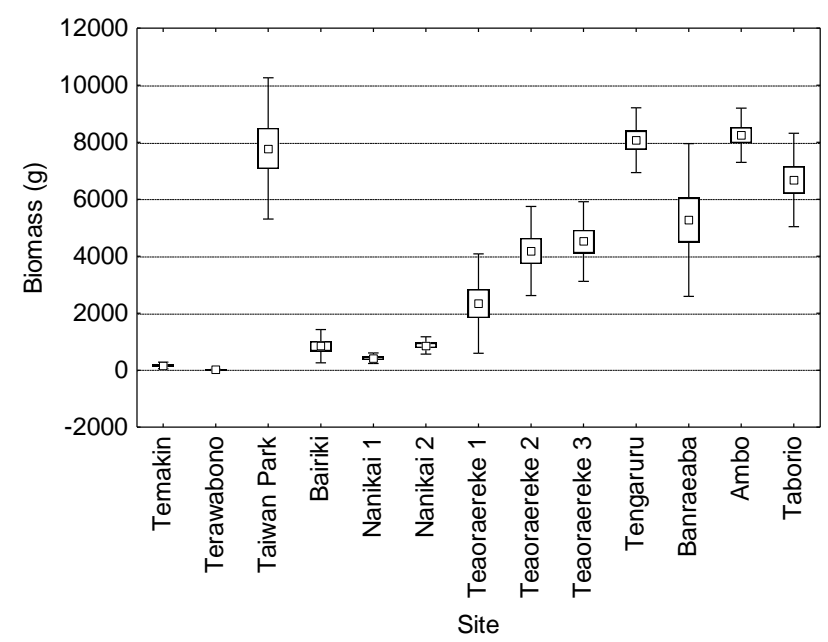

Figure 16. Variation in the transect biomass of lollyfish among the 13 sites. 
Table 14. Transect biomass - Kruskal-Wallis test for differences amongst sites: multiple comparison (p-values) results. Results in red are significantly different $(\mathrm{p}<0.05)$

\begin{tabular}{|c|c|c|c|c|c|c|c|c|c|c|c|c|c|}
\hline $\begin{array}{l}\text { Depend.: } \\
\text { Biomass }\end{array}$ & $\begin{array}{l}\text { Temakin } \\
\text { R:19.187 }\end{array}$ & $\begin{array}{c}\text { Terawabono } \\
\text { R:7.7500 }\end{array}$ & \begin{tabular}{|c|} 
Taiwan \\
Park \\
R:126.50
\end{tabular} & $\begin{array}{c}\text { Bairiki } \\
\text { R:47.750 }\end{array}$ & $\begin{array}{l}\text { Nanikai } 1 \\
\text { R:34.042 }\end{array}$ & $\begin{array}{l}\text { Nanikai } 2 \\
\text { R-52.042 }\end{array}$ & $\begin{array}{c}\text { Teacraereke } \\
1 \\
\text { R: } 68.500 \\
\end{array}$ & $\begin{array}{c}\text { Teacraereke } \\
2 \\
\text { R: } 87.833 \\
\end{array}$ & $\begin{array}{c}\text { Teaoraereke } \\
3 \\
\text { R: }: 1.583 \\
\end{array}$ & $\begin{array}{r}\text { Tengaruru } \\
\mathrm{R}: 133.08\end{array}$ & \begin{tabular}{|c|} 
Banraeaba \\
R:101.83
\end{tabular} & $\begin{array}{c}\text { Ambo } \\
\text { R:136.42 }\end{array}$ & $\begin{array}{l}\text { Taborio } \\
\text { R:116.00 }\end{array}$ \\
\hline Temakin & & 1.000000 & 0.000000 & 1.000000 & 1.000000 & 1.000000 & 0.801573 & 0.015352 & 0.006728 & 0.000000 & 0.000678 & 0.000000 & 0.000012 \\
\hline Terawabono & 1.000000 & & 0.000000 & 1.000000 & 1.000000 & 1.000000 & 0.112758 & 0.001101 & 0.000428 & 0.000000 & 0.000028 & 0.000000 & 0.000000 \\
\hline Taiwan Park & 0.000000 & 0.000000 & & 0.001528 & 0.000042 & 0.004221 & 0.089021 & 1.000000 & 1.000000 & 1.000000 & 1.000000 & 1.000000 & 1.000000 \\
\hline Bairiki & 1.000000 & 1.000000 & 0.001528 & & 1.000000 & 1.000000 & 1.000000 & 1.000000 & 1.000000 & 0.000290 & 0.262388 & 0.000119 & 0.018786 \\
\hline Nanikai 1 & 1.000000 & 1.000000 & 0.000042 & 1.000000 & & 1.000000 & 1.000000 & 0.276064 & 0.141126 & 0.000006 & 0.018507 & 0.000002 & 0.000690 \\
\hline Nanikai 2 & 1.000000 & 1.000000 & 0.004221 & 1.000000 & 1.000000 & & 1.000000 & 1.000000 & 1.000000 & 0.000868 & 0.541384 & 0.000372 & 0.040933 \\
\hline Teaoraereke 1 & 0.801573 & 0.112758 & 0.089021 & 1.000000 & 1.000000 & 1.000000 & & 1.000000 & 1.000000 & 0.023874 & 1.000000 & 0.011711 & 0.567871 \\
\hline Teaoraereke 2 & 0.015352 & 0.001101 & 1.000000 & 1.000000 & 0.276064 & 1.000000 & 1.000000 & & 1.000000 & 1.000000 & 1.000000 & 0.657905 & 1.000000 \\
\hline Teaoraereke 3 & 0.006728 & 0.000428 & 1.000000 & 1.000000 & 0.141126 & 1.000000 & 1.000000 & 1.000000 & & 1.000000 & 1.000000 & 1.000000 & 1.000000 \\
\hline Tengaruru & 0.000000 & 0.000000 & 1.000000 & 0.000290 & 0.000006 & 0.000868 & 0.023874 & 1.000000 & 1.000000 & & 1.000000 & 1.000000 & 1.000000 \\
\hline Banraeaba & 0.000576 & 0.000026 & 1.000000 & 0.262388 & 0.018507 & 0.541384 & 1.000000 & 1.000000 & 1.000000 & 1.000000 & & 1.000000 & 1.000000 \\
\hline Ambo & 0.000000 & 0.000000 & 1.000000 & 0.000119 & 0.000002 & 0.000372 & 0.011711 & 0.657905 & 1.000000 & 1.000000 & 1.000000 & & 1.000000 \\
\hline Taborio & 0.000012 & 0.000000 & 1.000000 & 0.018786 & 0.000890 & 0.040933 & 0.567671 & 1.000000 & 1.000000 & 1.000000 & 1.000000 & 1.000000 & \\
\hline
\end{tabular}


Based on variation in the ranked standard deviation among the 13 sites, Figure 16 reveals three different groupings of populations: (a) low variability (Temakin, Terawabono, Bairiki, Nanikai 1 and Nanikai 3), b) medium variability (Teaoraereke 1, Teaoraereke 2, Teaoraereke 3, Banraeaba, Ambo and Taborio), c) large variability (Taiwan Park and Banraeaba).

\subsubsection{2 - Parametric analysis}

The repeated measures ANOVA revealed that the transect biomass among the 13 sites, among the 3 weeks and site by week interactions were significantly different (Table 15).

Table 15. Repeated measures ANOVA of mean transect biomass as a function of site and time

\begin{tabular}{|l|l|l|l|l|l|}
\hline Effect & SS & $\begin{array}{l}\text { Degree. of } \\
\text { Freedom }\end{array}$ & MS & F & P \\
\hline Intercept & $2.252752 \mathrm{E}+09$ & 1 & $2.252752 \mathrm{E}+09$ & 938.9493 & 0.000000 \\
\hline Site & $1.48110 \mathrm{E}+09$ & 12 & $1.234251 \mathrm{E}+08$ & 51.4437 & 0.000000 \\
\hline Error & $9.356983 \mathrm{E}+07$ & 39 & $2.399226 \mathrm{E}+06$ & & \\
\hline WEEK & $1.155002 \mathrm{E}+07$ & 2 & $5.775012 \mathrm{E}+06$ & 8.4022 & 0.000496 \\
\hline WEEK*Site & $1.288045 \mathrm{E}+08$ & 24 & $5.366854 \mathrm{E}+06$ & 7.8083 & 0.000000 \\
\hline Error & $5.361125 \mathrm{E}+07$ & 78 & $6.873237 \mathrm{E}+05$ & & \\
\hline
\end{tabular}

From Table 15, the p-value for repeated measures is 0.00001 , which is less than $5 \%$ and thus the variation in site is significantly different. This shows that there are significant differences in average transect biomass of lollyfish among sites, regardless of week. Figure 17 shows a similar trend where the variation among sites are differ significantly. Secondly, the Table 15 also shows the p-value for biomass for repeated measures is 0.00049 which is less than $5 \%$ and thus significantly different. This variation is similar in trend to Figure 18. Variation in average transect biomass of lollyfish in the week by site interaction is highly significant with a p-value of 
0.000001. Figure 19 shows a similar pattern where the variation is less significantly different at week by site interaction.

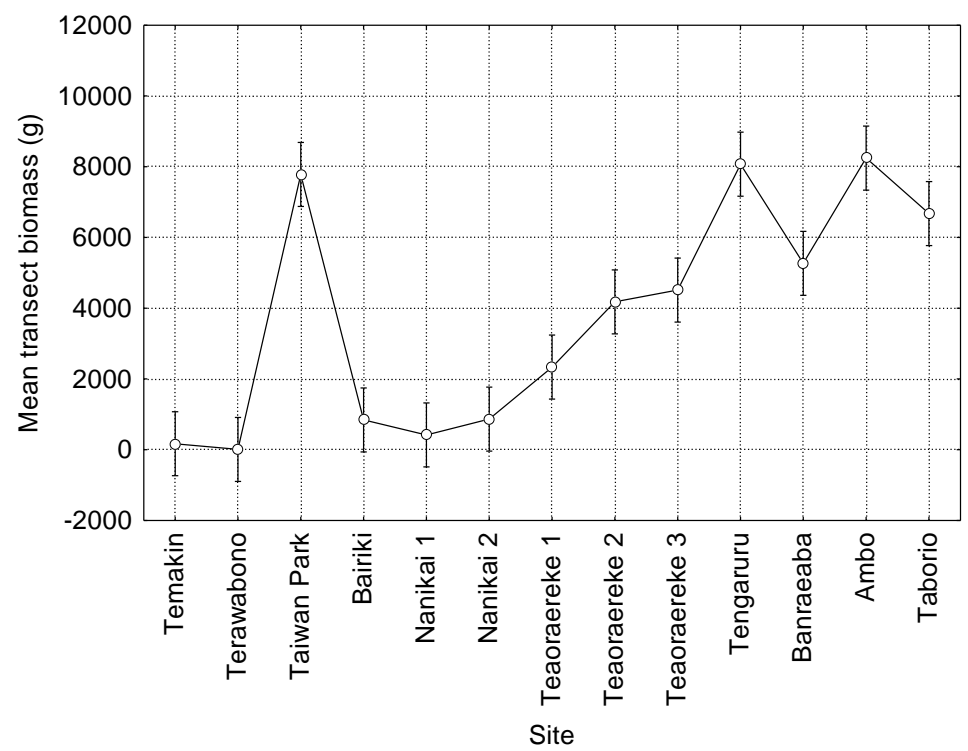

Figure 17. Variation in mean transect biomass of lollyfish among the 13 sites with vertical bars denoting 0.95 confidence intervals.

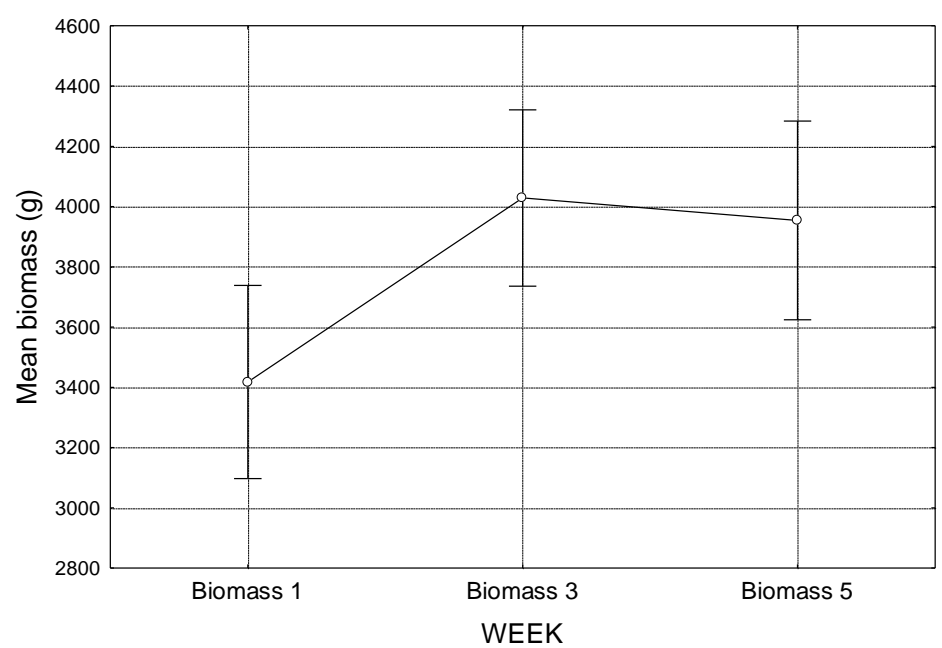

Figure 18. Variation in mean transect biomass of lollyfish among the 3 weeks with vertical bars denoting 0.95 confidence intervals. 


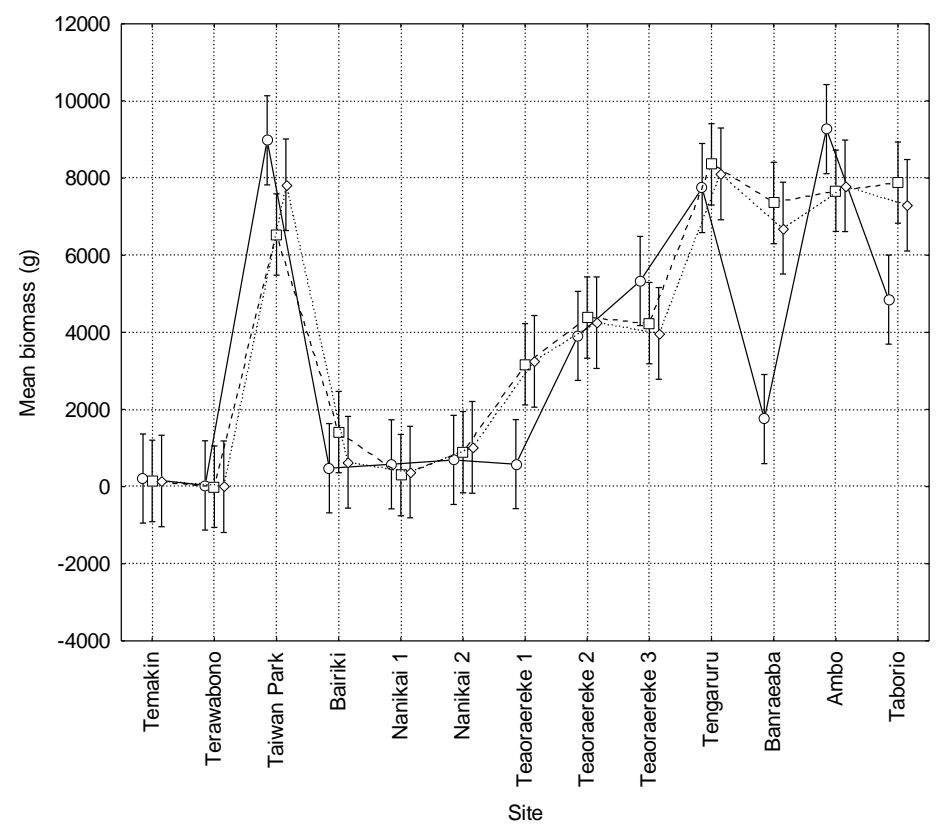

Figure 19. Variation in the transect biomass of lollyfish among site by week interactions with vertical bars denoting 0.95 confidence interavals.

The relationship between the mean weight of lollyfish among 13 sites, among three weeks, week by site interaction show differences which are significant. Table 21 illustrates these differences.

Table 16. Mean transect biomass, standard error, and the $95 \%$ confidence intervals.

\begin{tabular}{|c|c|c|c|c|c|c|}
\hline Cell No. & Site & $\begin{array}{l}\text { DV_1 } \\
\text { Mean }\end{array}$ & $\begin{array}{l}\text { DV_1 } \\
\text { Std.Err. }\end{array}$ & \begin{tabular}{|c|} 
DV_1 \\
$-95.00 \%$
\end{tabular} & $\begin{array}{c}\text { DV_1 } \\
+95.00 \%\end{array}$ & $\mathrm{~N}$ \\
\hline 1 & Temakin & 169.683 & 447.1415 & -734.746 & 1074.112 & 4 \\
\hline 2 & Terawabond & 11.167 & 447.1415 & -893.262 & 915.596 & 4 \\
\hline 3 & Taiwan Park & 7783.208 & 447.1415 & 6878.778 & 8687.637 & 4 \\
\hline 4 & Bairiki & 843.740 & 447.1415 & -60.689 & $1748.16 \mathrm{~g}$ & 4 \\
\hline 5 & Nanikai 1 & 419.995 & 447.1415 & -484.434 & 1324.424 & 4 \\
\hline 6 & Nanikai 2 & 869.447 & 447.1415 & -34.982 & 1773.877 & 4 \\
\hline 7 & Teaoraereke & 2336.678 & 447.1415 & 1432.249 & 3241.107 & 4 \\
\hline 8 & |Teaoraereke $2 \mid$ & 4183.152 & 447.1415 & 3278.723 & 5087.581| & $\mid 4$ \\
\hline 9 & Teaoraereke $\}$ & 4516.015 & 447.1415 & 3611.586 & 5420.444 & 4 \\
\hline 10 & Tengaruru & 8071.494 & 447.1415 & 7167.065 & 8975.923 & 4 \\
\hline 11 & Banraeaba & 5271.602 & 447.1415 & 4367.173 & 6176.031 & 4 \\
\hline 12 & Ambo & 8247.523 & 447.1415 & 7343.094 & 9151.952 & 4 \\
\hline 13 & Taborio & 6677.524 & 447.1415 & 5773.095 & 7581.953 & 4 \\
\hline
\end{tabular}

Table 16 shows three groupings of populations based on their transect biomass: 1) low (0-1000 g), 2) medium (1001-5000 g) and 3) high (5001-9000 g). Sites that have low transect biomass are Terawabono, Temakin, Bairiki, Naniakai 1 and Nanikai. Sites which have medium transect biomass are Teaoraereke 1, Teaoraereke 2 and 
Teaoraereke 3. Sites possess high transect biomass are Taiwan Park, Tengaruru, Banraeaba, Ambo and Taborio.

The Bonferroni test reveals the location of significant differences in transect biomass among the 13 sites (Table 17). 
Table 17. Transect biomass - Bonferroni test for differences amongst sites: multiple comparison ( $\mathrm{p}$ values) results.

Results in red are significant $(\mathrm{p}<0.05)$

\begin{tabular}{|c|c|c|c|c|c|c|c|c|c|c|c|c|c|c|}
\hline Cell Nc & Ste & $\begin{array}{c}\{1\}\} \\
169.68\end{array}$ & $\begin{array}{c}\{2\} \\
11.167\end{array}$ & $\begin{array}{c}\{3\}\} \\
7783.2\end{array}$ & $\begin{array}{c}[4]\} \\
843.74\end{array}$ & $\begin{array}{c}\{5\} \\
420.00 \\
\end{array}$ & $\begin{array}{c}\{6\}\} \\
869.45\end{array}$ & $\begin{array}{c}\{/\} \\
2336.7\end{array}$ & $\begin{array}{c}\{8\} \\
41832 \\
4\end{array}$ & $\begin{array}{c}\{\{9\} \\
4516.0\end{array}$ & $\begin{array}{c}\{10\} \\
8071.5\end{array}$ & $\begin{array}{c}\{11\}\} \\
5271.6\end{array}$ & $\begin{array}{c}\{12\} \\
8247.5\end{array}$ & $\begin{array}{c}\{13\} \\
6677.5\end{array}$ \\
\hline 1 & Temakin & & 1.000000 & 0.000000 & 1.000000 & 1000000 & 1000000 & 0.113306 & 0.000013 & 0.000002 & 0.000000 & 0.000000 & 0.000000 & 0.000000 \\
\hline 2 & Terawabono & 1000000 & & 0000000 & 1.000000 & 1000000 & 1000000 & 0.055266 & 0.000006 & 0.000001 & 0.000000 & 0.000000 & 0.000000 & 0.000000 \\
\hline 3 & Taiwan Park & 0.000000 & 0.000000 & & 0.000000 & 0.000000 & 0000000 & 0.000000 & 0.000108 & 0.000577 & 1000000 & 0.023235 & 1.000000 & 1000000 \\
\hline 4 & Bairiki & 1000000 & 1.000000 & 0.000000 & & 1000000 & 1000000 & 1.000000 & 0.000401 & 0.000075 & 0.000000 & 0.000002 & 0.000000 & 0.000000 \\
\hline 5 & Nanikai 1 & 1000000 & 1.000000 & 0000000 & 1.000000 & & 1000000 & 0.336529 & 0.000047 & 0000009 & 0000000 & 0.000000 & 0.000000 & 0.000000 \\
\hline 6 & Nanikai 2 & 1000000 & 1.000000 & 0.000000 & 1.000000 & 1000000 & & 1.000000 & 0.000457 & 0000085 & 0000000 & 0.000002 & 0.000000 & 0.000000 \\
\hline 7 & Teaoraereke 1 & 0.113306 & 0.055266 & 0000000 & 1.000000 & 0.336529 & 1000000 & & 0.451592 & 0.107225 & 0000000 & 0.003009 & 0.000000 & 0.000003 \\
\hline 8 & Teaoraereke 2 & 0.000013 & 0.000006 & 0.000108 & 0.000401 & 0.000047 & 0.000457 & 0.451592 & & 1000000 & 0.000025 & 1000000 & 0.000010 & 0.025201 \\
\hline 9 & Teaoraereke 3 & 0.000002 & 0.000001 & 0.000577 & 0.000075 & 0.000009 & 0000085 & 0.107225 & 1.000000 & & 0000135 & 1000000 & 0.000055 & 0.116113 \\
\hline 10 & Tengaruru & 0.000000 & 0.000000 & 1000000 & 0.000000 & 0.000000 & 0.000000 & 0.000000 & 0.000025 & 0.000135 & & 0.005828 & 1.000000 & 1000000 \\
\hline 11 & Banraeaba & 0.000000 & 0.000000 & 0.023235 & 0.000002 & 0.000000 & 0.000002 & 0.003009 & 1.000000 & 1000000 & 0.005828 & & 0.002458 & 1000000 \\
\hline 12 & Ambo & 0.000000 & 0.000000 & 1000000 & 0.000000 & 0.000000 & 0.000000 & 0.000000 & 0.000010 & 0.000055 & 1000000 & 0.002458 & & 1000000 \\
\hline 13 & Taborio & 0.000000 & 0.000000 & 1000000 & 0.000000 & 0.000000 & 0.000000 & 0.000003 & 0.025201 & 0.116113 & 1000000 & 1000000 & 1.000000 & \\
\hline
\end{tabular}




\section{2 - Bottom Sediment}

Table 18 shows the results of visual assessment for the 13 sediment samples. Size of sediments ranges from the medium fine coral sand with only few large particles to coarse sand with lots of large particles.

Table 18. Ranking of sites according to the size of sediment exists in each site

\begin{tabular}{|l|l|l|l|}
\hline $\begin{array}{l}\text { Bottle } \\
\text { No. }\end{array}$ & Description of the grain size & Rank & Site \\
\hline 1 & Medium fine coral sand, only few large particles & 1 & Teaoraereke 3 \\
\hline 2 & Medium sand, only few large particles & 5 & Taiwan Park \\
\hline 3 & $\begin{array}{l}\text { Coarse sand, some shells and some medium fine coral sand } \\
\text { and lots of large particles }\end{array}$ & 13 & Taborio \\
\hline 4 & Same in 3 except fewer large particles & 12 & Ambo \\
\hline 5 & Medium fine sand (same in 4 but fewer particles in 4) & 4 & Nanikai 2 \\
\hline 6 & Same in 3 but less large fragments ( like in 5) & 7 & Nanikai 1 \\
\hline 7 & Very coarse sand, some large fragments & 11 & Temakin \\
\hline 8 & Medium sand, some large fragments & 10 & Bairiki \\
\hline 9 & Fine sand, some large fragments & 8 & Teaoraereke 1 \\
\hline 10 & Fine/medium sand, few large particles & 2 & Banraeaba \\
\hline 11 & Medium sand, some shells and some large particles & 9 & Teaoraereke 2 \\
\hline 12 & Fine/medium sand, fewer large particles & 6 & Terawabono \\
\hline 13 & Medium sand and no large particles & 3 & Tengaruru \\
\hline
\end{tabular}

\subsection{1 - Organic matter}

Table 19 shows the range of percentage values obtained from the weight loss on ignition calculation. It shows that the average mean percentage organic matter content of the sediments calculated from the LOI process ranged from $4.6 \%$ to $15.1 \%$. Figure 20 shows a relationship of percentage organic matter verses geography (from west to east) is not significant $(\mathrm{p}=0.500)$. This explains only $4 \%$ of the variation in the data set. Secondly, the average percentage organic matter across all 13 sites is $6.088 \%$. Figure 20 highlights three different groups of sediment samples based on the percentage of organic matter. These variations are : 1) low percentage $(<4 \%)$ Banraeaba, 2) medium percentage (4-8 \%) - Temakin, Takoronga, Taiwan Park, Bairiki, Nanikai 2, Teaoraereke 1, Teaoraereke 3 and Ambo, and 3) high percentage 
(>8\%) - Nanikai 1, Teaoraereke 2, Tengaruru and Taborio. The figure also highlights the fact that the Teaoraereke 2 site had the highest percentage of organic matter (15.13\%) present in the sediment sample.

Table 19. Summary of dry sediment, organic matter content and percentage organic matter content of sediment samples collected from each of the 13 sites

\begin{tabular}{|c|c|c|c|c|c|c|}
\hline A & B & C & $\begin{array}{c}\text { D = } \\
\text { B -A }\end{array}$ & $\begin{array}{c}\text { E = } \\
\text { B -C }\end{array}$ & $\begin{array}{c}\text { F = } \\
\text { E/D } 100\end{array}$ & \multirow{2}{*}{ Site } \\
\hline $\begin{array}{c}\text { Pan } \\
\text { weight }\end{array}$ & $\begin{array}{c}\text { Pan + dry } \\
\text { sediment }\end{array}$ & Pan + ash & $\begin{array}{c}\text { Dry } \\
\text { sediment }\end{array}$ & $\begin{array}{c}\text { Organic } \\
\text { Matter }\end{array}$ & $\begin{array}{c}\text { \% } \\
\text { Organic } \\
\text { Matter }\end{array}$ & \\
\hline 2.5134 & 11.7327 & 11.2429 & 9.2193 & 0.4898 & 5.3128 & Teaoraereke 3 \\
\hline 2.5227 & 7.0296 & 6.8143 & 4.5069 & 0.2153 & 4.777 & Taiwan Park \\
\hline 2.5133 & 22.5676 & 19.8545 & 20.0543 & 2.7131 & 13.5287 & Taborio \\
\hline 2.5101 & 16.1747 & 15.4303 & 13.6646 & 0.7444 & 5.4476 & Ambo \\
\hline 2.5017 & 13.3812 & 12.6397 & 10.8795 & 0.7415 & 6.8156 & Nanikai 2 \\
\hline 2.5246 & 12.3887 & 11.7018 & 9.8641 & 0.6869 & 9.9636 & Nanikai 1 \\
\hline 2.5042 & 12.6324 & 12.1617 & 10.1282 & 0.4707 & 4.6474 & Temakin \\
\hline 2.5089 & 14.6353 & 13.7131 & 12.1264 & 0.9222 & 7.6048 & Bairiki \\
\hline 2.5329 & 17.3906 & 16.6999 & 14.8577 & 0.6916 & 4.6548 & Teaoraereke 1 \\
\hline 2.5175 & 9.8342 & 9.302 & 7.3167 & 0.5322 & 2.2737 & Banraeaba \\
\hline 2.5389 & 16.8801 & 14.7096 & 14.3412 & 2.1705 & 15.1347 & Teaoraereke 2 \\
\hline 2.5432 & 15.0968 & 14.3983 & 12.5536 & 0.6985 & 5.5641 & Terawabono \\
\hline 2.5308 & 10.0491 & 9.1033 & 7.5183 & 0.9458 & 12.5799 & Tengaruru \\
\hline
\end{tabular}

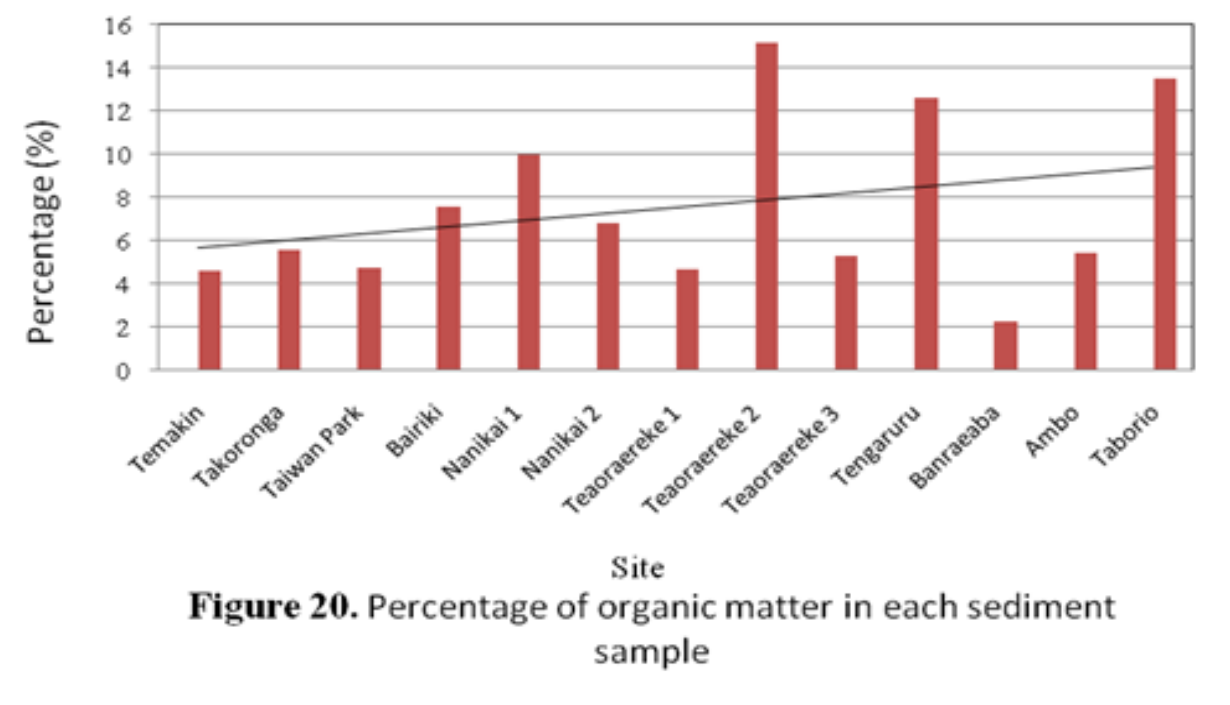

\subsection{2 - Sediment grain size}

The analyses provided five parametes - 1) mean, 2) median, 3) standard deviation, 4) $10^{\text {th }}$ percentile $\left(\mathrm{d}_{10}\right)$ and 5$)$ the $90^{\text {th }}$ percentile $\left(\mathrm{d}_{90}\right)$ - which are used to describe the particle size distributions of the 13 sites in Tarawa lagoon (Table 20). Among the 13 
sites, Table 20 shows that three different groupings of sediment may be defined: a) fine $(<500 \mu \mathrm{m})$-Terawabono, Nanikai 1, Teaoraereke 2, Teaoraereke 3 and Taborio, b) medum (500-600 $\mu \mathrm{m})$ - Temakin, Taiwan Park, Bairiki and Banraeaba, and c) coarse $(>600 \mu \mathrm{m})$ - Nanikai 2, Teaoraereke 1, Tengaruru and Ambo. These values correspond with the frequency distributions of grain size shown in Figure 21.

Table 20 - Details of the grain size analyses of sediment from 13 sites in Tarawa lagoon.

\begin{tabular}{|c|l|c|c|c|c|c|}
\hline Site & \multicolumn{1}{|c|}{ Name } & $\begin{array}{c}\text { Mean } \\
(\boldsymbol{\mu m})\end{array}$ & Median$(\boldsymbol{\mu m})$ & $\mathbf{S D}(\boldsymbol{\mu m})$ & $\mathbf{d}_{\mathbf{1 0}}$ & $\mathbf{d}_{\mathbf{9} \mathbf{0}}$ \\
\hline 1 & Temakin & 560.0 & 487.0 & 398.1 & 74.96 & 1124 \\
\hline 2 & Terawabono & 424.3 & 198.5 & 462.4 & 18.15 & 1138 \\
\hline 3 & Taiwan Park & 530.8 & 389.9 & 440.7 & 71.91 & 1191 \\
\hline 4 & Bairiki & 515.8 & 325.4 & 460.0 & 124.30 & 1265 \\
\hline 5 & Nanikai 1 & 498.0 & 478.5 & 470.7 & 106.30 & 1257 \\
\hline 6 & Nanikai 2 & 633.8 & 636.2 & 441.3 & 67.93 & 1228 \\
\hline 7 & Teaoraereke 1 & 695.6 & 667.9 & 375.0 & 226.70 & 1213 \\
\hline 8 & Teaoraereke 2 & 459.3 & 331.2 & 385.0 & 93.20 & 1017 \\
\hline 9 & Teaoraereke 3 & 433.6 & 276.4 & 407.5 & 66.74 & 1053 \\
\hline 10 & Tengaruru & 617.5 & 590.8 & 544.2 & 28.17 & 1288 \\
\hline 11 & Banraeaba & 504.4 & 352.5 & 438.0 & 79.97 & 1173 \\
\hline 12 & Ambo & 627.9 & 566.6 & 462.7 & 78.15 & 1284 \\
\hline 13 & Taborio & 418.5 & 274.9 & 381.5 & 105.60 & 972 \\
\hline
\end{tabular}

Figure 21 shows particle size distribution curves for the thirteen sites in Tarawa's lagoon (see CD 5- Sediment size). There are two distinct distributions: a) unimodal and b) bimodal. There are five sites that show unimodal distribution with long tails (i.e., Figure 21a, 21g, 21h, 21k, and $21 \mathrm{~m}$ ) and there are eight sites that show bimodal distributions with long tails (i.e., Figure 21b, 21c, 21d, 21e, 21f, 21i, 21j and 211). In general, both groups exhibited the medium and coarse sizes of sand, these were the most predominant among the 13 sites. 

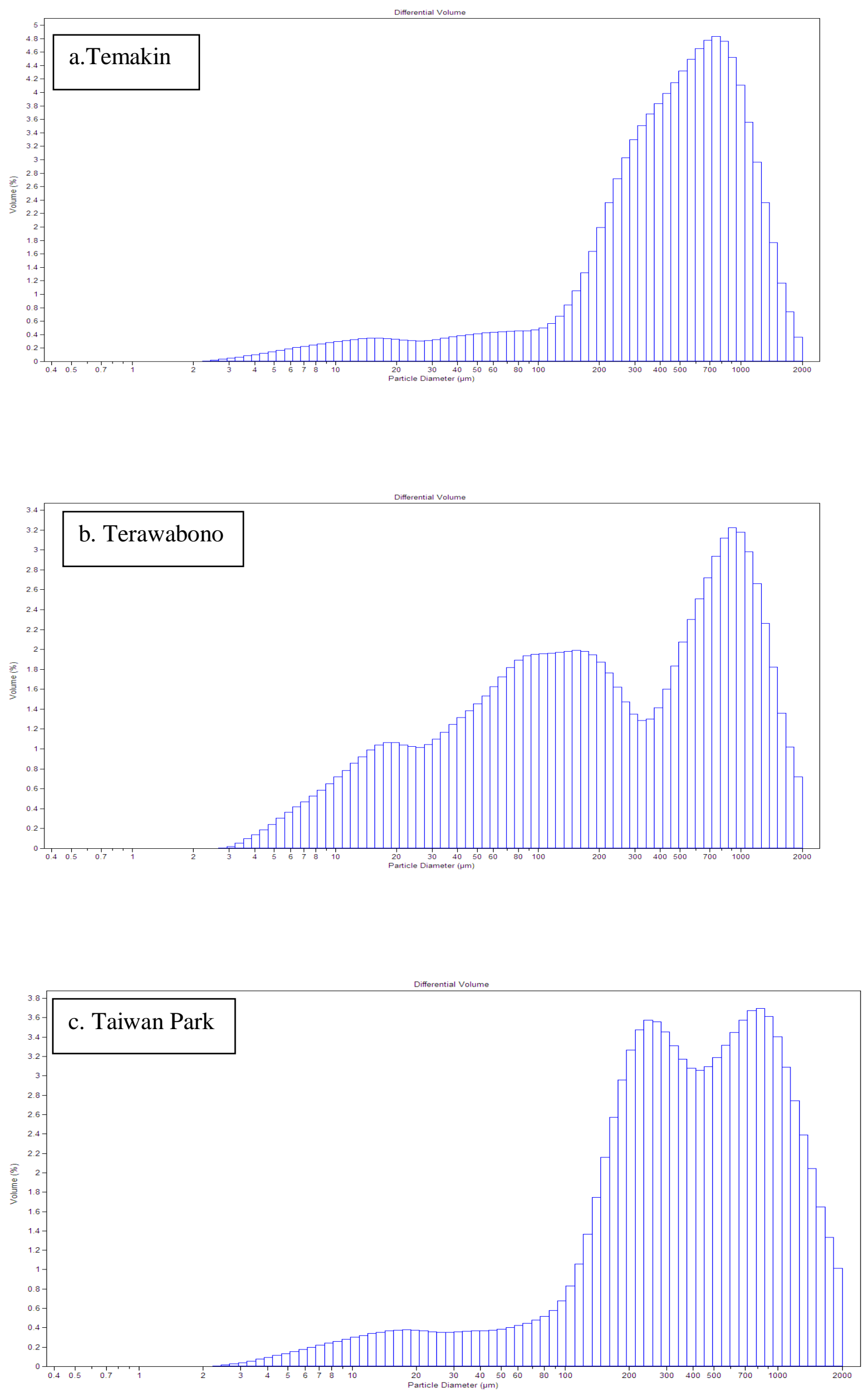
Differential Volume
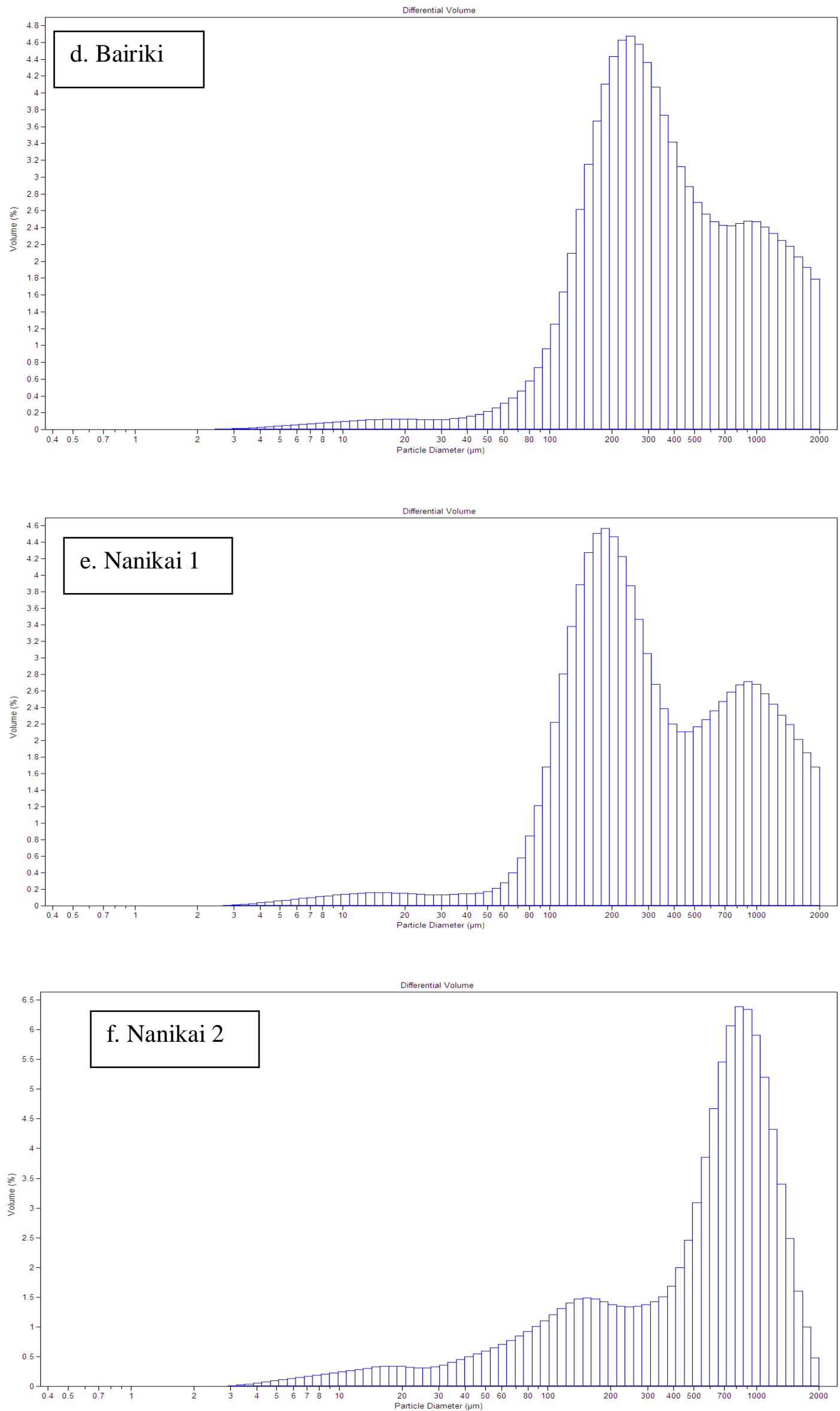
Differential Volume
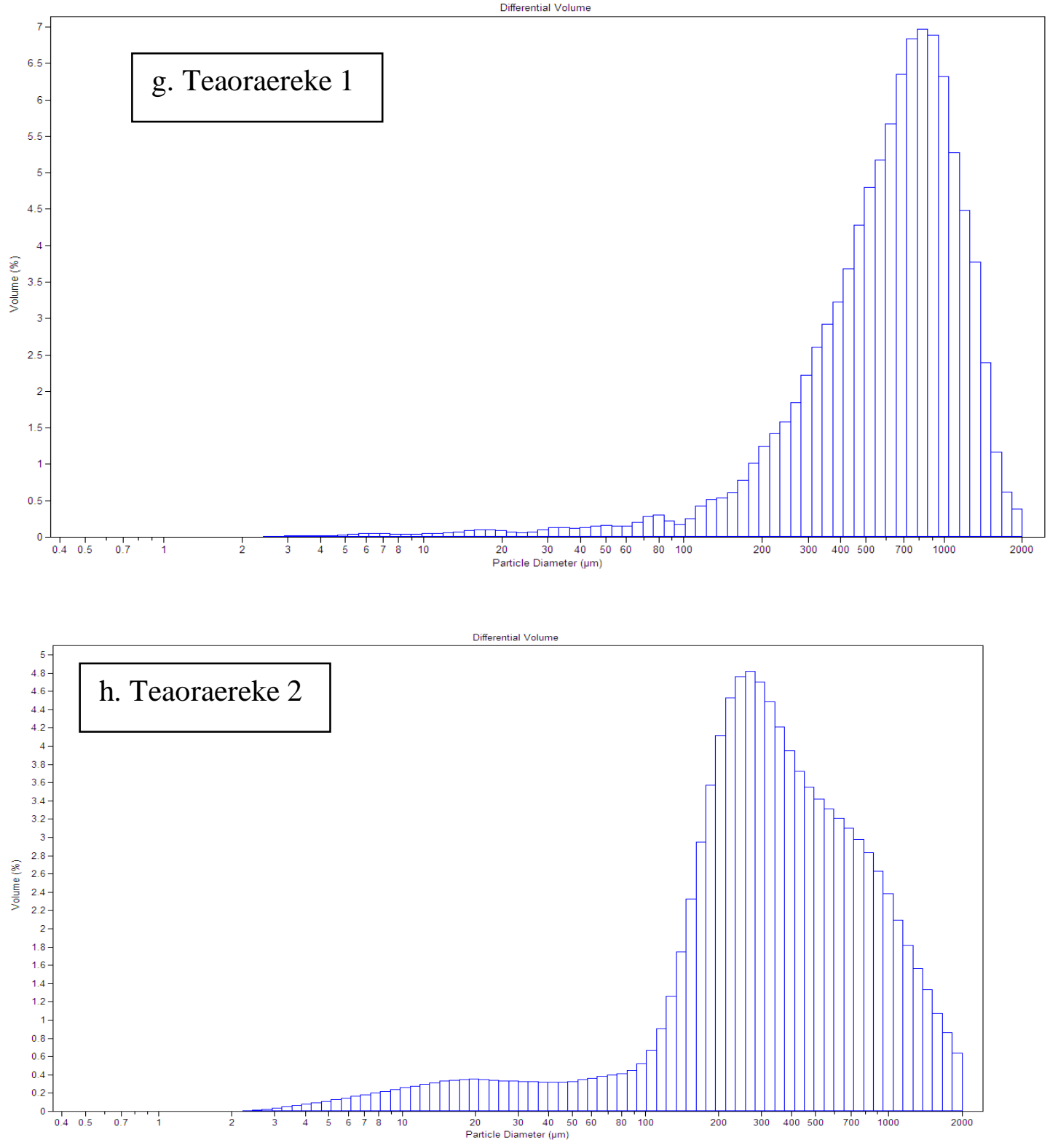

Differential Volume

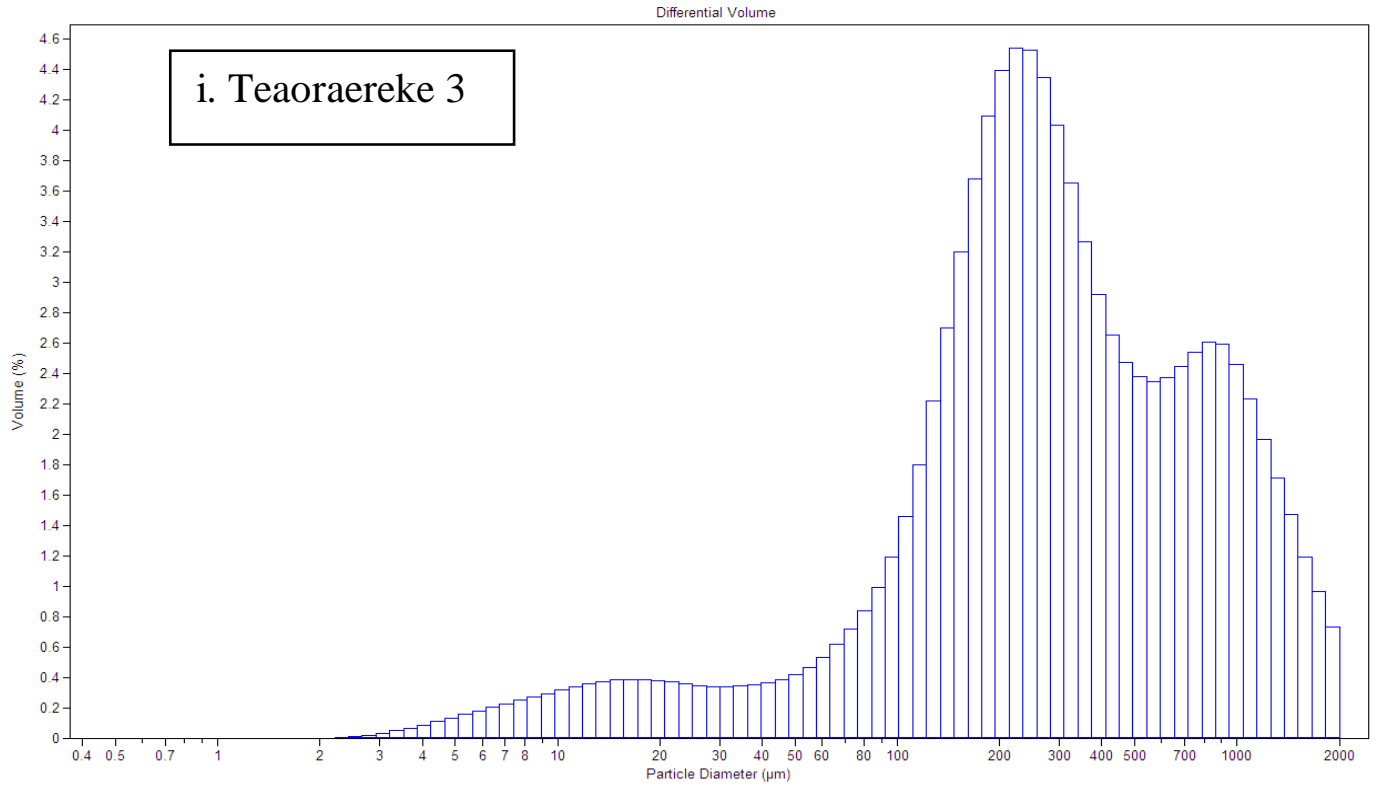


Differential Volume
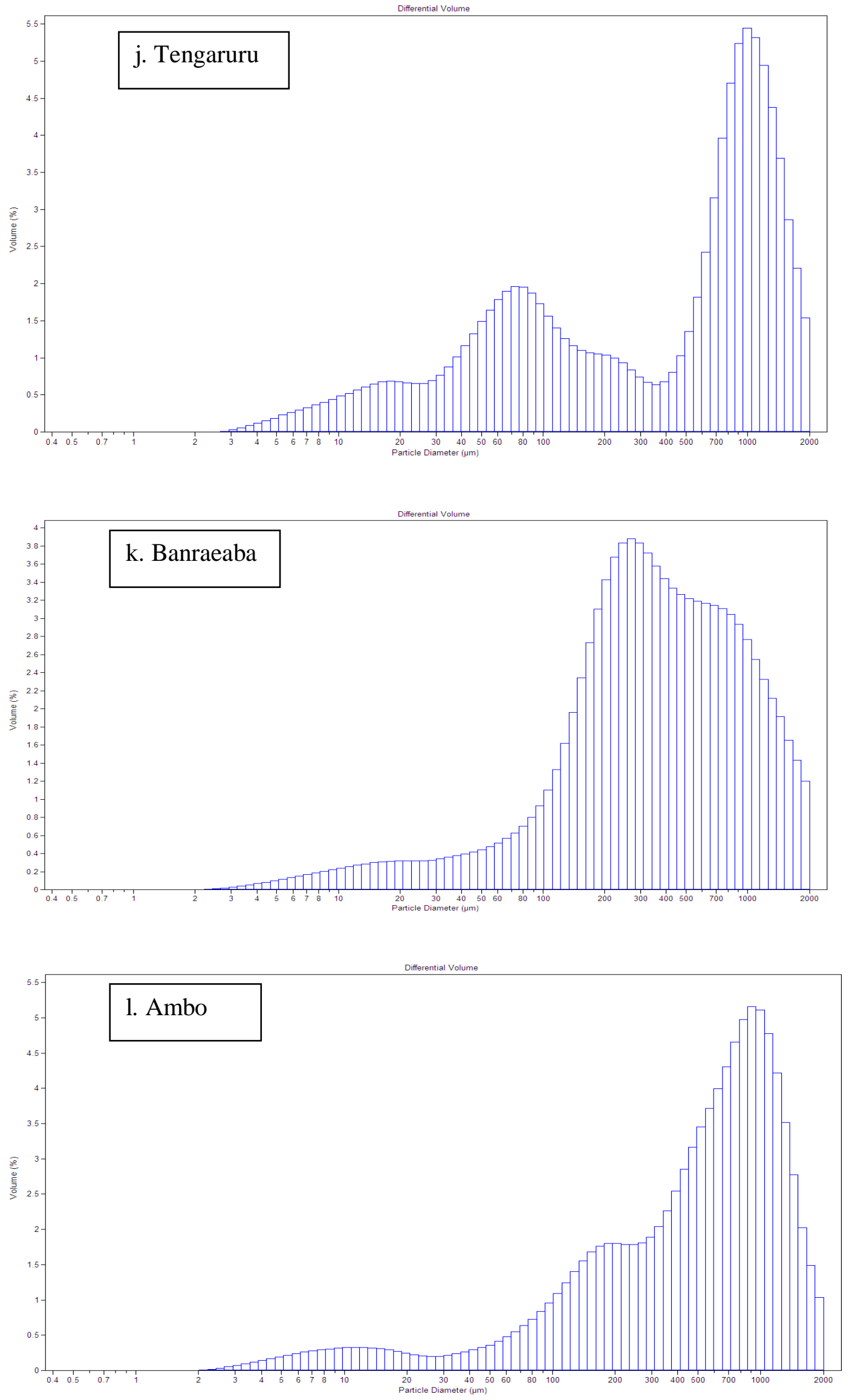


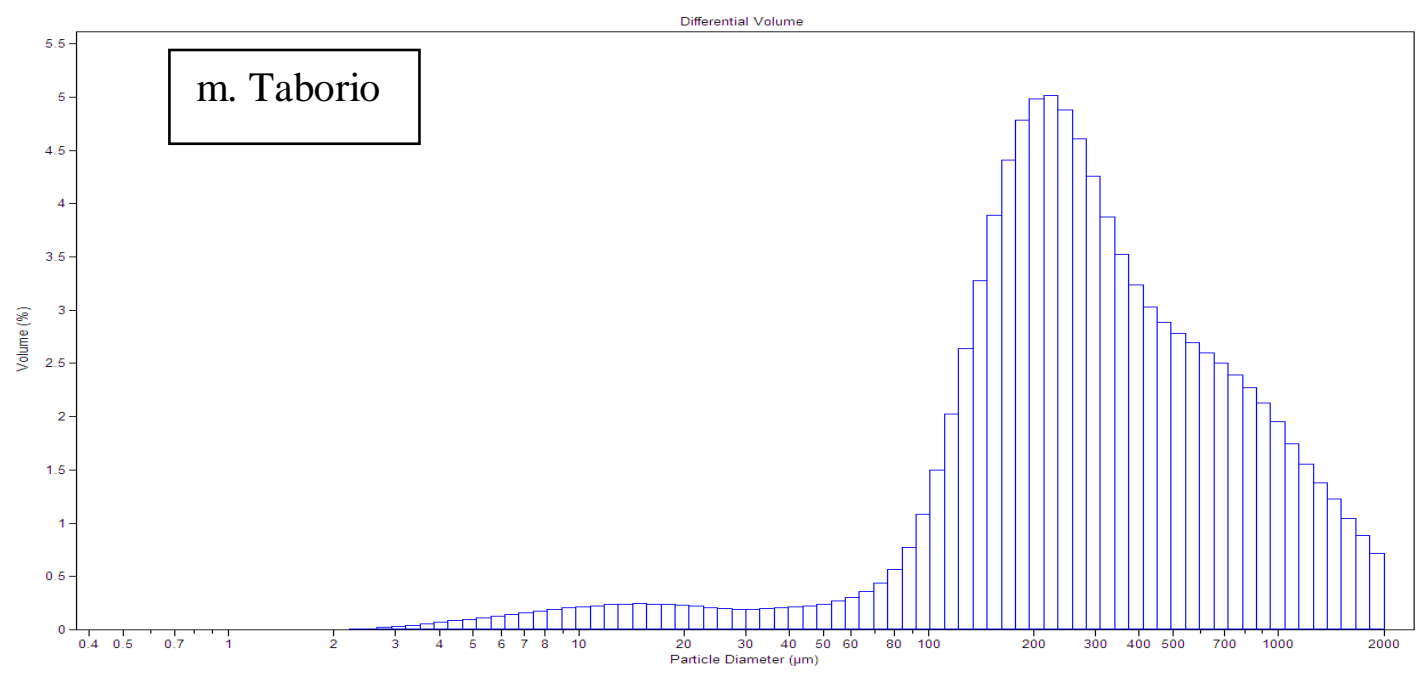

\section{Particle Diameter $(\mu \mathrm{m})$}

Figure 21. Details of sediment grain size plots for sediment from (a) Temakin, (b) Terawabono, (c) Taiwan Park, (d) Bairiki, (e) Nanikai 1, (f) Nanikai 2, (g) Teaoraereke 1, (h) Teaoraereke 2, (i) Teaoraereke 3, (j) Tengaruru, (k) Banraeaba, (l) Ambo, and (m) Taborio.

\section{3- Linking biological and environmental variables}

To find the linkage between the biological and environmental variables, it was appropriate to use the Principle Components Analysis (PCA). Principle Components Analysis (PCA) actually minimises the variables while retaining the maximum variability in terms of variance-covariance structure. Of the 4 biological variables, significant correlations were observed between individual weight and individual length, and between density and transect biomass (Table 21). Of the 7 environmental variables, d90 was significantly correlated with three other variables (sediment percent organic matter, median sediment size, standard deviation of sediment) and median sediment size was statistically correlated with mean sediment size (Table 21). Table 21 suggests that there were no significant correlations between any biological variable and any environmental variable.

Results of the PCA were unable to identify similar patterns or commonality in Figures 22 and 23. However, each figure shows different data. Figure 22 shows site groupings based on six environmental variables and resulted with sites 4, 6 and 2 were positively correlated, but they were negatively correlated to sites 8,10 and 9 . 
Table 21. Correlations between biological and environmental variability

\begin{tabular}{|c|c|c|c|c|c|c|c|c|c|c|c|}
\hline Variable & \begin{tabular}{|l|} 
Density \\
\end{tabular} & Length & Weight & Transect biomass & Sediment rank & Sedt \% OM & Mean sedt & Median sedt & SD of sedt & $d 10$ & d90 \\
\hline \multirow[t]{2}{*}{ Density } & $1.000 c$ & $-.116 \epsilon$ & $-.461 \varepsilon$ & $.971 \subseteq$ & $.003 \AA$ & $.197 i$ & $.053 C$ & .0304 & $.238 C$ & -.2267 & $-.003 k$ \\
\hline & $\mathrm{p}=---$ & $p=.704$ & $\mathrm{p}=.11 \mathrm{c}$ & $\mathrm{p}=.00 \mathrm{c}$ & $\mathrm{p}=.991$ & $\mathrm{p}=.51 \varepsilon$ & $\mathrm{p}=.864$ & $\mathrm{p}=.92^{\prime} \mathrm{c}$ & $\mathrm{p}=.434$ & $\mathrm{p}=.45 \mathrm{\epsilon}$ & $\mathrm{p}=.99 \mathrm{c}$ \\
\hline Length & $-.116 t$ & $1.000 c$ & $.802 \varepsilon$ & -.0331 & .1864 & $.224 \mathrm{C}$ & .2501 & .3864 & $-.220 c$ & .4051 & $.052 \epsilon$ \\
\hline \multirow[t]{2}{*}{ Weight } & $-.461 \varepsilon$ & $.802 \varepsilon$ & 1.000( & $-.388 C$ & $-.130 \epsilon$ & -.0507 & $.399 \overline{1}$ & .4711 & $-.151 \varepsilon$ & $.401 \AA$ & $.241 \varepsilon$ \\
\hline & $\mathrm{p}=.11 \mathrm{c}$ & $\mathrm{p}=.001$ & $p=---$ & $p=.19 c$ & $\mathrm{p}=.671$ & $\mathrm{p}=.86 \mathrm{c}$ & $\mathrm{p}=.17 \epsilon$ & $p=.104$ & $\mathrm{p}=.62 \mathrm{c}$ & $\mathrm{p}=.174$ & $\mathrm{p}=.42 \epsilon$ \\
\hline \multirow[t]{2}{*}{ Transect biomass } & $.971 \mathrm{~s}$ & -.0331 & $-.388 C$ & 1.000( & -.0581 & |182i & .0735 & .0494 & $2.181 \mathrm{~s}$ & $-.173 c$ & -.033ق \\
\hline & $\mathrm{p}=.00 \mathrm{C}$ & $\mathrm{p}=.91 \mathrm{E}$ & $p=.19 c$ & $p=---$ & $\mathrm{p}=.85 \mathrm{C}$ & $\mathrm{p}=.551$ & $\mathrm{p}=.81 \kappa$ & $\mathrm{p}=.87 \AA$ & $\mathrm{p}=.55 \kappa$ & $\mathrm{p}=.57 \iota^{\prime}$ & $\mathrm{p}=.914$ \\
\hline \multirow[t]{2}{*}{ Sediment rank } & .003E & .1864 & $-.130 \epsilon$ & -.0581 & 1.0000 & .2985 & $=017 C$ & .009: & $-.345 \mathrm{c}$ & .349? & -.154ع \\
\hline & $\mathrm{p}=.991$ & $\mathrm{p}=.54 \varepsilon$ & $\mathrm{p}=.671$ & $\mathrm{p}=.85 \mathrm{c}$ & $p=---$ & $\mathrm{p}=.32 \mathrm{c}$ & $\mathrm{p}=.95 \epsilon$ & $\mathrm{p}=.97 \epsilon$ & $p=.24 i$ & $\mathrm{p}=.24 \iota^{\prime}$ & $\mathrm{p}=.614$ \\
\hline \multirow[t]{2}{*}{ Sedt \% OM } & . $.197 \AA$ & $.224 \mathrm{C}$ & -.0507 & "182i & .2985 & 1.000( & -.2644 & -.0995 & $.058 i$ & $-.067 \varepsilon$ & -.3145 \\
\hline & $\mathrm{p}=.51 \varepsilon$ & $\mathrm{p}=.46 \mathrm{C}$ & $\mathrm{p}=.86 \mathrm{c}$ & $\mathrm{p}=.551$ & $\mathrm{p}=.32 \varepsilon$ & $p=---$ & $\mathrm{p}=.38 \varepsilon$ & $p=.74 \epsilon$ & $\mathrm{p}=.85 \mathrm{C}$ & $\mathrm{p}=.82 €$ & $\mathrm{p}=.295$ \\
\hline \multirow[t]{2}{*}{ Mean sedt } & $.053 C$ & .2501 & .3997 & .0735 & $.017 C$ & -.2644 & 1.000( & $\overline{.949 \varepsilon}$ & .1890 & $.374 \varepsilon$ & .6894 \\
\hline & $p=.864$ & $p=.41 c$ & $p=.17 \epsilon$ & $\mathrm{p}=.81^{\prime} \mathrm{c}$ & $\mathrm{p}=.95 \mathrm{t}$ & $\mathrm{p}=.38 \mathrm{E}$ & $p=---$ & $p=.00 C$ & $p=.53 t$ & $\mathrm{p}=.207$ & $\mathrm{p}=.00 \mathrm{~s}$ \\
\hline \multirow[t]{2}{*}{ Median sedt } & .0304 & .3864 & .4717 & .0494 & .009: & -.0995 & $.949 \varepsilon$ & 1.0000 & $.186 \varepsilon$ & (340ई & .625 s \\
\hline & $\mathrm{p}=.92 \kappa$ & $\mathrm{p}=.19 \kappa$ & $p=.104$ & $\mathrm{p}=.87 i$ & $p=.97 \epsilon$ & $\mathrm{p}=.74 \mathrm{\epsilon}$ & $\mathrm{p}=.00 \mathrm{C}$ & $p=---$ & $\mathrm{p}=.541$ & $\mathrm{p}=.25 \mathrm{E}$ & $\mathrm{p}=.02 \mathrm{c}$ \\
\hline SD of sedt & $.238 \mathrm{C}$ & - $-.220<$ & $-.151 \varepsilon$ & ".181؟ & $-.345 \mathrm{~s}$ & $.058 \tilde{f}$ & $.189 \mathrm{C}$ & .186\& & 1.0000 & $-.552 c$ & $=.714 \varepsilon$ \\
\hline \multirow[t]{2}{*}{ d10 } & $-.226 \overline{1}$ & .4051 & .401£ & $-.173 \mathrm{C}$ & "349€ & -..067£ & $=.374 \varepsilon$ & .340ई & $-.552 \varsigma$ & 1.0000 & $.036 \mathrm{~s}$ \\
\hline & $\mathrm{p}=.45 t$ & $\mathrm{p}=.17 \mathrm{C}$ & $p=.174$ & $\mathrm{p}=.57 \mathrm{c}$ & $\mathrm{p}=.24 \varepsilon$ & $\mathrm{p}=.82 \mathrm{\epsilon}$ & $\mathrm{p}=.20 \overline{1}$ & $\mathrm{p}=.25 \mathrm{E}$ & $\mathrm{p}=.05 \mathrm{C}$ & $p=---$ & $\mathrm{p}=.90 \mathrm{E}$ \\
\hline \multirow[t]{2}{*}{ d90 } & - $-.003 \varepsilon$ & $.052 \epsilon$ & 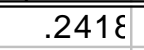 & -.033i & $\begin{array}{l}-.154 \varepsilon \\
\end{array}$ & -3145 & ".6894 & .625؟ & $=714 \varepsilon$ & $.036 \mathrm{~s}$ & 1.0000 \\
\hline & $\mathrm{p}=.99{ }^{\prime}$ & $\mathrm{p}=.864$ & $\mathrm{p}=.42 \mathrm{t}$ & $\mathrm{p}=.91<$ & $\mathrm{p}=.614$ & $\mathrm{p}=.29 \mathrm{E}$ & $\mathrm{p}=.00 \mathrm{c}$ & $\mathrm{p}=.02 \varepsilon$ & $\mathrm{p}=.00 \mathrm{\epsilon}$ & $\mathrm{p}=.905$ & $p=--$ \\
\hline
\end{tabular}


Site 10 and 11 were positively correlated, but negativity correlated to site 1 . This $2 \mathrm{D}$ plots explains $96 \%$ of the variation in the biological data set. Figure 23 shows site groupings based on four biological variables which resulted in having sites 1, 5, and 7 were positively correlated and negatively correlated to site 3,10, 12 and 13. Sites 4 and 6 were highly correlated. Thus, site 1(Teaoraereke 1), 13(Taborio) and 8 (Teaoraereke 2) were more different to site 10(Tengaruru), 2(Terawabono) and 9 (Teaoraereke 3 ) in respect to the large cluster. This 2D plots explains $67.78 \%$ of the total variation.

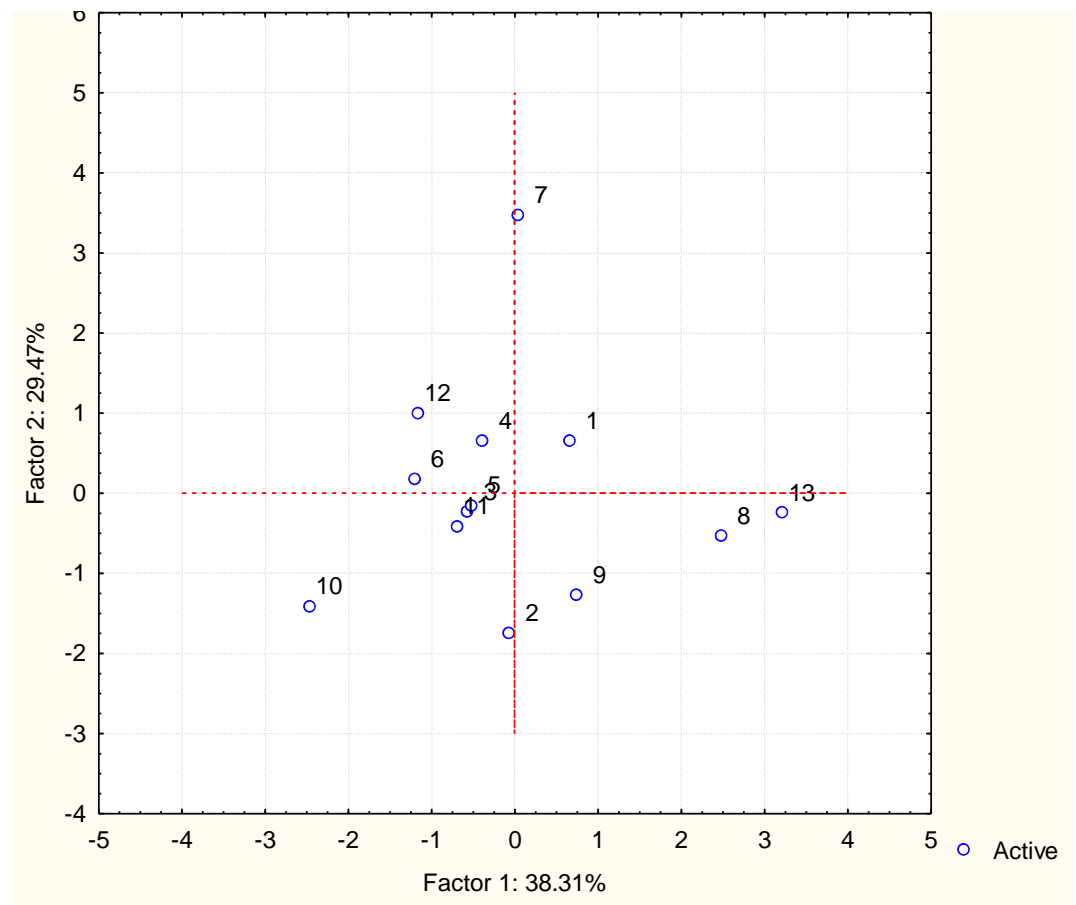

Figure 22. Projection of site groupings based on six environmental variables on the factor-plane (1x 2). 


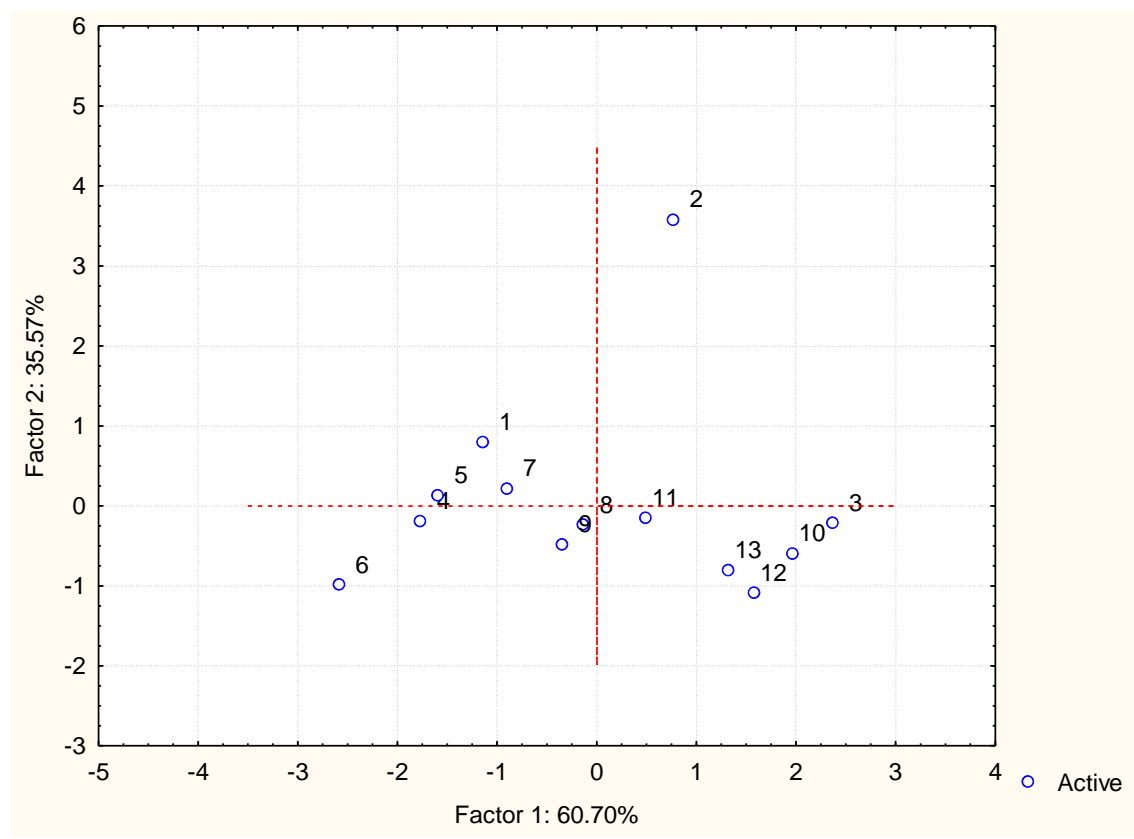

Figure 23. Projection of site groupings based on four biological variables on the factor-plane $(1 \times 2)$.

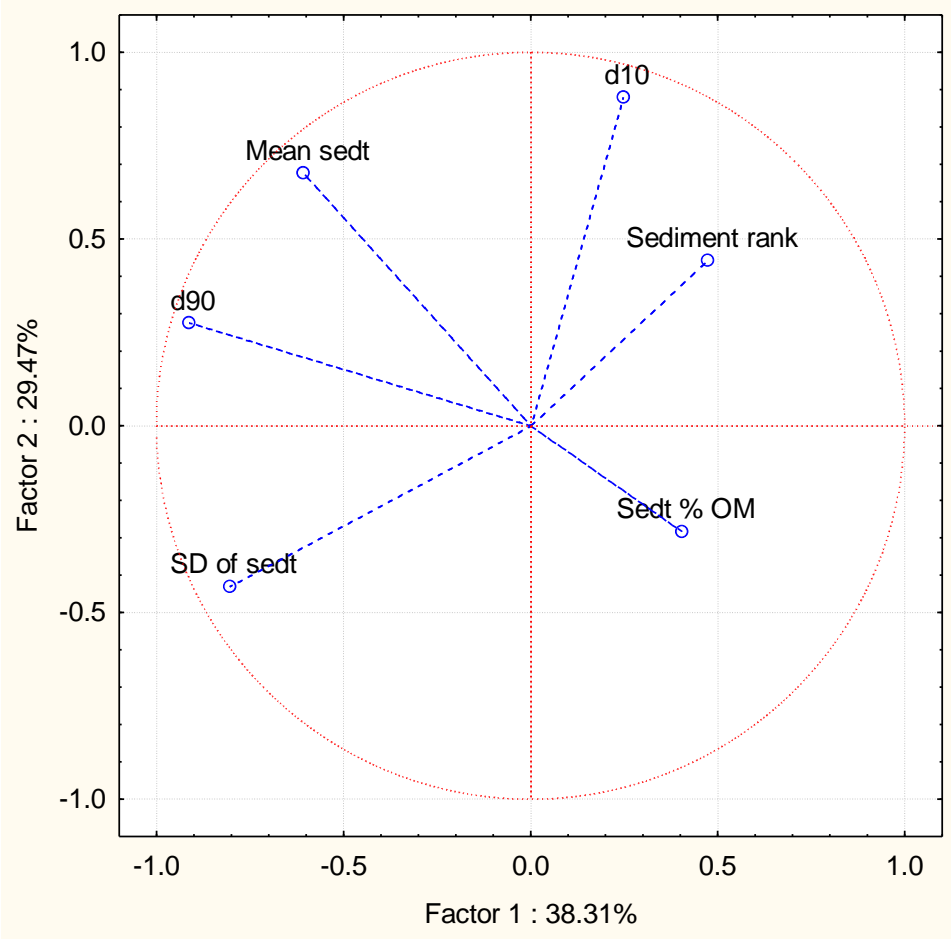

- Active

Figure 24. Relationship of the six independent environmental variables on the factorplane (1 x 2). 
Figure 24 represents the vectors relative to the centre and reduced variables, selected as active in this meta-analysis, were located on the circumference. In this case, median sediment was reduced and so the seven variables were also reduced to six in relation to the dropped of median sediment. Mean sediment and d90 were highly correlated while sediment rank was more related to d10 than the sediment percentage organic matter.

\section{4 - Fishermen Questionnaires}

Twenty fishermen responded to all 19 questions of the questionnaire. Their responses are summarised below on a question by question basis.

Question 1: At what sites do you presently collect lollyfish?

The 20 different fishermen identified 13 different fishing sites that are currently being used to collect lollyfish. Figure 22 shows the answers to this question, where one fisherman collects lollyfish from four different sites, while another 14 fishermen collect lollyfish from two sites. Lastly another five fishermen collect lollyfish from one site only.

Responses of the fishermen are grouped for analysis. Figure 25 presents four different groups of respondents based on their first, second and third fishing sites preferences: each preference is coloured differently. Grey colour is the first preference showing four sites with $>14 \%$ responses (Temakin, Teaoraereke, Tengaruru and Banraeaba). This indicates that these sites are the most frequently visited fishing grounds. The high percentage of people visiting these sites suggests that the number of lollyfish in the past could have been high compared to the present status, which is now depleted. Nanikai was the second most frequently visited fishing ground with 7-14\% responses. The response indicates that the site used to have a moderate abundance of lollyfish which is now declining. Lastly, there were those sites with $<7 \%$ responses (Bairiki, Ambo, Taborio, Bikemaan, Bikenimatang and Causeway). The fishermen visited these sites less frequently. This could indicate that only a few lollyfish exist in these sites. It could also indicate that either the fishermen were not aware of the existence of lollyfish in these sites or the sites were far away and not economical for them to harvest. 
The second preference site is represented by the brick red. Firstly, the graph shows that Ata and Takoronga have $>14 \%$ percent responses. These are the fishing sites most commonly selected as the second fishing ground. Lollyfish could be found here in great abundance and only few knew their existence in these sites. This indicates a shift in the fishing site from a low to high lollyfish abundance. Secondly, there were three sites (Takoronga, Nanikai and Bikemaan) with 7-14\% of the responses. These responses indicate that a moderate abundance of lollyfish is present in these sites. Lastly, there were five sites (Bairiki, Teaoraereke, Tengaruru, Taborio and Bikenimatang) that show $<7 \%$ of the responses. This response reflects that there is a low number of lollyfish present in these sites.

Third and fourth preferences were Bikemaan and Bikenimatanga with $5 \%$ responses, respectively. The isolation and remoteness of these sites are possible reasons for the low responses.

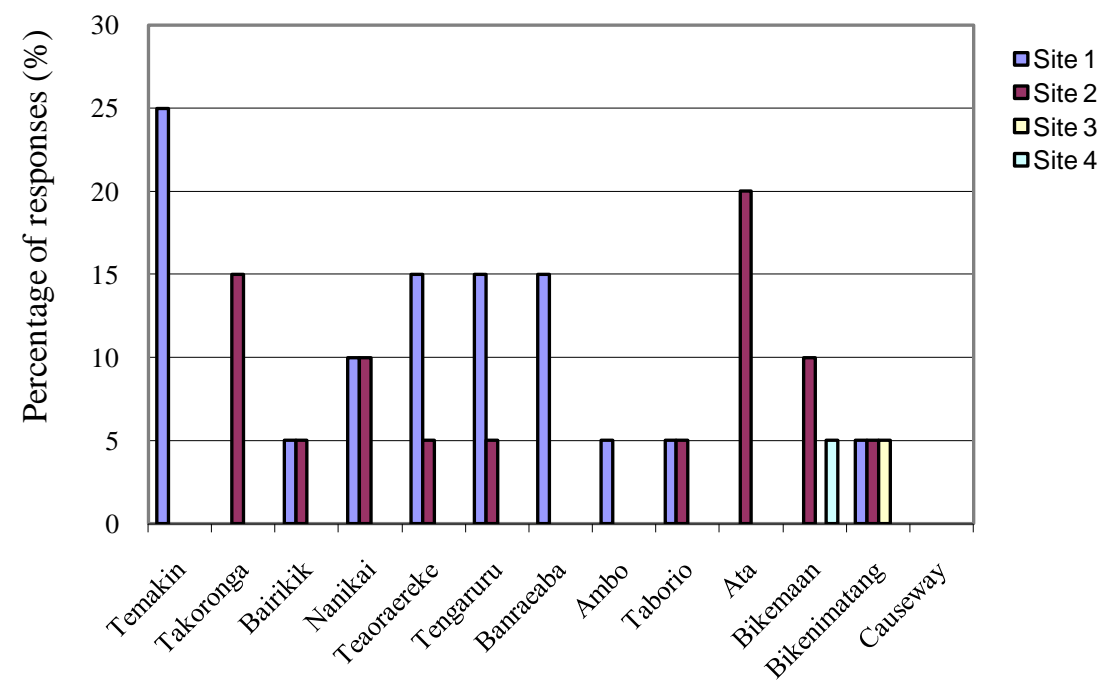

Name of sites

Figure 25. Sites use for collecting lollyfish

Question 2: How long have you been collecting lollyfish from these sites?

The various responses in terms of different units of fishing time were converted into week(s), a consistent unit. The results are shown in Figure 26 which shows thirteen different pie-charts representing a respondent with his fishing time at a particular site. 
Figure 26a shows $25 \%$ of respondents said that they had fished at the Temakin site for different lengths of time. One respondent (5\%) said that he had fished at this site for a week, another said 2 weeks, another said 10 weeks, another said 12 weeks and another said 16 weeks. Figure $26 \mathrm{~b}$ shows $15 \%$ of respondents said that they had fished in Takoronga for different lengths of time. One respondent (5\%) said that he had fished at Takoronga for 4 weeks, one said 6 weeks and another said 28 weeks. Figure 26c shows one respondent (5\%) said that he had fished at Causeway for 24 weeks. Figure 26d shows two respondents $(10 \%)$ said that they had fished at Bairik for 20 and 24 weeks, respectively. Figure 23 e shows that one respondent (5\%) said that he had fished at Nanikai for 16 weeks, one said 28 weeks while another two respondents (10\%) said they had fished there for 12 weeks. Figure $26 \mathrm{f}$ shows two respondents $(10 \%)$ said that they had fished at Teaoraereke for 12 weeks, while another 5\% said that they had fished there for 16 and another said 48 weeks respectively. Figure $26 \mathrm{~g}$ shows two $(10 \%)$ respondents said that they had fished at Tengaruru for 6 and 24 weeks while another two (10\%) respondents had fished there for 16 weeks. Figure $26 \mathrm{~h}$ shows two respondents (10\%) said that they had fished at Banraeaba for 16 and 28 weeks, respectively. Figure 26i shows one (5\%) respondent said that he had fished at Ambo for 12 weeks. Figure 26j shows two (10\%) of respondents said that they had fished at Taborio for 16 and 48 weeks, respectively. Figure 26k shows one (5\%) respondent said that he had fished at Ata for 4 weeks, while another three (15\%) respondents said that they had fished there for 12, 12 and 16 weeks, respectively. Figure 261 shows that two (10\%) respondents said that they had fished at Bikemaan for 16 and 24 weeks, respectively. Lastly, Figure 26m shows that two (10\%) respondents said that they had fished at Bikenimatang for 12 and 24 weeks, respectively.

\section{a. Percentage of fishing time spent at Temakin}

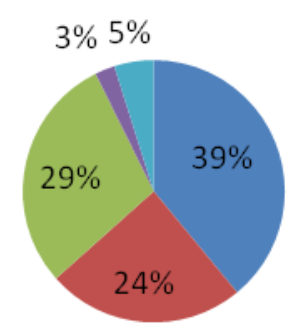

\section{b. Percentage of fishing time spent at Takoronga}

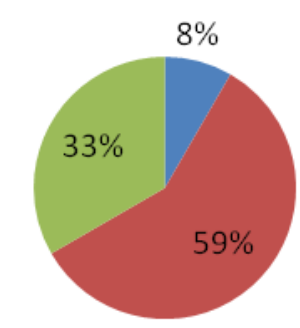


c. Percentage of fishing time spent at causeway.

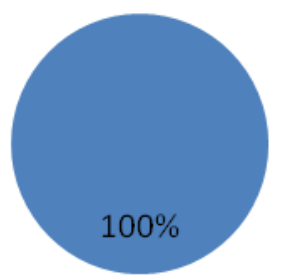

e. Percentage of fishing time at Nanikai

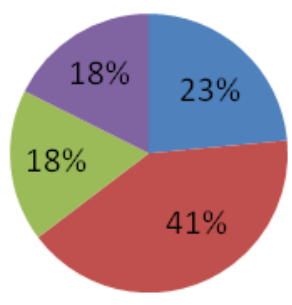

g. Percentage of fishing time spent at Tengaruru

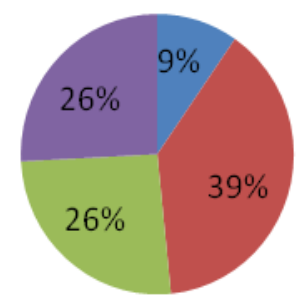

i. Percentage of fishing time spent at Ambo.

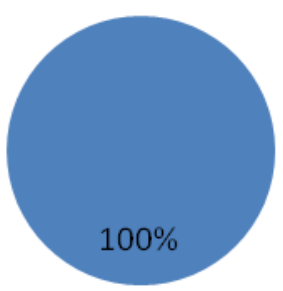

d. Percentage of time spent at Bairiki

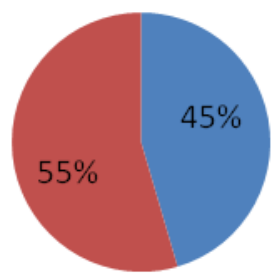

f. Percentage of fishing time spent at Teaoraereke.

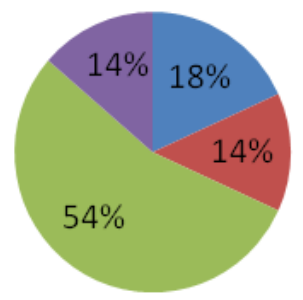

h. Percentage of fishing time spent at Banraeaba.

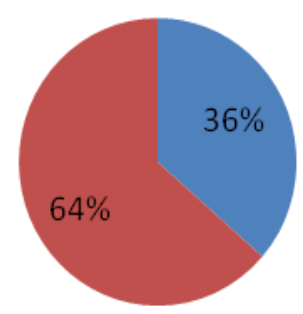

j. Percentage of fishing time spent at Taborio.

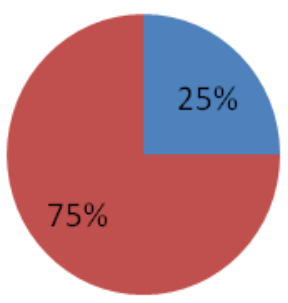


k. Percentage of fishing time

spent at Ata.

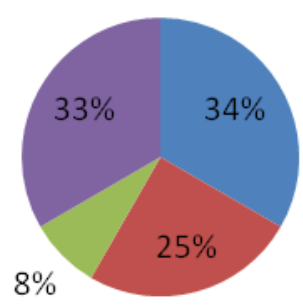

m. Percentage of fishing time spent at Bikenimatang.
I. Percentage of fishing time spent at Bikemaan.

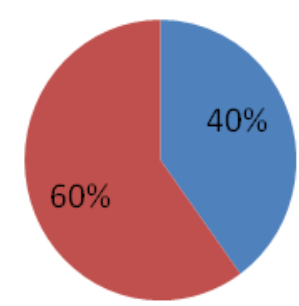

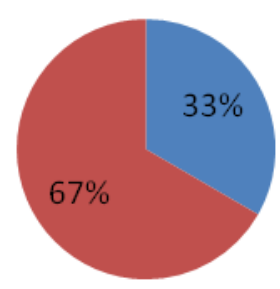

Figure 26. Responses to the question - How long have you been collecting lollyfish at this site?

Question 3: How often do you collect lollyfish from each site?

$30 \%$ of respondents often collect lollyfish every day (a), another $15 \%$ of respondents sometime collect lollyfish once a week (b), while $10 \%$ of respondents rarely collected lollyfish once every two weeks (c), and $20 \%$ of respondents collected lollyfish only when the abundance and price of the lollyfish is good.

Question 4: How many lollyfish do you collect from each site on each visit?

None of the fishermen selected choices a (1 to 20 lollyfish), b (21 to 30) or c (31-40) as their answers. However, 5\% of fisherman collected 41-50 lollyfish per trip, and $95 \%$ of fishermen collected more than 51 lollyfish per trip.

Question 5: What is the average size, the minimum size and the maximum size of the lollyfish that you collect from each site?

Because these fishermen were harvesting 50 or more lollyfish daily, it is important to establish the correct data about the average, minimum and maximum length of the 
lollyfish. Question five investigated this information and it was apparent from the results that the lollyfish were fished from each site when they have reached an average length of $16.25 \pm 0.85$, minimum length of $13.5 \pm 0.83$, and a maximum length of $20 \pm 1.78 \mathrm{~cm}$.

Question 6: What depth range do you collect the lollyfish from?

The results show that lollyfish were normally collected from an average depth of 1.01 $\pm 0.48 \mathrm{~m}$, minimum depth of $0.62 \pm 0.23$ and a maximum depth of $2.10 \pm 0.87 \mathrm{~m}$.

Question 7: At what sites (villages) did you used to, but now no longer collect lollyfish?

Results show $25 \%$ of fishermen used to fish at Temakin. Another $10 \%$ of the respondents said that they used to fish at Teaoraereke, and a further $10 \%$ used to fish at Tengaruru. Thirdly, this figure also highlights that $15 \%$ and $10 \%$ of respondents said that they used to fish at Nanikai and Bairiki, respectively. Lastly, 5\% of the respondents used to fish at Banraeaba, Ambo, Taborio and Ata, making a total of $20 \%$ (Figure 27).

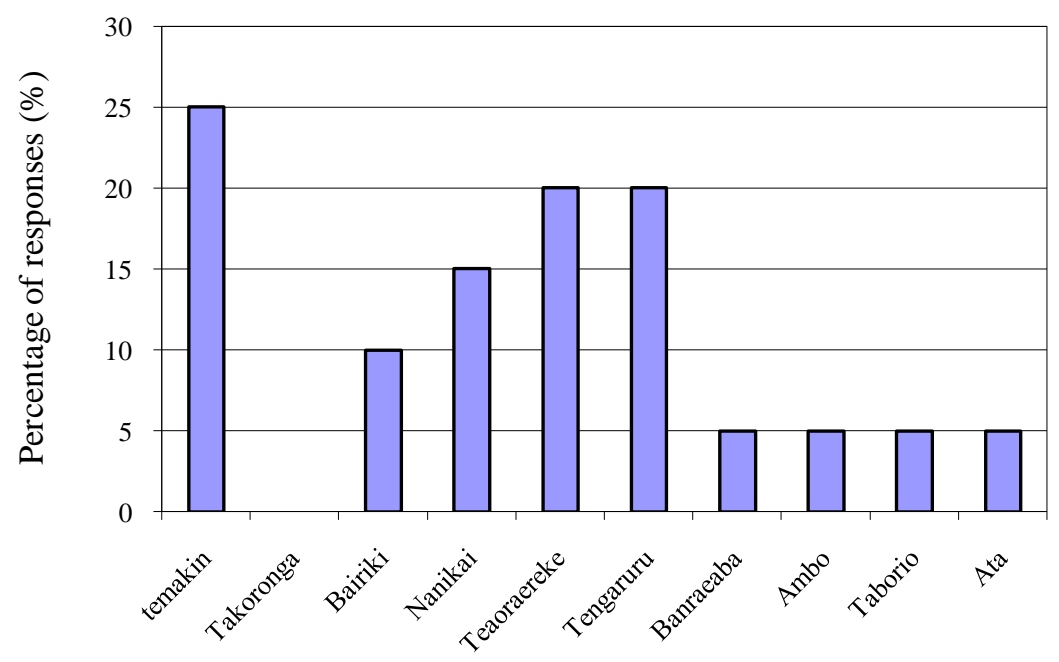

Name of fishing sites

Figure 27. Sites where collecting lollyfish used to occur

Question 8: When did you stop collecting lollyfish from these sites?

No respondents selected responsed a (after one day), b (after few days), or c (after two weeks). Most respondents selected responses d (after one month) and e (after a year), with 60 and $40 \%$ respectively. 
Question 9: Why did you stop collecting from these sites?

No respondents selected options a (site too difficult to get to), c (site too deep to work at safety) or d (site to expensive to get to). The responses b (site has too few lollyfish), e (site too polluted to be safe to work at) and f (other reasons (what this other reason) were selected by $70 \%, 5 \%$ and $25 \%$ of respondents, respectively.

Question 10: In question 9 above, if you answered 9b (site has too few lollyfish) why do you think that site has too few lollyfish? If the answer to question 9 above was not $9 \mathrm{~b}$ then ignore question 10 and go on to question 11 .

This question was relating to the interviewee's perception of why stocks of lollyfish may have declined. One respondent had selected option a (the site has changed naturally and is no longer suitable for lollyfish), while another 6 respondents (30\%) selected option $b$ (the site is now too polluted for lollyfish (sewer pipe outflow), another 4 respondents (20\%) selected option c (all the lollyfish have been collected and not enough remain for a fishery), and 3 respondents (15\%) selected option e (some other reason - 1) hard working and low price) as their answers. None had selected option $d$ (the sites has been modified by human activity-such as building, causeway, no longer suitable for lollyfish), and 3 respondents had ignored this question, while another 3 had nothing to say as an answer.

Question 11: What other species (marine plants and animals) do you collect when you are out there collecting lollyfish? (Seaweed, invertebrate and fish species that were collected).

Interviewees were asked to list other species (marine plants and animals) that they had been collecting besides lollyfish. Results show $55 \%$ of respondents said that they would collect the strawberry conch (gastropod) Strombus luhuanus, 15\% of respondents said that they would collect sea hare egg masses, while $20 \%$ of respondents said that they would collect nothing. One respondent $(5 \%)$ said he would collect S. luhuanus and the bivalve Anadara uropigimelana when fishing. Responses to this question show that fishermen harvested lollyfish as well as other marine plants and animals like te nouo (Strombus luhuanus), te iaia

(sea hare eggs masses) and te bun (Anadara uropigimelana), but S. luhuanus was more exploited than the others. 
Question 12: What other species (marine plants and animals) did you used to collect when you were out collecting lollyfish?

$65 \%$ of respondents said that they used to collect S. luhuanus, while $10 \%$ of respondents said sea slug egg masses, another $10 \%$ of respondents said $A$. uropigimelan, and $15 \%$ said nothing concerning this topic. It is clear that S. luhuanus was the most species collected besides lollyfish.

Question 13: During which months of the year do you collect lollyfish?

No respondents selected May, August, September and November for fishing months for lollyfish. While a $15 \%$ of respondents selected for these three months, February, March, and April, respectively. Another 10\% of respondents have selected January and October, respectively. Another $20 \%$ of respondents have selected July and December, while $25 \%$ of respondents have selected June as the right month for fishing. June, July and December were months in which lollyfish were normally collected.

Question 14: Which month or months of the year provide the best catch of lollyfish?

Two respondents stated January, while another four stated that February, March, April, and October, respectively were the best month for catching of lollyfish. While five respondents stated June, another three stated July is the best month for catching lollyfish. It appears that the two months, June and December, are the best months for fishing.

Question 15: Which month or months of the year provide the poorest catch?

$85 \%$ of respondents stated that they did not know what month had the poorest catch. Another respondent stated April, while another stated May, and yet another stated October as the months of the poorest catch.

Question 16: In your experience what is the state of the lollyfish fishery compared to 10 years ago?

This question deals with the recent change in status of the fishery over the last 10 years. $100 \%$ of the fishermen selected option " $16 \mathrm{e}-$ much worse" as their answer.

Question 17: In your experience, what is the state of the lollyfish fishery compared to 20 years ago? 
This question asks about the long term status of the fishery over the last 20 years. Five answers were provided for the fishermen to select from for their most appropriate response. $95 \%$ of respondents had selected option " $17 \mathrm{e}$ - much worse" as their answer for this question.

Question 18: Is the lollyfish fishery in Tarawa lagoon sustainable in its present form? On a scale of ONE (not at all confident) to FIVE (extremely confident) please rank your answer.

$100 \%$ of respondents stated that they were "not all confident" that the lolyfish fishery in Tarawa's lagoon is sustainable in its present form.

Question 19: In your opinion, what is the single greatest threat to the ongoing sustainability of lollfyfish fishery?

$65 \%$ of respondents thought that overfishing was the single greatest threat to the ongoing sustainability of the lollyfish fishery. Another $30 \%$ of respondents thought pollution, while5\% thought that alga is the single largest threat to the ongoing sustainability of the lollyfish fishery. 


\section{CHAPTER FOUR}

\section{GENERAL DISCUSSION AND CONCLUSIONS}

\section{1- Introduction}

The results of this project provide the first comprehensive regional-scale assessments of the environmental and socio-economic aspects of the tropical sea cucumber species, Holothuria atra (lollyfish) occurrence and exploitation in the lagoon at South Tarawa, Kiribati. Environmental factors such as site health, and the socio-economic aspect such as fishing activities as an example, are implicated in this project as significant key findings in regulating the variability in lollyfish biological data (density, distribution, length, weights and biomass) in Tarawa lagoon. These findings have been statistically confirmed by using nonparametric Kruskal-Wallis (KW) and parametric Repeated Measures (RM) ANOVA tests. These findings will pave the way to (1) better understand the population of lollyfish, (2) better understand the exploitation of lollyfish, and (3) make recommendations to ensure the sustainability of this resource.

The holothuroid fauna, $H$. atra or lollyfish, of the Tarawa lagoon is not different to that observed in many Indo-Pacific nations' marine ecosystems (Massin \& Doumen, 1986; Rowe et al., 1995). However, its biological data such as density and biomass may vary from one place to another (see Table 22), depending on anthropogenic effects and local coastal environmental conditions. Overfishing of lollyfish is the main human activity that can alter the biological data of the species (FAO, 2008). Coastal perturbations such as waves and current are examples of environmental conditions which are the most significant factors regulating echinoderm distribution (Yamanouchi, 1939; Sloan \& Bodungen, 1980). In addition, other researchers have identified several potential regulating factors for lollyfish populations: for example fission (Harriott, 1982), season's (Chao et al., 1993; Uthicke, 1998), nutrient loads (Conand, 1996), emersion or high water temperature (Conand \& De Ridder, 1990), water depth (Chao et al., 1993) and size of sediment (Harriott, 1980). 
Table 22. Comparative densities (individual $/ \mathrm{m}^{2}$ ) and biomass (g wet weight) of Holothuria atra at some regions of the South Pacific

\begin{tabular}{|c|c|c|c|c|}
\hline Species & Location & Density & Biomass & Reference \\
\hline \multirow{9}{*}{$\begin{array}{c}\text { Holothuria } \\
\text { atra }\end{array}$} & $\begin{array}{l}\text { Laing Is, } \\
\text { PNG }\end{array}$ & $\begin{array}{l}0.033-1.46 \\
\text { mean }=0.54\end{array}$ & 0.00 & $\begin{array}{c}\text { Massin \& } \\
\text { Douman } \\
1986\end{array}$ \\
\hline & $\begin{array}{l}\text { Lizard Is, } \\
\text { GBR }\end{array}$ & $0.06-0.15$ & $11.6-13.6$ & Uthick 1994 \\
\hline & $\begin{array}{c}\text { New } \\
\text { Caledonia }\end{array}$ & $\begin{aligned} \operatorname{mean} & =0.06 \\
\max & =0.7\end{aligned}$ & mean $=7.6$ & Conand 1989 \\
\hline & $\begin{array}{l}\text { Heron Is, } \\
\text { GBR }\end{array}$ & $0.17-0.84$ & $8.2-11.34$ & Harriot 1980 \\
\hline & Palau & $0.28-0.51$ & 0.00 & $\begin{array}{c}\text { Yamanouti } \\
1939\end{array}$ \\
\hline & Guam & $\operatorname{Max}=0.22$ & 0.00 & $\begin{array}{c}\text { Rowe \& Doty } \\
1977\end{array}$ \\
\hline & Solomon Is & $0.42 \times 10^{-3}$ & 0.00 & $\begin{array}{c}\text { Lincoln } \\
\text { Smith el } \\
\text { al.1997 }\end{array}$ \\
\hline & Enewetak & $0.24-4.06$ & $\begin{array}{l}20.6- \\
251.75\end{array}$ & $\begin{array}{c}\text { Webb el. Al } \\
1977\end{array}$ \\
\hline & $\begin{array}{l}\text { South } \\
\text { Tarawa }\end{array}$ & $0.01-1.52$ & $\begin{array}{l}9.25- \\
182.23\end{array}$ & $\begin{array}{l}\text { Present } \\
\text { article }\end{array}$ \\
\hline
\end{tabular}

No scientific explanation has been given to support the variability in spatio-temporal distribution of the Holothuria atra along the coastal lagoon of South Tarawa. Although many scientists like Bakus (1973), Harriott (1980, 1982, 1985), Chao et al., (1992), Conand (1996) and Uthicke (1997) have explained the variability in biological data of Holothuria atra, none of these researchers have explained the synergestic effects of the environmental parameters such as the availability of organic matter, site health (water quality, dissolved oxygen, and nutrients), and the size of sediment sample), and fishing activities which are major indices of this project. Even scientists who have researched in Tarawa lagoon such as Kimmerer (1995), Paulay 
(1997), and Kimmerer \& Walsh (1981) did not integrate these factors into their study in Tarawa lagoon. Therefore, this makes the project the first of its kind to investigate the population biology, environmental variability and socio-economic aspects of lollyfish occurrence and exploitation in the lagoon at Tarawa.

\section{2 - Biological and Environmental Survey}

The population biology of $H$. atra changes according to the environment. The actual mean and variability of density density, length, weight and biomass of H.atra are different from site to another due to the environmental variabilities. For example, site or environmental health [clean (excellent, partially polluted (good), polluted (unsatisfactory), highly polluted)], depth of the water, organic matter, habitat types, stability of substrates, hydrodynamics, and sediment size, and fishing activities are some of the factors associated with lollyfish biological variability.

\subsection{1 - Density distribution}

Kruskal-Wallis and Repeated Measures ANOVA tests revealed that the density of lollyfish among the 13 sites and between site-by-week interactions differed statistically. In addition, the RM test showed that the density of lollyfish among the three weeks was not significant.

\subsubsection{1 - Statistical analyses}

The use of the Kruskal-Wallis and Repeated Measures ANOVA tests have confirmed statistically that the variations in density distribution of Holothuria atra or lollyfish amongst the 13 sites along Tarawa lagoon are different (see Table 7 and Table 10). These variations are based on two variable factors: the biological and environmental variabilities affect the density of lollyfish to be different from one site to another. However, the results of the PCA tests showed that these two factors were not correlated.

\subsubsection{1 - Actual mean density}

Differences in the variations resulted in the formation of three distinct groupings of populations: 1) low, 2) medium and 3) high density. Figures 3 and 4 give a general trend in the increase of density for lollyfish from low in the West to high in the East. 


\subsection{1 - Low mean density}

Low-mean density of lollyfish occurs in these sites: Temakin, Terawabono, Bairiki, Nanikai 1 and Nanikai 2 related to health, fishing pressure and hydrodynamics. Table 1show that the health description of four sites are: "highly polluted", "partially polluted" or "good", but Bairiki and Nanikai 1 are described as "clean" or "excellent". Although these two are only "clean" on the shoreline, they are not clean beyond $100 \mathrm{~m}$ out into the lagoon. At Bairiki lagoon side, there was a large amount of rotten brown algae, while at Nanikai 1 seagrass beds were also covered with rotting brown algae. Historically, Nanikai 1 used to be a dumping ground during the British Era. Thus, it is suggesting that both sites are polluted rather than "clean".

The difference in low-mean density of lollyfish at these six sites (Temakin, Terawabono, Bairiki, Nanikai 1 and Nanikai 2) was possibly due to insufficient dissolved oxygen in the surrounding waters. The presence of leachate streams and a high biomass of decaying brown algae with the strong smell of hydrogen sulphide in these sites suggesting that oxygen may be depleted in the surrounding water. The presence of hydrogen sulphide in these areas is a sign of anoxia indicating low oxygen in the water. The occurrence of anoxic water in these sites are due to the oxidation of other pollutants from landfills, decomposition of brown algae present in the surrounding water environments, and the stagnant water. This finding is consistent with the findings of Massin \& Doumen (1986) who proposed that an anoxic environment can alter the density of lollyfish. According to Yamanouchi (1939), habitats with a high concentration of hydrogen sulphide are lethal to sea cucumbers, suggesting sea cucumbers have a high demand in oxygen. In fact, $H$. atra has a respiratory rate of $13 \mu \mathrm{g} / \mu \mathrm{l}$ of oxygen/g wet body/hour (Lawrence, unpublished data). The moving of lollyfish toward more dissolved oxygen is an early behavioral response to the shortage of oxygen (U.S.EPA 2000). So, it is necessary that the concentration of dissolved oxygen in a marine environment is sustainable and available for living organisms.

Low organic matter present in each site is indicated in this project as another cause of the variation in low-mean density of H. atra in South Tarawa lagoon. Figure 20 shows the increase in organic matter from Betio to Nanikai 2. Although the trend may not be a compelling evidence it reflects the increase in density of $H$. atra from Betio to Nanikai 2 as indicated in Figure 3. The findings of this study are consistent with 
other researchers works where they stated that $H$. atra inhabiting low nutrients habitats would have a low density (Conand 1996; Uthicke 1997)

High fishing activity is another possible cause of low-mean density in lollyfish. The low-mean density sites are surrounded by highly populated villages, whose people have minimal financial support and often alleviate their poverty by collecting and selling lollyfish to local and foreign buyers. I was informed during an interview that lollyfish used to be abundant on the reef, but this is no longer the case after both locals and foreigners have engaged in the fisheries. This suggests that Holothuria atra in these areas have been overfished, thus only a few have survived the harvest. Fishing activities have long been globally recognized as one of the determinant factors in depleting sea cucumber abundance (Akamine 2004; Kinch, Purcell et al. 2008).

Thirdly, the difference in low-mean density of lollyfish at Temakin may be due to the hydrodynamics and unstable substrates in this site. The finding of this study is consistent with the results of other researchers (Sloan and Bodungen 1980; Massin and Doumen 1986). At high tide around this site, there is a strong current which sweeps and shifts sands from here to another site. In a similar way, substrates underneath the sea cucumbers would be washed away leaving sea cucumbers detached. In a situation like this, lollyfish often shrink into the shape of a ball and roll with the current to a better habitat. In the field, many lollyfish were often seen using this mode of escape. Despite the lack of literature to support this assumption, future research could aim to verify this behavioral phenomenon. Thus, environmental variability (hydrodynamics, unstable substrates, low DO and low organic matter) and high fishing activity are indicated as important factors in regulating the $H$. atra lowmean density.

\subsection{2 - Medium-mean density}

The medium-mean density population of $H$. atra were significantly different because of their environmental health [clean (excellent), partially polluted (good), polluted (unsatisfactory), highly polluted], and fishing activities. Sites (Teaoraereke 1, Teaoraereke 2 and Teaoraereke 3 ) have been classified as partially polluted or good in Table 1. 
The medium-mean density of lollyfish occurred in these sites because of medium water quality, suggesting that oxygen in water may have a moderate concentration due to the oxidation of other organic matter and pollutants present in these sites. This assumption could not be verified during the course of this research and there is no published scientific information available to support this assumption. However, a comparison could be drawn from other aquatic experiments to support this idea. According to Cerco \& Cole (1995) dissolved oxygen is the most important indicator of the health of aquatic environment. They further reiterated that many important morphological aspects of higher organisms (e.g. sea cucumbers) such as reproduction and respiration would be in jeopardy in an environment where no oxygen is available.

Medium organic matter present in Tearaereke 1, Teaoraereke 2 and Tearaereke 3 caused the variation in medium-mean density of $H$. atra in South Tarawa lagoon. Figure 20 shows the increase in organic matter from Teaoraereke 1 to Teaoraereke 3 which may be connected with the increase in density of $H$. atra from Teaoraereke 1 to Teaoraereke 3 as indicated in Figure 3. The findings of this study are consistent with other reports where it is stated that $H$. atra inhabiting medium nutrient habitats would have a medium density (Conand 1996; Uthicke 1997).

The low or absent fishing activity in the three sites, Teaoraereke 1, Teaoraereke 2 and Teaoraereke 3 is suggested as the potential cause of lollyfish medium-mean density. These three sites are situated adjacent to three densely populated villages, Teaoraereke, Tengaruru and Banraeaba. I was informed during an interview that seven years ago $H$. atra used to be in great abundance on the lagoon sides of these three villages before they were fished out. It is possible that the existing populations of medium-mean density are the leftovers or undersized ones from past harvesting. Now, they have grown bigger and may be ready to be fished again. This observation is consistent with other observation in areas where there is no fishing or where fishing is controlled (Miller 2008; Vroom, Musburger et al. 2010). Thus, the environmental variability such as the site health depicting low DO due to high hydrogen sulphide, and low fishing pressure are two regulatory factors for lollyfish mean-medium density.

\subsection{3 - High-mean density}

High-mean density is the third grouping of populations namely, Tengaruru ( $n=1635)$, Ambo $(n=1519)$ and Taborio $(n=1320)$ and Taiwan Park $(n=1824)$ situated to the 
West of South Tarawa. These sites had a higher mean density of $H$. atra or lollyfish than the other sites situated in the more central area of South Tarawa due to environmental variability, including site health variables such as dissolved oxygen and nutrients, hydrodynamics such as current movements and etc, and the fishing activity. The site health of Taiwan Park, Ambo and Taborio has been described as "clean" or "excellent", suggesting water quality (nutrients and dissolved oxygen) is available at all times to the four sites (Tengaruru, Ambo, Taborio and Taiwan Park). Quality water for these sites comes from the nutrient-enriched equatorial oceanic upwelling waters. This water is very rich in nitrate, nitrogen, phosphorus, and chlorophyll-a which makes the Tarawa's lagoon the most productive water with the highest benthos (benthic organisms) in any atoll of the Pacific (Kimmerer and Walsh 1981; Paulay 2000).

At high tide, the enriched equatorial water enters the lagoon through several entrances such as the boat channel, Betio-Bairiki causeway and seeping through the closed hoas at Ambo-Taborio constriction (see Figure 1). Figures 3 and 4 show five sites with the highest density in lollyfish indicated as Taiwan Park, Tengaruru, Banraeaba, Ambo and Taborio. These sites had dense lollyfish because they are situated close to the source of quality water, suggesting suspended and dissolved nutrients and oxygenated water are highly available.

Quality water provides a nutritive support for the development of benthic organisms. For example, Taiwan Park site is the most dense in lollyfish because it is closest to the source of new incoming water which enters the Betio-Bairiki causeway (see Fig.1). According to Kimemerer \& Walsh (1982) the mean nitrogen concentration in southern Tarawa is about $8.6 \mathrm{mg}-\mathrm{at} / \mathrm{m}^{3}$, almost equivalent to the oceanic mean of 9.4 $\mathrm{mg}-\mathrm{at} / \mathrm{m}^{3}$. This suggests that lollyfish would have the first opportunity to use the incoming dissolved nitrate and nitrogen from the water which enters the causeway. The absorption and assimilation of the nutrients in to the lollyfish would tend to increase their densities and survival rates. Similarly Taborio and Ambo sites are also close to the source of quality water which comes from the ocean side seeping through the blocked hoas (constriction) feeding these sites (see Figure 1). As expected, lollyfish here had high density owing to quality water, indicating enriched DO, nitrates, nitrogen and phosphorus are abundant. 
This finding shows the quality water is the regulating factor of high density, implicating dissolved nutrients in the water as one important regulator of lollyfish density, contradicts past findings (Uthicke 1997; Lee, Byrne et al. 2008). These authors advocated that high density in the $H$. atra population is associated with the nutrient availability in sediments. However, this project did not support this assumption and hypothesis. But, rather it supports the idea that the dissolved nutrients in the water column are more important than the deposited organic matter on sand sediment for the existence and survival of $H$. atra. This suggests that $H$. atra has two modes of feedings; suspension and deposit-feeders. However, suspension-feeders are more significant than deposit-feeders as seen in this project. This suggestion supports research work stating that in areas of strong water movement holothurians became suspension-feeders (Wildish and Krishtmanson 1979). Verification of this idea will be quantified in later discussion on the organic percentage of sediment obtained from each site.

Divergence in options on the cause of high density of $H$. atra obtained from both the present research and the past works differed in the localities of the study sites, the proximity of the sites to human habitations and the presence of equatorial waters. This project has taken in to consideration all these factors in attempting to verify the results. However, Conand (1996) and Uthicke (1997) have not arrived at the same conclusion because they did not incorporate the three factors above.

Interestingly, other researchers have pointed out that asexual reproduction is another regulatory factor in H. atra density (Harriott 1982; Chao, Chen et al. 1992; Uthicke 2001). These authors concluded that $H$. atra inhabiting shallower waters reproduce asexually and increase the lollyfish density. However, field observation contradicts this hypothesis because all the 13 sites are similar in mean depth. This indicates that not even one of these sites is found to be more deeper than 0.5 metres at low tide, but the variability in density of $H$. atra among the 13 sites was observed and significant. This assumption has been statistically confirmed by Lee et al., (2008).

Dissolved oxygen (DO) is another aspect of quality water which has been associated with the high density of lollyfish in Taiwan Park, Banraeaba,Tengaruru, Ambo and Taborio. There are three main sources of oxygen. The first source of oxygen for Taiwan, Ambo and Taborio comes from the equatorial water while Banraeaba and 
Tengaruru comes from the seagrass beds, Thalassia hemprichii. The last source associates with the movement of water (high and low tides).

The first source of dissolved oxygen for Tarawa lagoon is from the equatorial upwelling oceanic water. On a rising high tide, the water enters the causeway and ship channel creating average current of $15 \mathrm{~cm} / \mathrm{sec}$ with a horizontal shear and a higher flow rate near the channel also indicating the presence of an eddy or jet (Kimmerer and Walsh 1981). As results of the incoming current, oxygen is trapped in water and the bottom organic matter are stirred and brought to the surface. These are two functions of the hydrodynamics which promote high density of $H$. atra. Taiwan Park, Ambo and Taborio are very close to the causeway where high oxygenated water is readily available with suspended organic matter. So with more dissolved oxygen available in the water, the $H$. atra could function more physiologically, suggesting more respiration and reproduction. This finding agrees with a very recent paper stating that oxygen may set the limit of asexual reproduction (Lee, Byrne et al. 2008). A suspected high concentration of oxygen in these three sites (Taiwan Park, Ambo and Taborio) has resulted in a high density in lollyfish in them. High density of $H$. atra in association with high water-current has been observed in marine ecosystems, but the author did not give a solid reason to support his finding as to why there was a high density of $H$. atra in such areas (Uthicke 2000). Evidently, at the present time, there is no scientific work available to support this assumption. However, it has been suggested by other scientists that the concentration of oxygen is responsible for respiration and production (Cerco and Cole 1995; Lee, Byrne et al. 2008).

High densities of lollyfish observed in these two sites (Banraeaba and Tengaruru) were associated with high vegetation. This finding agrees with Massin \& Doumen's (1986) work with the same species, Holothuria atra on Laing Island (4' $10^{\prime} 30^{\prime \prime} \mathrm{S}$, $144^{\circ} 52^{\prime} 42^{\prime \prime}$ E) in Madang Province of Papua New Guinea. The authors failed to mention the reason(s) as to why there was a higher density in these sites, although, $H$. atra was the only predominant species in seagrass beds. Even in Pago Bay of Guam, H. atra was found moderately in moat areas where seagrass (Enhalus acoroides) and brown algae (Padina boryana) are dominant (Denton and Morrison 2009). These clearly show that lollyfish flourishing amongst seagrass beds. 
In this study the predominant seagrass species, is Thalassia hemprichii. It is believed that high densities of lollyfish in these sites are strongly associated with the seagrass beds, signifying that high dissolved oxygen is generated from seagrass beds. This hypothesis is consistent with past works done with seagrass indicating that they are able to attenuate anoxic sediment conditions where they are present (Marba and Duarte 2001). They also indicated that oxygen is produced and responsible for the other oxidation processes around the seagrass beds. Higher concentration of dissolved oxygen and high organic matter in seagrass beds than the surrounding environments, are two vital contributing factors to high lollyfish density. There is an absence of literature in this area regarding holothurians in oxygenated water, but it may create opportunities for further studies regarding this assumption. Actually other researchers have confirmed that dissolved oxygen, in any aquatic water is the most important indicator of the health of that aquatic habitat (Cerco and Cole 1995). They further restated the importance of dissolved oxygen in sustaining larger living organisms and its involvement in the various redox reactions. The lollyfish will be associated with the seagrass beds because they will eat the detritus matter generated in/from the seagrass bed. Increased availability of oxygen as a by-product of photosynthesis may also be important.

The movement of water during low and high tides causes more oxygen to be dissolved in the pools near the dry areas during low tide. At low tide the sediments are exposed to air: during emersion, the pools and dry areas are aerated, thus increases the amount of oxygen entrapped under the pebbles and stones, and in the water. So, by the time the high tide comes, there is more oxygen available in this area for organisms inhabiting nearshore areas such as $H$. atra. High density of this species inhabiting nearshores is correlated well with this increase in concentration of DO. This assumption is consistent with the field observation made by Massin \& Doumen (1986) where they observed high density of $H$. atra at pools of Laing Island of Papua New Guinea. Thus, DO concentration is higher in shallower water than the deeper waters. This is why only few larger $H$. atra found in deep water.

Behavioural responses of $H$. atra to insufficient oxygen are suspected in this project as another cause of high density in these sites. The movement of an organism from a place where oxygen is low to a place where oxygen is high could be considered a significant factor for the survival of the organisms (U.S.EPA 2000). H. atra have been seen to be using this mode of movement. In more than several occasions during 
the field study, rolling lollyfish have been observed to roll with the rising in tide to high oxygenated areas (strong current and seagrass beds). This behavioural shift has been noted to be high, especially at Taiwan Park, Tengaruru, Banraeaba, Ambo and Taborio sites. Therefore, it could be surmised that the shrinking of lollyfish into a "ball-like" shape is another important factor in regulating the lollyfish density. This is a novel assumption which has not yet been tested and documented. Maybe, future research could be done on the assessment of lollyfish weights before and after they have rolled.

No fishing activity is another suggested reason as to why there was high density in these sites. Remoteness of these sites from the people made them non-accessible for fishing and they would definitely result in having more $H$. atra. This suggestion agrees with other findings and confirming that the absence of fishing activity can increase marine resources (Miller 2008; Vroom, Musburger et al. 2010).

Thus, the environmental variability, for examples, the site health indicating the water quality (DO, nutrients), hydrodynamic [movement of water (tide, emersion)], behavioural responses of animal, and fishing activity are some factors regulating the $H$. atra high density.

\subsection{4 - Variability in density}

The spatial and temporal variability (SD) in the density distribution of lollyfish among the 13 sites vary from one site to another. This variability gives rise to three groups of populations; 1) low, 2) medium and 3) high.

Low variability in density of lollyfish shows a homogeneous distribution among four sites (Temakin, Terawabono, Bairiki and Nanikai 1). This homogeneous distribution may represent a population of lollyfish where the density is "the same" in each transect. The set of data obtained from this homogeneous distribution are said to be high precision, suggesting that the data are more reliable and dependable when comparison work is needed.

Medium and high variability in density show a heterogeneous distribution among nine sites (Taiwan Park, Nanikai 2, Teaoraereke 1, Teaoraereke 2, Teaoraereke 3, Tengaruru, Banraeaba, Ambo and Taborio). These populations of lollyfish heterogeneous distribution may represent a population of lollyfish where the density is "very different" in each transect. This set of data obtained from the this 
heterogeneous distribution is said to have low precision because of some common thread which links the sites of one group together, for example geography and environmental health.

\subsubsection{2 - Parametric analysis: Repeated Measures ANOVA tests}

The Repeated Measures (RM) ANOVA tests showed similar results to KruskalWallis tests in the density and distribution of lollyfish among the 13 sites based on the actual mean and variability in density. Even RM ANOVA tests showed that density among the three weeks and between the sites by week interaction were found to be statistically significant. Thus, the actual mean density and the variability in density among the three weeks and between the sites by week interaction differed statistically.

Environmental variability such as site health, e.g., water quality (dissolved oxygen and nutrients), hydrodynamic (current, water movement), and social factors such as fishing activities are some regulators of $H$. atra density among the 13 sites.

The increase in density of $H$. atra from week 1 to week 3 was due to new recruitments, indicating that the total number of the populations has expanded. This shift in density could be set by environmental variability such as hydrodynamic forces (current, turbulence and eddy). Migration of adult lollyfish to the surveyed sites by rolling with the water movement is a probable explanation to this increased in density. This finding agrees with the idea that Holothuria atra can migrate from one site to another (Uthicke 1994). Explanation for the stable phase observed from week 3 to week 5 was caused by equal rates of sexual and asexual reproduction balancing the mortality rate and (recruitment) migration (Harriott 1980; Ebert 1993; Lee, Byrne et al. 2008). Migration of holothurians from one location to another is common to few holothurians (Conand 1993b; Uthicke 1994).

Figure 6 shows that the mean density distribution of lollyfish between site-by-week interactions differed significantly. The actual difference and variation in both density and distribution of Holothuria atra were due to the marine environmental variability such as site health, e.g., water quality (dissolved oxygen and nutrients), hydrodynamics (current, water movement), and fishing pressure. Secondly, the results may express the actual change in density and distribution in each individual site because of the mortality and migration or recruitment. 


\subsection{2 - Length Distribution}

The variability in spatial and temporal distribution in the actual mean ranked length and in the standard deviation of $H$. atra among the 13 sites and between site-by-week interactions have been tested and both were found to be statistically different. However, the variability in spatial and temporal distribution in the actual meanranked length and in the standard deviation (SD) of $H$. atra was not differed statistically.

\subsubsection{1 - Nonparametric Kruskal-Wallis Test}

The variations in length were based on two variable factors: the actual mean and the variability in length (standard deviation). Both of these clearly showed that the length of lollyfish were different from one site to another.

\subsubsection{1 - Actual mean-ranked length}

Differences in the variations resulted in the formation of three distinct groupings of populations: 1) small or low, 2) medium or moderate, and 3) high.

\subsection{1 - Small-mean ranked length}

The difference in small-mean length of lollyfish in this site (Terawabono) associated with environmental variability [e.g. health (water quality such as dissolved oxygen and nutrients)], and fishing activities are indicated statistically to be associated with this group of population of $H$. atra. Table 1 shows that the health description of Terawabono was described as highly polluted and, therefore it suggests that the quality of water was not good. This indicates that the amount of dissolved oxygen available to $H$. atra, may be limited for proper metabolism because pollutants or leachate streams in the environment which may use up the oxygen for redox reactions (Cerco and Cole 1995). Yamanouchi (1939) suggests that an anaerobic environment was lethal to sea cucumbers in general.

Fishing activity is another possible cause of this smallest -mean length of $H$. atra in Terawabono. This site is located near to a village with a high human habitation, indicating that the people here may have been involved in fisheries of the $H$. atra species (see fishing activities). This assumption is consistent with many published reports indicating that fishing activity is one of the causes of depletion in sea cucumber around the world today (Toral-Granda, Lovatelli et al. 2008; Uthicke 
2004). Thus, the fishing activity amongst the 13 sites is considered as important factors in regulating Holothuria atra small length or size.

\subsection{2 - Medium-mean ranked length}

The second population group is the medium-mean ranked length of $H$. atra which consists of the following sites (Temakin, Taiwan Park, Teaoraereke 1, Teaoraereke 2, Teaoraereke 3, Tengaruru, Banraeaba, Ambo and Taborio). Health condition explains why this population had the medium-mean in length. Within this group, there were three sites (Taiwan Park, Ambo and Taborio) that were labelled as 'clean' or 'excellent'. Then, there were three sites (Teaoraereke 1, Teaoraereke 2, Teaoraereke 3 and Banraeaba) that were labelled 'partially polluted' or 'good'. Lastly, one site (Tengaruru) was labelled as 'polluted' or 'unsatisfactory'. Overall, the average health condition of these eight sites is 'good', suggesting that the water quality (dissolved oxygen and nutrients, etc etc) is at the maximal level of requirement to support the various physiological and morphological functions of $H$. atra. This assumption agrees with past researches stating oxygen is important for reproduction in higher organisms, while the absence of oxygen from the environment is fatal to holothurians (Yamanouchi 1939; Cerco and Cole 1995).

Fishing activity is another factor that can affect the $H$. atra length. These sites (Temakin, Taiwan Park, Teaoraereke 1, Teaoraereke 2, Teaoraereke 3, Tengaruru, Banraeaba and Ambo) are names of the adjacent villages. Figure 10 and 12 show that these areas have been used intensively as fishing sites for $H$. atra in the past and present. Therefore, it can be deduced that these sites could have been overfished, leaving few small and undersized lollyfish to continue the next generations. This deduction is consistent with the conclusions of other researchers stating that fishing activities are one of those factors that can influence the $H$. atra length (FAO 2008; Friedman, S.Purcell et al. 2008). Thus, environmental variability in the health conditions and fishing pressure amongst the 13 sites is suggested as potentially important regulatory factors in $H$. atra medium mean length.

\subsection{3 - Large-mean ranked length}

High-mean ranked length is the third grouping of population in these sites (Bairiki, Nanikai 1 and Nanikai 2). These sites had a higher mean ranked length because of environmental variability [e.g., site health (water quality e.g., dissolved oxygen and 
nutrients), hydrodynamics (water movement, sediment size, organic matters)] and fishing activities.

The health index is one parameter that has shown to be associated with this high-mean ranked length of $H$. atra in these three sites (Bairiki, Nanikai 1 and Nanikai 2). The health conditions of these three sites have been delineated in Table 1, showing that Bairiki and Nanikai 1 are both "clean", while Nanikai 2 is highly polluted. Only the beaches of Bairiki and Nanikai 1 were "clean", but 100 metres away out into the lagoon side, patches of rotting of brown algae were visible on seagrass beds. So, technically both sites were not "clean", they were polluted just like Nanikai 2.

It is surmised in this project that the quality of water had caused the largemean length of $H$. atra. Quality water is a component of an health environment which is normally associated with the concentration of dissolved oxygen and nutrients in the water (Donald, Nakatani et al. 1975). Because these sites are polluted, it is expected that the concentration of dissolved oxygen (DO) in the surrounding water will be low or become metabolically unavailable to lollyfish. The presence of organic matters (dead and rotting brown algae) on seagrass beds, and perhaps seeped leachate streams from the landfill are evidences that indicate that DO is at low level. When DO is a low concentration, physiologically, the larger lollyfish are more efficacy in metabolising the limited dissolved oxygen in the water than the small ones, indicating that length is a biologically important feature in lollyfish distribution. The fact that smaller lollyfish are not found here is an indication that oxygen is insufficient for them. This suggests that small lollyfish are more sensitive to environments with low concentration in DO. This is why only the larger lollyfish are abundant in these three sites. This is consistent with past research which is noted that water circulation in these three sites was restricted, implying that these sites received less water and oxygen (Kimmerer and Walsh 1981). Uthicke (1998) state that only the large sea cucumbers are more efficient in living in environments with low oxygen (Uthicke 1998). Due to the lack of literature related to this topic, more studies could be done in areas such as chemical oxygen demand (COD) and biochemical oxygen demand (COD) to shed more light on this occurrence.

Another possible explanation to the large size (length) of these $H$. atra in these sites is due to the nutrients, implying the presence of micronutrients. The 
circulation and nutritive aspects of Tarawa lagoon have been shown to be the most productive Atoll in the Pacific (Kimmerer and Walsh 1981; Paulay 2000). According to Kimmerer \& Walsh (1981) South Tarawa lagoon is richer in particulate organic carbon (POC), inorganic carbon (PIC), and nitrogen (PN), dissolved organic nitrogen (DON), and chlorophyll a than North Tarawa. They strongly affirmed that the lagoon is a sink for nitrogen and phosphate. When considering all these factors; high nutritive water and the existence of large $H$. atra in the vicinity of the landfill, where water circulation is restricted, this project intuitively deduced that the presence of trace-elements (micronutrients) such as iron and others is the cause of this variation. Variation in the length observed here is associated with higher concentration in nutrients and importantly the presence of micro-nutrients, potentially including iron leaking or seeping from the landfill to the lagoon. Studies have shown that $H$. atra can incorporate trace elements into their systems (Denton and Morrison 2009).

Absence of fishing is the reason as to why the large lollyfish were found here. It has been known that in unfished lagoonal ecosystems, larger fishes would be predominant in these ecosystems (McClanahan and Arara 1996). Even, if fishing activities have been occurred in the past, the smaller lollyfish should be more predominant in these sites, but this was not the case. Few larger lollyfish were distributed heterogeneously over a large surface of seagrass beds. Thus, it is possible to infer that the environmental variability in water quality and hydrodynamics, and fishing activity plays an important role in regulating the Holothuria atra large-mean length.

\subsection{4 - Variability in length}

The spatial and temporal variability in mean-ranked length of $H$. atra amongst the 13 differed significantly. Low variability in length of lollyfish occurred in these sites (Taiwan Park, Teaoraereke 1, Teaoraereke 2, Teaoraereke 3, Tengaruru, Ambo and Taborio), which shows a heterogeneous distribution along Tarawa lagoon. This variability represents a population of lollyfish where the length is considered to be very different in each transect.

Medium and large variabilities are represented by (Bairiki, Nanikai 1, and Nanikai 2) and (Temakin and Terawabono), respectively. Both variabilities show a homogeneous distribution of $H$. atra length along Tarawa lagoon. The variability is also indicative of a population of $H$. atra where the length is considered to be the 
same in each transect. Data obtained from these homogeneous distributions have low precision, and thus are less reliable to work with.

\subsubsection{2 - Parametric Analysis: Repeated Measures (RM) ANOVA tests}

Figures 8 and 10 statistically support the results of Kruskal-Wallis ANOVA tests, indicating that mean-ranked length and variability in length amongst the 13 sites and between site-by-week interactions were different because of the environmental variability such as health, for example water quality (dissolved oxygen and nutrients), hydrodynamics and fishing activities.

The declining in mean-ranked length distribution of $H$. atra over the span of the survey (3 times) as depicted in Figure 9, was probably due to their ability to expand and contract physically to stimulus. This hypothesis is consistent with past studies reaffirming that holothurians changes their shapes (Conand 1981; Sewell 1990; Sewell 1991).

\subsubsection{3 - Size-frequency distribution}

The spatial and temporal of size-frequency distributions of $H$. atra along South Tarawa lagoon were varied amongst the 13 sites as depicted in Figure 11. There were four different types of size-frequency distributions. These variations in spatial and temporal distributions were due to the environmental variabilities such as site health (water e.g., DO and nutrients), hydrodynamics (water current or movement), and fishing activities. In response to these environmental variabilities, the $H$. atra orient themselves in accordance to these variations, in an attempt to acquire better habitats that are more conducive for them. Recruitment of lollyfish might be occurred in F11d and F11d and suspected to be caused by migration of adults due to rolling action with the water movement.

\subsection{3 - Weight Distribution}

The Kruskal-Wallis and Repeated measures ANOVA tests in this project confirmed statistically that the actual mean-weight distribution and variability in weight of $H$. atra among the 13 sites and between site-by-week interactions along Tarawa lagoon were different (see Table 15, Figure 12 and Table 18). The RM test did not show any 
differences in the mean-weight amongst the three weeks (see Table 16 and Figure $14)$.

\subsubsection{1 - Nonparametric Analyses (Kruskal-Wallis ANOVA tests)}

Differences in the actual mean-ranked weight and variability (SD) in weight were affected by the environmental variability in the site health [e.g., water quality (dissolved oxygen and nutrients)], hydrodynamics (water currents and movements), habitat types, sizes of sediment sample, and organic matters, and fishing activity.

\subsubsection{1 - Actual mean-weight}

Based on the actual mean-weight and variability in weight, three selected groupings of populations were: 1) lighter or low, 2) medium or moderate, and 3) large.

\subsection{1 - The lighter or (low)-weight distribution}

The lighter-weight of $H$. atra observed in Terawabono, Taiwan Park, Tengaruru and Taborio were affected by environmental variability such as water movement, depth and temperature. These four sites are closer to the shores, which means that they are higher up on the drier sandflat. The fact that they are situated on the upper part of the shore would suggest a problem for lollyfish. When $H$. atra inhabit these sites, they are affected by the movement of the water especially during low tide (receding tides), because they are exposed to air (emersion). The effects of emersion on intertidal organisms like $H$. atra are commonly associated with problems such as water conservation, energy conservation and energy acquisition (Shick, Widdows et al. 1988). Certain aspects of these three problems are associated with metabolic functions of $H$. atra, for example, feeding and respiration. At low tide, $H$. atra faces desiccation and also absence of food in their systems for the semi-diurnal movement of tidal water. The loss of water and lack of food in lollyfish for $12 \mathrm{hrs}$ would certainly make them lighter in weight. This finding contradicts past findings where they suggested that smaller size (lighter) were products of fission in shallow water where food availability is high (Chao, Chen et al. 1992; Uthicke 1998; Uthicke 1999; Uthicke 2001). At present, it is not known how H. atra conserves water during emersion. Behavioural movements such as sheltering in crevices and under rocks or even covering itself under white sand are probable strategies that lollyfish would employ to conserve water and energy loss. 
Another metabolic effect of emersion is respiration. Sea cucumber draws water which contains DO through its anus in the tree where respiration takes place before it expels. Emersion could potentially decrease the rate of respiration due to the shortage of oxygen, suggesting that $H$. atra could use other pathways, for example anaerobic in order to compensate for the lack of oxygen (Widdows, Bayne et al. 1979). Limitation of oxygen in water could result in increased activity of muscular and nervous tissues (Lutz 1930). A prolonged emersion could become too costly for the $H$. atra in terms of digestion and assimilation (Shick, Widdows et al. 1988). So, if there is no digestion and assimilation, then, biologically an animal such as $H$. atra would have an empty stomach because it was not feeding. Thus, the animal became more lighter in weight. The absence of research on the effect of oxygen on $\mathrm{H}$. atra could provide a new door for future research.

Fishing activity is another important regulator of lollyfish weight. In an area where fishing activities is flourishing, usually lots of small and light sea cucumbers would be found lying on seagrass beds or sand flats. This suggests that the larger and bigger ones have been harvested, and the presence of the smaller and lighter lollyfish is an evidence that the area has been overfished. And, the second scenario to come, is the depletion follows by extinction of the species. This assumption agrees with the global idea that in heavily fished areas, only few small and lighter juveniles would become predominantly presence (Toral-Granda 2005). Thus, the environmental variability in hydrodynamics especially emersion affects the Holothuria atra light weight distribution. Similarly, fishing activity affects the $H$. atra light weight distribution.

\subsection{2 - The medium-weight distribution}

The medium-weight distribution of lollyfish was observed in Temakin, Nanikai 1, Teaoraereke 1, Teaoraereke 2, Teaoraereke 3, Banraeaba and Ambo. A probable explanation for this medium-weight population was environmental variability in being covered with the water (immersion). These eights sites have a similar mean depth of $0.5 \mathrm{~m}$ which suggests that $H$. atra from each site would have an equal time of immersion and time of feeding. As the immersion time of $H$. atra increases, thus the feeding time would also increase correspondingly. Technically speaking, the more time the lollyfish spends in water browsing for food, the more they would gain energy for their growth and reproduction (Sebens 2002). Sebens reiterates that 
energetic costs increase with temperature and exposure time in regard to immersion time, resulting in small individuals often at the upper limits of distribution.

Another explanation for the medium-weight population was related to fishing activity. These seven sites (Temakin, Nanikai 1, Teaoraereke 1, Teaoraereke 2, Teaoraereke 3, Banraeaba and Ambo) are situated adjacent to highly populated villages, with the exception of Ambo. H. atra used to be found in great abundance on the ocean and lagoon sides, before it was harvested as one of the bech-de-mer (dried) products. However, now only a few medium ones are left in the lagoon on sand flats and seagrass beds. It is likely that these medium-weight lollyfish are the leftover ones from the last harvest. Fishermen could have left the $H$. atra because they were undersized and the price was not good, at that time. So they were left for another fishing time when the price was better. Harvesting of sea cucumber species around the world has been identified as one of the main cause of depletion of high valued sea cucumber species from many oceans and lagoons (Akamine 2004; Uthicke 2004). Thus, the environmental variability in the immersion time and fishing activity are two factors contributing to the medium-mean weight distribution of $H$. atra.

\subsection{3 - Heavy-weight distribution}

The last population group was the heavy-weight $H$. atra found in these sites (Bairiki and Nanikai 2). This population group was heavy-weight because of these four indices: 1) health site, 2) organic matter, 3) sediment size, 4) fishing activity. As an example of environmental variability the health condition of these two sites was classified as 'clean' only at the shoreline, but $100 \mathrm{~m}$ down to the lagoon, rotting brown algae are visible on the seagrass beds. Therefore, it would be true to call them highly polluted or polluted rather than 'clean'. The presence of rotting algae at these two sites implies two points; 1) lack of oxygen and 2) stagnant water.

A site health condition is one of the examples of environmental variability which could affect $H$. atra heavy-weight distribution. A low dissolved oxygen (DO) in the water environments for these two sites is suggested here as a probable explanation as to why the heavy-weight $H$. atra existed in them. This suggestion seems to be supported in one study where it stated that DO concentration is a good sign of a healthy environment because of its importance in respiration and redox reactions (Cerco and Cole 1995). Another study showed that DO is a vital component of the total energy demand for respiration-oxygen of $H$. atra (Mukai, Koike et al. 
1989). They calculated a total energy demand of $H$. atra in oxygen to be around 1.35 $\pm 0.811 \mathrm{mlO}_{2} \cdot \mathrm{h}^{-1} \cdot \mathrm{ind}^{-1}$ in $6.56 \mathrm{ha}$. The results imply that a lower concentration of DO than this one would be considered a non-conducive environment for small lollyfish. The fact that only the heavier-weight are found at Bairiki and Nanikai 2 is evidence for this assumption. This project would like to hypothesize that in an anoxia environment, only large or heavier lollyfish can survive, because they are more efficient at utilising low DO. This hypothesis agrees with an a recent paper stating that heavier (larger) organisms are confronted with a low food energy demand even though metabolic cost per unit biomass is lower, in other words larger organisms have more efficacy than younger ones (Sebens 2002).

Stagnant water or limited water circulation around Bairiki and Nanikai 2 is another cause of low DO in these two sites. Concentration of DO is supposed to be renewed every high tide, however, at these sites the water circulation is limited due to the geomorphology of the land (Kimmerer and Walsh 1981). The results of this circulation would cause an increase in salinity and temperature of the seawater, and this causes more oxygen to be evaporated off the water. As expected, the concentration of DO will decrease and become unavailable to other marine organisms. Therefore, it is possible to suggest that a low concentration of DO in these two areas means that they are non-conducive for young $H$. atra to inhabit. This suggestion is consistent with the observation made in the larval rearing of H.fuscogilva in Kiribati, where the new small juveniles were at the top of the raceways, where more oxygen was available, while the new bigger juveniles were found at the bottom of the raceways, where there was more food but less oxygen due to redox reactions (Sato 2000). This suggests that smaller white teatfish are less efficient in metabolising oxygen, while large or heavier ones have more efficacy at utilising low DO. If this is true, then only the heavier $H$. atra would be found in these two sites because low DO concentration in the water column (Bairiki and Nanikai 2).

Behavioural responses of $H$. atra to low DO is another factor that is worth noting when the weights of these organisms become heavier. Strategically, small and medium $H$. atra were observed forming a "ball-like" shape to roll away from these two polluted sites (Bairiki and Nanikai 2) to a place where DO is more concentration, for example, Taiwan Park. This would result in having heavier lollyfish in these two sites because they are more capable of absorbing DO from the water column. The absorption of oxygen via respiration would permit $H$. atra to produce more energy 
and metabolites, thus increasing their weight. Future research will shed more light on these findings.

The synergestic effect of organic matter and the size of the sediment sample are suggested in this project as possible causes of this heavier weight in $H$. atra from Bairiki and Nanikai 2. Both sites hold reasonably good quantities of organic matter and have a larger size of sediment which are beneficial to $H$. atra. When $H$. atra ingest sand sediment particles, they would certainly take in organic matter with bacteria. Ingestion and digestion of food obtained from sand sediments will increase the overall weight of $H$. atra. Future research will verify this assumption.

The absence of fishing activity is suggested in this project as another factor which caused the weight of $H$. atra to be heavier in certain locations. During the interviews, it was obvious that many fishermen were not fishing anymore. This was for two reasons:1) the price of dried product, and 2) the size of the harvested lollyfish. Interestingly, the fishermen were not fishing because the price offered for their dried sea cucumbers at that time was far too low when compared to the amount of work put in to get a quality dried product. This period of no fishing activity or no taking of lollyfish had allowed more small and medium lollyfish to grow larger and already heavy lollyfish to become even heavier. This finding is consistent with the findings in the Baker and Howland islands where an increase in benthic communities was found because of no fishing activity (Vroom, Musburger et al. 2010). Both islands have not been inhabited for about 60 years. A baseline study conducted in 2000 and 2006 showed that there were increases in benthic communities in both islands. Fish species, such as Ctenochaetus marginatus on Howland had increased from 9.53 in 2004 to 21.89 in 2006. The same happened in Baker island, where this species increased from 16.50 in 2004 to 33.33 in 2006. In part, when no fishing activity occurs marine organisms increase. Thus, the absence of fishing of activity, animal behaviour and environmental variability in the synergetic effects of organic matter and size of the sediment sample, the water circulation and DO concentration can affect the lollyfish heavy-mean weight distribution along South Tarawa lagoon.

\subsection{4 - Variability in weight}

The spatial and temporal variability in weight of lollyfish among the 13 sites differed. The variability gave rise to three groups of populations; 1) lighter (low), 2) medium (moderate) and 3) heavy (larger). 
Low variability in the weight of lollyfish occurred in these sites Terawabono, Taiwan Park, Tengaruru, Banraeaba, Ambo and Taborio. This shows a homogeneous distribution along Tarawa lagoon. This variability represents a population of lollyfish where the weight is considered to be same in each transect. Factually, this set of data is said to be high precision, implying that they are more statistically significant.

Medium and large variabilities are represented by Nanikai 1, Teaoraereke 2 and Teaoraereke 3) and (Temakin, Bairiki, Nanikai 2 and Teaoraereke 1, respectively. Both variabilities show a heterogeneous distribution of $H$. atra weight along Tarawa lagoon. The variability is also indicative of a population of $\mathrm{H}$. atra where the weight is considered to be very different in each transect. Data obtained from these homogeneous distributions have low precision, and are thus less reliable to work with.

\subsubsection{2 - Parametric Analyses: Repeated Measures ANOVA tests}

The Repeated Measures (RM) ANOVA tests show similar results in the weight and distribution of lollyfish amongst the 13 sites based on the actual mean and variability in density of Holothuria atra. Also, RM tests show that weights between the site-byweek interactions were different, but not the weight amongst the three weeks. Differences in significance were due to environmental variability [e.g., health (water quality-DO and nutrients) ], hydrodynamics (current, water movement), size of sediment sample and organic matter, and social pressure such as fishing activities. These are some regulators of H.ara weight amongst the 13 sites.

Table 16 shows the significance difference in mean weight and variability in the weight of $H$. atra amongst the 13 sites, among the three weeks and between the site-by-week interactions. Figure 13 supports that the actual mean weight and variability in density of $H$. atra amongst the 13 sites was significantly different.

The weight distribution of $H$. atra over time is shown in Figure 14, depicting that the actual mean-weight and variability in density of $H$. atra amongst the three weeks was not significant. It also reveals a slow growth in weight from week one to week three, indicating recruitment had occurred over time. This increase in weight is surmised as being due to $H$. atra having migrated with the water movement. Suggested reasons for migration are that they are searching for conducive habitats (DO and nutrients). This finding agrees with the idea that sea cucumbers can move to 
another place when there is not enough DO available and nutrients in any environment (U.S.EPA 2000; Uthicke 2004). From week 3 to week 5, the weights of the $H$. atra remained stable. This stable weight may have been caused by equal rates of reproduction (sexual and asexual) balanced by mortality rate and recruitment (migration) (Ebert 1993; Lee, Byrne et al. 2008). Sea cucumbers can migrate, but only few species have been observed in the field (Conand and Byrne 1993; Conand 1993b; Uthicke 2001).

Figure 15 shows the overall variations in mean-weight of lollyfish between site-by-week interactions are significantly different. Difference in significance was due to the environmental variability [(health, such as water quality (DO and nutrients), hydrodynamics (jets, currents and water movement), size of sediment sample, organic matter)], and fishing activities.

Table 17 supports that figure 12 that the mean-weights of lollyfish in different sites were statistically different. Figure also has similar group of populations: 1) light (low)-mean weight, 2) medium (moderate-mean weight) and 3) heavier (larger-mean weight) lollyfish. Differences in these groups of population of lollyfish can be explained using environmental variability [(health, for example, water quality (DO and nutrients), hydrodynamics (jets, current and water movement), size of sediment sample, organic matter)], and fishing activities.

Table 18 shows $68 \%$ significance in mean-weight of lollyfish amongst the 13 sites. This test showed similar results obtained from KW tests depicted in Table 15 which was significant too.

Thus, the differences exhibited in the mean-weight distribution of lollyfish were associated with marine environmental variability in site health where there is low DO due high pollutants and nutrients, hydrodynamics (eddies or jets, current and water circulation), the synergetic effects of size of sediments and organic matter, and fishing activities. The "ball-like" shape formed and used by $H$. atra may be a behavioural response or morphological feature which assists lollyfish to avoid harsh environmental variability such as anoxia water, suggesting that lollyfish can migrate from one place to another. The size of $H$. atra is a morphological adaptation that has caused the variation in their weight distribution. 


\subsection{4 - Biomass distribution}

Kruskal-Wallis and Repeated Measures ANOVA tests revealed statistically that the biomass of $H$. atra amongst the 13 sites, amongst the three weeks, and between siteby-week interactions differed significantly.

\subsubsection{1 - Nonparametric analyses}

Differences in the actual mean-ranked biomass and variability (SD) in biomass were caused by environmental variability [health e.g., water quality (dissolved oxygen and nutrients), hydrodynamics (water currents and movements), habitat types, size of sediment sample, and organic matters], and fishing activity.

\subsubsection{1 - Actual mean-biomass}

Based on the actual mean-biomass, three distinct groupings of populations were formed: 1) lighter or low, 2) medium or moderate, and 3) high.

\subsection{1 - Low-mean biomass}

The low mean-biomass of $H$. atra observed in Temakin, Terawabono, Bairiki, Nanikai 1 and Nanikai 2 was caused by environmental variability [such as aquatic health (dissolved oxygen and nutrients)], fishing and asexual reproduction. This low mean-biomss observed in these five sites was associated with the site health which had been described as highly polluted, (except for Bairiki and Nanikai 1 (Table 1)). Bairiki and Nanikai have been labelled as 'clean' only at the beach side, but $100 \mathrm{~m}$ down toward the lagoon sides an abundance of dead rotten brown algae were predominant on seagrass beds. Technically both these sites were not clean but highly polluted. Decaying brown algae from these two sites and pollutants (e.g., organic matter, leachates, and etc) from Temakin, Terawabono, and Nanikai 2 caused the dissolved oxygen (DO) concentration in the water column to be decreased.

DO is a good indicator of quality water and the aquatic health (Quigg, Broach et al. 2009). Every living marine organism is dependent on DO and nutrients in water columns for their proper development when temperatures are right (Slack 1971; Chao, Chen et al. 1992; Cerco and Cole 1995). If DO concentration in the water column is low, then it means that the organisms will not develop properly. The same is true for H. atra that are found living around here, they would not develop properly because of low DO (anoxia). This suggests that there is low productivity in these sites 
Temakin, Terawabono, Bairiki, Nanikai 1 and Nanikai 2, which leads to a low $H$. atra gonad development. It is assumed that this low gonad development would result in $H$. atra having a low-mean biomass. The absence of literature on the low-mean biomass of $H$. atra opens the way for future research to verify this assumption.

Fishing activity is a suggested as another cause for the $H$. atra low-mean biomass at the five sites (Temakin, Terawabono, Bairiki, Nanikai 1 and Nanikai 2). These sites are located near large villages whose inhabitants fished $H$. atra from time to time. Removing many individuals of $H$. atra from the flat sands through fishing activity causes the species density to dwindle and indirectly affect the $H$. atra biomass. When the Holothuria atra density is low, then their biomass will also be low. This study agrees with findings from research conducted on the organic content and biomass of Abyssal Holothuroids from the Bay of Biscay, which found that the low biomass was correlated with low in density of the holothuroids (Sibuet and Lawrence 1981; Uthicke 2001).

Another possible explanation for this low-mean biomass was due to the low asexual reproduction rates. Production of lollyfish through fission would increase their density. However, when there is no fission, then the density of lollyfish will decrease. This assumption agrees with recent work where the author mentioned that low biomass in both species, Holothuria atra and Stichopus chloronotus was due to the low rates of transverse fission. It may be possible that this population had gone through fission and much of their reproductive organs had all gone, making them not eat and this would lead to the reduction in their weight (Uthicke 2001) Transverse fission has been identified by many as an alternative reproductive strategy to the normal sexual reproduction of $H$. atra (Ebert 1978; Harriott 1982; Chao, Chen et al. 1992). Thus, low recruitment due to asexual and sexual reproduction, environmental variability in health conditions, and high intensity of fishing are suggestive factors contributing to the variations in low biomass of lollyfish.

\subsection{2 - Medium-mean biomass}

The second population group was the medium-mean biomass in these three sites (Teaoraereke 1, Teaoraereke 2, and Teaoraereke 3). This phenomenon of mediummean biomass of $H$. atra in these three sites was strongly related to the environmental variability. This variability in aquatic health conditions in association to low water quality depicting DO and nutrients, hydrodynamics (water movement, current, etc), 
organic matter, size of sediment sample and fishing activity affects the medium-mean biomass of $H$. atra.

Aquatic health for these three sites was partially polluted (clean) according to Table 1. It is worth noting that these sites are clean and not too far from the seagrass beds. It is possible to postulate that the clean health of these sites and their closeness to the seagrass beds are indications of moderate DO concentration in the water column. DO is an indicator for the water quality, and aquatic health, which is also essential for living organisms for their respiration and the oxidation of other organic matter (Cerco and Cole 1995; Quigg, Broach et al. 2009). Because these sites were close to seagrass beds, it was expected that a reasonable amount of DO concentration would diffuse through them. With sufficient oxygen available to them, the $H$. atra could ingest sediment with organic matter and assimilate them physiologically for their growth and development. As they continue feeding and growing, their mean weight and biomass will grow proportionally.

Moderate fishing activity is another possible reason to this medium-mean biomass. This moderate fishing activity could be associated to a low price of the lollyfish. Because of this concern, it was likely that many fishermen would not go out fishing. They would rather wait until the price increases in the future. So, this lack of fishing activity would add more lollyfish to these sites. As time passed on, many of them would become bigger and heavier, and thus causing the density, weight and biomass to change. Similar observations have confirmed this suggestion (Miller 2008; Vroom, Musburger et al. 2010). Thus, environmental variability and fishing play essential role in regulating lollyfish medium-mean biomass.

\subsection{3 - High-mean biomass}

The last group of population was the heavy-mean biomass $H$. atra found in these sites (Taiwan Park, Tengaruru, Banraeaba, Ambo and Taborio). This population group had a high-biomass because of these four indices: 1) health site, 2) organic matter, 3) sediment size, 4) fishing activity. As an example of environmental variability the health condition of these five sites were classified as three clean, one partially polluted and one polluted. Although, Tengaruru and Banraeaba were classified as polluted and partially polluted, the actual site where the surveys were carried out were closer to the seagrass beds. Therefore, they should be called 'clean' or 'excellent'. 
The observed high-mean biomass in the five sites (Taiwan Park, Tengaruru, Banraeaba, Ambo and Taborio) is suggested to be correlated with high DO concentration in the water column surrounding these five sites. All these five sites are surrounded with oceanic water enriched with nutrients and oxygen (Kimmerer and Walsh 1981). At high tide, this water enters the lagoon at three points; 1) the causeway, 2) the boat channel, 3) the constriction between Ambo and Taborio (Fig 1). Eddies and jets are often created during the incoming of this water which enhances more absorption and dissolving of atmospheric oxygen in to the water column. In this way, more DO available to organisms in the water. Prolonged exposure of reef flats during low tide (emersion) is another way in which oxygen concentration can be increased. Entrapment of oxygen underneath the stones and rocks during low tide is another source of DO for the lagoon (Taiwan Park and Taborio). Seagrass beds are the third source of DO for marine organisms at all sites except Taiwan Park and Taborio. Seagrass releases oxygen during photosynthesis which dissolves in the water column can be used in respiration and other redox reactions (Yarbro, Carlson et al. 2008).

When considering the synergetic effects of high DO concentration from these sources, nutrients and the absence of pollutants in these sites, it is possible that these sites had a higher capacity to support a high density of lollyfish which would indirectly cause an increase in the biomass of $H$. atra. This assumption agrees with a recent studies where it was concluded that a reduction in biomass of Abyssal holothuroids was due to a reduction in weight (Sibuet and Lawrence 1981). High DO concentration in the water column in these three sites is vital for the proper growth development and reproduction of any organism including $H$. atra (Cerco and Cole 1995; Quigg, Broach et al. 2009).

The absence of fishing activity is suggested in this project as another factor which caused the heavy-mean biomass of $H$. atra in the five sites (Taiwan Park, Tengaruru, Banraeaba, Ambo, and Taborio). This period of no fishing activity or no taking of lollyfish had allowed more small and medium lollyfish to grow larger and heavy lollyfish to become heavier. During this time, more recruitment are expected because there are more adults now which have reached their reproductive age and could contribute to the reproduction of new juveniles. No fishing could also allow more adults to migrate from others sites to these five sites in search of for more conducive environments. Therefore, this project suggests that the no fishing activity 
increases the biomass of $H$. atra. Fishery recovery due to the decline in fishing activities has been globally recognised as a logical management tool in building up the depleted marine stock (McClanahan and Arara 1996).

\subsection{4 - Variability in biomass}

The spatial and temporal variability in the biomass of lollyfish among the 13 sites differed. The variability gave rise to three groups of populations; 1) lighter (low), 2) medium (moderate) and 3) heavy (larger) as depicted in Fig 16.

Low variability in the biomass of lollyfish occurred in these sites (Temakin, Terawabono, Bairiki, Nanikai 1 and Nanikai 2), which shows a homogeneous distribution along Tarawa lagoon. This variability represents a population of lollyfish where the biomass is considered to be the same in each transect. Factually, this set of data are said to be of high precision, implying that they are more statistically significant.

Medium and heavy variability biomasses are represented Teaoraereke 1, Teaoraereke 2, and Teaoraereke 3 and Taiwan Park, Tengaruru, Banraeaba, Ambo and Taborio, respectively. Both variabilities show a heterogeneous distribution of $H$. atra biomass along Tarawa lagoon. The variability is also indicative of a population of $H$. atra where the biomass is considered to be very different in each transect. Data obtained from these homogeneous distributions have low precision, and are thus less reliable to work with.

\subsubsection{2 - Parametric Analyses: Repeated Measures ANOVA tests}

The Repeated Measures (RM) ANOVA tests show similar results with KW tests in the biomass distribution of lollyfish amongst the 13 sites based on the actual mean and variability in biomass of Holothuria atra. Also, RM tests show that biomass among the three weeks and between the site-by-week interactions were different (Table 20). The biomass distribution of $H$. atra among the 13 sites (Fig. 17), over time (Fig. 18), between the site-week interactions (Fig. 19) are all different. Table 21 and 22 confirm significantly that the RM tests were consistent with the KW tests. Differences in significance were due to environmental variability [e.g., health (water quality-DO and nutrients)], hydrodynamics (current, water movement)], and fishing activities. These all acted as regulators of H.ara biomass amongst the 13 sites, amongst three weeks, and between the site-by-week interactions. 


\section{3 - Environmental survey}

Organic matter content of the 13 sediment samples and the size of sediment has been used to find any commonality in the spatial and temporal changes in density, length, weight and biomass of Holothuria atra along South Tarawa lagoon.

\subsection{1 - Organic matter}

The spatial variation in organic matter content of the 13 sediment samples obtained from the 13 sites is depicted in Table 20 and Figure 20.

\subsubsection{Density}

Figure 20 shows a linear gradient with an upward trend in organic matter from Temakin to Taborio. It is evident from Figure 20 that the spatial distribution of organic matter found in each site is more correlated to the change in density of $H$. atra as depicted in Figure 3. The increase in organic matter in the sediment of each site is well reflected in the increase of density, suggesting that density is nutrientdependent. Thus, it is possible to infer that the $H$. atra density had increased because the organic matter had increased. In other words the low, medium and high rates of organic matter are reciprocally related to the low, medium and high density of $H$. atra. This suggestion agrees with the results of others researchers (Uthicke 1997; Uthicke 2001).

\subsubsection{2 - Length}

Figure 20 shows no relation at all with the actual mean length of $H$. atra in the 13 sites as depicted in Figure 7. Figure 7 shows no obvious trend which is comparable to Figure 20. Although Figure 7 was statistically different by showing an effect, it was hard to explain the difference in length in relation to the organic matter composition in the sediment. Despite the lack of consistency and parallelism in both graphs, it is known that the variability in food supply is one of the major controlling factors in any benthic organism population, especially holothurians (Moriarty 1982). It is also known that without eating they would not grow to a mature reproductive age (Conand 1993). 


\subsubsection{3 - Weight}

Figure 12 shows the mean weight distribution of Holothuria atra found in the 13 sites at Tarawa lagoon. The fluctuation gradient in this figure is a reflection of the kind of food materials (organic matter and etc) present in the sediment which caused the variability in $H$. atra weights. However, Figure 20 shows an upward trend in the gradient showing the variability in distribution of organic matter amongst the 13 sites in South Tarawa lagoon too. Both graphs display different trends with no sign of commonality visible to be explained. At this point, it is enough to say that there is no compelling evidence to support that the organic matter had influenced the variability in $H$. atra weight. While it is well-known that $H$. atra feed on organic matter in the sediment, this study's results show no relation between the weight of lollyfish the and the organic matter (Massin and Doumen 1986; Mahmoud and Ahmand 2006).

\subsubsection{4 - Biomass}

Figure 16 shows three population group of Holothuria atra, low, medium and high biomass. Figure 16 shows an upward trend or an increase in biomass from the Temakin to Taborio site. This increase in H. atra biomass corresponds to the increase in organic matter of the 13 sediments as depicted in Figure 20. This means that the $H$. atra of low or light, medium and heavy biomass are conformed to the presence of low, medium and high amount of organic matter. Thus, $H$. atra with low biomass would exist in sites with low organic matter. Those with medium biomass be found with medium organic matter to feed on. Lastly, those with the high biomass would be found in sites with the largest organic matter composition available for them as their food. Variability in supply of food may cause differences in $H$. atra biomass (Moriarty 1982; Higgins 2000). Thus, organic matter in the sediment is one of the regulating factors for the variability in $H$. atra biomass.

\subsection{2 - Size of sediment}

The spatial distribution in the variability of sediment size amongst the 13 sites at South Tarawa is an environmental factor which may regulate the Holothuria atra density, length, weight, and biomass. Table 24 and Figure 21 show the 13 variations in sediment sizes for the 13 sites, suggesting that sediment sizes are different from one site to another. 


\subsubsection{Density}

There was no conclusive evidence found for the connection between the spatial variability of sediment size as presented Tables 23, 25 and Figure 21 and the connection to the variation in $H$. atra density as presented in Figure 3. This might suggest that $H$. atra is a generalist when considering the particle size of bottom sediment. This suggestion agrees with other scientists view where they stated that $H$. atra was a non-selective species (Lawrence 1979; Massin and Doumen 1986). Although this project could not produce feasible evidence in explaining the relation between the sizes of sediments to the variation in density, the sediment permeability and porosity may do. Smaller size particles would have less permeability than the larger size particles. The larger size particles would have more oxygen than the finer sized particle sediment. Therefore, it is hypothesized that a high density of $\mathrm{H}$. atra corresponds to large size sediment with a high DO concentration or to smaller size sediment with high DO due to seagrass beds or eddies.

\subsubsection{2 - Length}

The size of sediment cannot explain the variations observed in $H$. atra length. However, fine-grained sediments hold more organic matter than the large or sandy sediments (Sørensen, Glazer et al. 2007). This suggests that H. atra can grow into longer sea cucumbers because there is plenty of organic matter to feed on, whereas in sandy sediments they will grow slower because there is less organic matter to feed on.

\subsubsection{3 - Weight}

The variability in $H$. atra weight as depicted in Figure 12 is due to the size of sediment sample ingested by the holothurian. The weight of $H$. atra can be increased or decreased depending on the amount of sediments being ingested (Moriarty, Pollard et al. 1985; Uthicke 1999). When $H$. atra ingests more sediments, its weight increases and, thus it becomes heavier due to the assimilation of organic matter (Mangion, Taddei et al. 2004). Conversely, when H. atra consume less sediment, they become lighter because there is less organic matter. 


\subsubsection{4 - Biomass}

It is difficult to offer any explanation for the relationship between the spatial variability in biomass as depicted in Figure 16 and the size of the sediment samples obtained from the 13 sites. However, this project surmises that $H$. atra could increase and decrease their biomass by ingesting sediment samples. By ingesting sediment their biomass increased while their biomass decreased when they did not ingest any sediment. This hypothesis is consistent with past works implying that $H$. atra can ingest much sediment and assimilate much organic matter from it (Moriarty, Pollard et al. 1985; Mangion, Taddei et al. 2004). Sediment is important for H. atra as it collects organic matter for them. Fine sediment collects more organic matter but less DO while larger sized sediment collects less organic matter but more DO.

\subsection{Summary paragraph}

The correlation analyses indicate that none of the environmental (sediment property) variables explains variation in the biological properties of the sea cucumbers. Whilst it is well established that factors such as sediment grain size and sediment organic matter content do effect benthos distribution and abundance (add in references here), this is apparently not the case for the 13 study sites within Tarawa lagoon. This may be the case because some other environmental factor or combination of factors has greater explanatory power, or it may be because no such relationships are now apparent as a result of heavy fishing pressure at some or perhaps all sites. This matter is addressed in the next section.

\section{5 - Fishing Pressure}

\subsection{1 - Variability in distribution and abundance of Holothuria atra}

At least some of the spatial and temporal variability in distribution and abundance of $H$. atra in the lagoon at South Tarawa was due to fishing activity as shown in Figure 22. Fishing activities are a human created problem, which have been associated with the depletion of marine resources such as sea cucumbers (Uthicke 2004). This problem of sea cucumber depletion is also common in Kiribati (Tangai and Sopolu 2006). When fishing activity affects the density of $H$. atra, the length, weight, and 
biomass are also affected. Even their spatial and temporal abundance and distribution can be affected.

Sites that are situated adjacent to densely populated villages are more subject to overfishing than those sites which are more remote from the villages. Therefore, the sites that are further from the villages do have higher $H$. atra density and abundance than the sites which are closer to the villages. In this project, fishing sites that are further from the villages are Ambo, Taborio, Causeway (Taiwan Park), Bikemaan and Bikenimatang. In these sites it is expected that the $H$. atra density should be high. Temakin site is an example of the most heavily fished site, according to Figure 24.

The frequency and intensity of fishing activity for $H$. atra were primarily controlled by the monetary needs of the people, the price, size and the availability (abundance) of the lollyfish. For these reasons, the fishermen fished for different lengths of time, some fished only for a week while others fished for more than a week. On average, a fisherman would catch 51 lollyfish per day at an average depth $0.5 \mathrm{~m}$, and a minimum and maximum depth of $0.5 \mathrm{~m}$ and $1.5 \mathrm{~m}$. If one extrapolates this catch to a yearly figure, it would amount to $1,861,500$ pieces, for just twenty people. But, there are more than twenty lollyfish fishermen in Kiribati, so the expected total number of lollyfish harvested for five years would be more than the carrying capacity of the coastal shores could offer. This implies that the lollyfish fishery may not be sustainable for the people.

The fishermen would stop harvesting lollyfish after a month due to the scarcity of the sea cucumber. The fishermen associated this scarcity in lollyfish with the change in sea cucumber habitats. This suggestion supports the idea that either the lollyfish had migrated to new places or they may have been already overfished. Harvesting lollyfish in Kiribati, especially in South Tarawa, is associated with other the collection of other marine plants and animals. Examples such as te nouo (Strombus luhuanus), te iaia (sea hare mass-eggs) and te bun (Anadara uropigimelana) were commonly fished along with lollyfish. However, the $S$. luhuanus was more exploited than the others because of its high economic value.

Holothuria atra were normally fished in the months of June, July and December. The high peak in fishing during these three months corresponds to the Kiribati public holidays; for example Independence Day in July and Christmas in December. One of the reasons for fishing in these months was to support the family 
financially. June and December were the two best months for fishing lollyfish. The fishermen did not know the worst time for fishing. This indicates that the people were only part-time lollyfish fishermen.

The fishing status of lollyfish in South Tarawa lagoon for the past 10 year period and the past 20 year period both showed that it is much worse. The sustainability of the lollyfish was not viable. Subsequently, the sustainability of the fishery at Tarawa lagoon does not portray a viable or encouraging outlook for the fishermen. It was thought and perceived that overfishing was the single greatest threat to the ongoing sustainability of the lollyfish fishery, while others thought pollution and algae were also threats to the ongoing sustainability of the lollyfish fishery. Thus, fishing activity contributes immensely in the variability of Holothuria atra density, length, weight, biomass and its distribution pattern along South Tarawa lagoon. Presently, the Fisheries Department is carrying out the management of sea cucumber species in Kiribati.

\section{6 - Conclusions and Recommendations}

In conclusion, this study shows that the current status of tropical sea cucumber Holothuria atra or lollyfish amongst the 13 sites on South Tarawa's lagoon varies according to the environmental variability, animal responses and fishing activity.

Using site health as an example of environmental variability, the influence of hydrodynamics in creating eddies and jets as the source of dissolved oxygen (DO), is one of the most important regulating factors for the observed distribution patterns of $H$. atra at the 13 sites. It is also certain that the presence of seagrass beds and the greater porosity of sediment facilitate the increase in DO in the water which affects the $H$. atra density, length, weight, and biomass distribution. The high level of DO concentration in the water is an indicator of a healthy ecosystem (Quigg, Broach et al. 2009). The suggests that lack of DO due to pollutants in the water is lethal to the survival of sea cucumber $H$. atra (Yamanouchi 1939). Thus, the variation in the biological data of the $H$. atra observed in the 13 sites is due to the variation in the DO concentration in the water, suggesting that site health is one of the determining factors. 
Behavioural responses such as migration of $H$. atra from one site to another by rolling during the high tide is suggested here as another determining mechanism that affects the biological data amongst the 13 sites on South Tarawa lagoon. This migration is associated with the environmental variability such as the change in the DO concentration in the water (Cerco and Cole 1995).

Other environmental variability in organic matter and the particle size of the sediment sample are not such important factors in determining the variability in the biological data of $H$. atra along the 13 sites on South Tarawa lagoon. However, the suspended organic matter may be more important in areas of high flowing water such as the channel at Betio-Bairiki causeway.

Although, this thesis has established the stock status of lollyfish in South Tarawa lagoon by using the effects assessment of the environmental variability and fishing pressure, it is evident that there is a lack of information concerning the effect of dissolved oxygen (DO). The argument for the long-term influence of environmental variability in lollyfish distribution and abundance has not been completely solved. However, this thesis proposes a future research based on the assessment effects of DO concentration upon lollyfish distribution and abundance in association with the variability in food supply. This future study should bring more light to the present understanding of the lollyfish distribution patterns. At the present, the effect of DO in relation to lollyfish distribution is poorly understood, thus, it makes the research cutting edge.

Understanding the effects of DO upon lollyfish is essential because it is one of their basic needs. As part of this research, the behavioural responses of lollfish to various DO concentrations in the water should be tested and investigated. Hopefully the results from this research should provide important answers in the aspects of lollyfish migration from low DO to high DO or vice versa. By doing this research, a real cause of the lollyfish distribution patterns would be better understood.

Fishing activity is another determining factor that can regulate the biological data of $H$. atra amongst the 13 sites of South Tarawa lagoon. The effect of fishing pressure upon the $H$. atra population distribution along these sites is more common in the sites that are closer to highly populated villages than in the remote ones. Thus, the environmental variability and fishing pressure can alter the biological data of $H$. atra across the 13 sites in South Tarawa lagoon. 
The project acknowledges the facts that certain problems were encountered during the course of doing the surveys. In particular, it is worth mentioning that the project has limitations in accuracy in measuring the actual length, weight, and biomass of Holothuria atra. These limitations arose because of the difficulties in the elasticity of the sea cucumber (Sewell 1991). For example, errors in the length of the animal may occur over the three surveys because the animals were not fully relaxed when measurements were taken. This means that the actual mean length of each animal should have a margin of error. In fact it is difficult to put this margin error in the actual measurements because the elasticity expansion of this species is not known. Another error may be derived from the actual mean weight of $H$. atra which was caused by excess water and sediments inside the animals. All these would cause the increase in weight and biomass of the sea cucumber, thus, making the measurements less reliable to work with.

This project shows that $H$. atra fisheries in South Tarawa are under severe fishing pressure, therefore I would like to make several recommendations for the preservation and management of the marine source, lollyfish. It would be highly desirable for the Government in conjunction with the stakeholders to protect and manage this marine resource in sustainable ways before it becomes depleted and extinct from the wild. Given the fact that I was supposed to be working on teatfish, and could not find any broodstock as it is already low in abundance. Similar situation could happen to lollyfish if not managed sustainability. In order to achieve this sustainable level of lollyfish fisheries, both the Government and the stakeholders should form a national committee whose functions are to govern the overall management and exploitation of lollyfish. The committee should thoroughly cover the areas of resource regulations and interventions including the seasonal closures, area closures, size limits, gear restrictions, licensing, restocking, education and extension, and research. Stated below are some suggested effective tools for the management of the lollyfish fishery.

Firstly, the fisheries should develop and implement suitable stock assessment and monitoring programmes for Holothuria atra equivalent to white teatfish run by OFCF. These could be achieved if the fisheries' authorities could work in partnership with recognized institutions such as the Secretariat of the Pacific Community (SPC) or University of the South Pacific. An efficient system for managing and archiving 
information about total catch and export trade statistical reports would be the outcome of this consultation.

Secondly, there should be a continuous research grounded on the biology, fisheries and trade of lollyfish. Other important parameters including studies on growth, mortality and recruitment of lollyfish stock are essential for lollyfish fisheries' management.

Thirdly, there is great need to build the country's capacity to control and manage the lollyfish fishery. However, such measures as surveillance, enforcement and training come with costs. Fisheries officers and lollyfish stakeholders who are involved in this country's capacity building should be knowledgeable about the exportation survey, data collection and monitoring, which could be used to implement management interventions.

Fourthly, the fisheries authorities and the stakeholders should develop lollyfishspecific management plans, including specific regulations such as regulations on gear use, size limitations, seasonal and depth closures, and total allowable catches. In addition, action plans should: a) be founded on the most trusted scientific facts; b) consider the most feasible and preventative measures of fisheries' management; and c) incorporate stakeholders at the implementation of the management strategic plan.

Fifthly and fnally, it is important to educate the stakeholders about harvesting, processing and adding value to $H$. atra or lollyfish in its dried form as "beche-demer" in order to get the best price. Also, it is essential to develop a land-based hatchery or mariculture where more lollyfish could be produced commercial and restocking purposes. It is envisaged that the fisheries' authority in conjunction with the stakeholders should establish Marine Protected Areas (MPAs) as a tool for the conservation and management of the lollyfish fishery. There is a whole programme of locally managed marine areas (LMMAs) in Fiji set-up by Bill Aaalbersberg at USP (http://www.Immanetwork.org). 


\section{References}

Abdel-Razek, F. A., S. H. Abdel-Rahman, et al. (2005). "Reproductive biology of the tropical sea cucumber Holothuria atra (Echinodermat : Holothuroidea) in the Red Sea coast of Egypt." Egyptian Journal of Aquatic Research 31(2): 16874285 .

Akamine, J. (2004). "The status of sea cucumber fisheries and trends in Japan: past and present. P. 39-47." Advances in sea cucumber aquaculture and management. A Lovatelli (com,/ed.); Conand, C; Purcell. S; Uthicke,S; Hamel, J-I; Mercier, A. (eds) FAO FisheriesTechnical Paper. 463.

Alexandra, H. (1994). "The beche-de-mer industry in the Solomon Islands: recent trends and suggestions for management." SPC Beche-de-mer Information Bulletin 6 2-9.

Asmedi, R. (2009). "Sea cucumber: a promising mainstay commodity. Oxfarm, Great Britain."

Baker, J. R. (1929). "On the zonation of some coral reef Holothuria." J.Ecol. 17: 141143.

Bakus, G. J. (1968). "Defense mechanisms and ecology of some tropical holothurian " Marine Biology 2: 23-32.

Bakus, G. J. ( 1973). " The biology and ecology of tropical holothurians. In: Jones, O.A., Endean, R. (Eds.), ." Biology and Geology of Coral Reefs. VII. Biology 1. Academic Press, New York, : 325-367.

Battaglene, S. C. (1999). "Culture of Tropical Sea Cucumbers for Stock Restoration and Enhancement." Naga, The ICLARM Quarterly 22(4): 4-11.

Bruckner, A. W., K. A. Johnson, et al. (2003). "Conservation strategies for a sea cucumbers:Can CITES apendix ii. Listing Promote Sustainable Interntional Trade,." SPC Beche-de-mer Information Bulletin 18: 24-32.

Cerco, C. F. and T. Cole (1995). Users guide to the CE-QUAL-KM Three Dimensional Eutrophication Model, Release Version 1.0, . Technical Report EL-95-15, U.S Army Corps of Engineers Waterways Experiment Station. Vicksbury, MS.

Chao, S. M., P. C. Chen, et al. (1992). "Fission and its effect on population structure of Holothuria atra (Echinoderamata:Holothuroidea) in Taiwan." Marine Biology 116: 109-115.

Clark, A. M. and W. E. Rowe (1971). "Monograph of shallow water Indo-West Pacific echinoderms." Br.Mus.Nat.Hist.Publ. 690: 1-238. 
Conand, C. (1981). "sexual cycle of three commercially important Holothurian species (Echinodermata) from the Lagoon of New Caledonia." Bullentin of marine science 31(3): 523-543.

Conand, C. (1990). "The industry past and present in the South Pacific Countries: Part 2. Holothurian." FAO Fisheries Technical Paper

Conand, C. (1993). "Reproductive biology of the holothurians from the major communities of the New Caledonian Lagoon." Marine Biology 116( ) ): 439450 .

Conand, C. (1993b). "Ecology and reproductive biology of Stichopus variegatus, an Indo-Pacific coral reef sea cucumber (Echinodermata:Holothuroides)." Bulletin of Marine Science 52: 970-81.

Conand, C. (1996). "Asexual reproduction by fission in Holothuria atra: variability of some parameters in populations from the tropical Indo-Pacific " Oceanol Acta 19: $209-216$.

Conand, C. (1997). "Are holothurian fisheries for export susutainable? ." Proceedings 8th int coral Reef Symp (Lessios: HA, Macintyre I (eds). Smithsonian Tropical Research Institute, Panama 2: 2021-2026.

Conand, C. (1998). "Holothurians. In: K.E, Capenter and V.H Niem (eds). FAO species idenitification guide for fishery purposes. The living marine resources of the Western Central Pacific. Volume 2. Cephalopods, Crustaceans, Holothurians and sharks. FAO. Rome.".

Conand, C. and M. Byrne (1993). "A review of Recent Developments in the World Sea Cucumber Fisheries." Marine Fisheries Review 55(4): 1-13.

Dean, W. E. (1974). "Determination of carbonate and organic matter in calcareous sediments and sedimentary rocks by loss of ignition: Comparison with other methods." J.Sed.Petrol 44: 6.

Denton, G. R. W. and R. J. Morrison (2009). "The impact of a rudimentary landfill on the trace metal status of Pago Bay, Guam." Marine Pollution Bulletin 58: 150162.

Dilek, I.-E. and G. Denis (2007). "The effect of sea cucumber Holothuria tubulosa (G.1788) on nutrient and sediment of Aegean Sea Shore." Pakistan Journal of Biological Sciences 10: 586-589.

Donald, L. B., R. E. Nakatani, et al. (1975). " Effects of Salmon Cannery Wastes on Water Quality and Marine Organisms, ." Journal (Water Pollution Control Federation) 47(7): 1857-1869.

Ebert, T. (1978). "Growth and Size of the Tropical Sea Cucumber Holothuria (Halodeima) atra Juger at Enewetak Atoll, Marshall Islands." Pacific Science 32(2): 183-191. 
Ebert, T. A., Ed. (1993). Recruitment in echinoderms. Echinoderms Studies, AA Balkema: Rotterdam.

Eriksson, H. ( 2006). " The Subsistence and Artisinal Sea cucumber Fishery, with Particula Focus on Stichopus horrens in Samoa. In: Sea cucumber Abundance, Diversity and Fishery in Samoa: An Assessment of Lagoon Occurring Species. ." Uppsala University Minor Field Study 122: 54-73.

Fabianek, F. T., A. ( 2005). "Distribution des populations d'holothuries peuplant le récif de St Gilles/La Saline, à l'île de La Réunion." Report. MBPE, Univ. de La Réunion: 1-33

FAO (2008). "The industry past and present in the South Pacific." FAO Fisheries and Aquaculture Technical Paper 272.2.

Fox, J. J. and S. Sen (2002). "A study of socio-economic issue facing traditional Indonesian fishers who access the MOU box." A report for Environmental Australia: 64.

Friedman, K., S.Purcell, et al. (2008). "Changes in the composition and relative abundance of species are therefore a good indicator of overfishing." ACIAR: Research taht works for developing countries and Australia.

Harriott, V. J. (1980). "The ecology of holothurian fauna of Heron Reef and Moreton Bay." Master Thesis, Zoology Department, University of Queensland, Australia: 1-153.

Harriott, V. J. (1982). " Sexual and asexual reproduction of Holothuria atra at Heron Island Reef, Great Bamer Reef." Mem. Aust. Mus. 16: 53-66.

Harriott, V. J. (1985). "Reproductive biology of three congeneric sea cucumber species, Holothuria atra, H.impatiiens and. H. edulis, at Heron Reef, Great Barrier Reef." Aust.J.Mar.Freshw.Res. 36: 51-57.

Higgins, M. (2000). "Sea cucumber in deep pickle, environmental new feeder Stichopus japonicus on algal bloom and organic matter contents of bottom sediments of the enclosed sea." Marine Biology 8(293-300).

Kimmerer, W. J. and T. W. Walsh (1981). "Tarawa Atoll lagoon: Circulation, Nutrient fluxes, and the impact of human wastes." Micronesica 17(1-2): 19.

Kinch, J., M. James, et al. (2007). " Socio-economic Assessment of the Beche-deMer Fisheries in the Western, Central and Manus Provinces, Papua New Guinea." Report prepared for the National Fisheries Authority, Port Moresby, Papua New Guinea.

Kinch, J., S. Purcell, et al. (2008). Sea cucumber : A global review of fisheries and trade, FAO Fisheries and Aquaculture Technical Paper. 516: 7-55.

Kiribati National Statistic Office (2005). K. N. S. Office, Ministry of Finance, P.O Box 76, Bairiki, Tarawa, Republic of Kiribati. 
Kitano, M., K. Kurata, et al. (2003). "Effects of deposit feeders Stichopus japonicus on algal bloom and organic matte contents of bottom sediments of the enclosed se." Mar.Poll.Bull. 47: 118-125.

Lawrence, J. (1979). " Numbers and Biomass of the Common Holothuroids on the Windward Reff Flat at Enewetak Atoll, Marshall Islands." Proceedings of the European Colloquium on Echinoderms 1: 210-204.

Lee, J., M. Byrne, et al. (2008). "The influence of population density on fission and growth of Holothuria atra in natural mescosms." J Exp Mar Biol Ecol 365: 126-135.

Lutz, B. R. (1930). "The effect of low oxygen tension on the pulsations of the isolated holothurian cloaca." Bermuda Biological Station for Research 158: 74-84.

Mahmoud, D. and H. Ahmand (2006). "The feeding selectivity and ecological role of shallow water holothurians in the Red Sea." Secretariat the Pacific Community 24: 11 .

Mangion, P., D. Taddei, et al. (2004). Feeding rate and impact of sediment reworking by two deposit feeders Holothuria leucospilota and Holothuria atra on a fringing reef (Réunion Island, Indian). In: Echinoderms München, Heinzeller and Nebelsick (eds.). London, Taylor and Francis,: 311-317.

Marba, N. and C. M. Duarte (2001). "Growth and sediment space occupied by seagrass (Cyamodocea nodosa) roots." Mar Ecol Prog Ser 224: 291-298.

Massin, C. and C. Doumen (1986). "Distribution and feeding of epibenthic holothuroids on the reef flat of Laing Island (Papua New Guinea) " MARINE ECOLOGY - PROGRESS SERIES Mar. Ecol. Prog. Ser. 31: 185-195.

McClanahan, T. R. and K. Arara (1996). "Fishery recovery in a coral-reef marine park and its effect on the adjacent fishery." Conservation Biology 10: 11871199.

Miller, S. L. (2008). A quantitative assessment of Raui (a traditional approach to marine protected areas) on the fishes and invertebrates of Rarotonga, Cook Islands. School of Biological Science. Wellington, Victoria University of Wellington. Doctor of Philosophy in marine biology: 228.

Moriarty, D. J. W. (1982). "Feeding of Holothuria atra and Stichopus chloronotus on bacteria, organic carbon and organic nitrogen in sediments of the GBR, Australia." J.Mar. Freshwater Res 33: 255-263.

Moriarty, D. J. W., P. C. Pollard, et al. (1985). "Productivity of bacteria and microalgae and the effect of grazing by Holothurians in sediments on coral reef flat." Mar.Biol 85(293-300).

Mukai, H., I. Koike, ,, et al. (1989). "Oxygen consumption and ammonium excretion of mega-sized benthic invertebrates in a tropical seagrass bed." $\underline{J \operatorname{Exp} M a r}$ Biol Ecol 134. 
Mulvaney, D. J. (1975). "The prehistory of Australia. Melbourne: Pelican."

Otero-Villanueva, M. and V. T. Ut (2007). "Sea cucumber fisheries around Phu Quoc Archipelago: a cross-boarder issue between South Vietnam and Cambodia." Secretariat the Pacific Community Beche-de-mer Information Bulletin 25: 5.

Paulay, G. (2000). "Benthic Ecology and Biota of Tarawa Atoll Lagoon: Influence of Equatorial Upwelling, Circulation, and Human Harvest.". Atoll Research Bulletin, 487: 1-41.

Paulay, G. and K. Alexander (2001). "Patterns of coral reef development on Tarawa atoll (Kiribati)." Bulletin of Marine Science(69): 16.

Purwati, P. (2005). "Teripang Indonesia: komposisi jenis dan sejarah perikana." Oseana 30(2): 8.

Quigg, A., L. Broach, et al. (2009). "Water quality in the Dickinson Bayou watershed (Texas, Gulf of Mexico) and health issues." Marine Pollution Bulletin 58: 896-904.

Sato, Y. (2000). "The project for the protection of environment and conservation of fishery resources in the coral reef area: Summary of the project and results." Overseas Fisheries Cooperation Foundation: 1-140.

Schoppe, S. (2000). "Sea cucumber fishery in the Philippines (1991)." SPC Bechede-mer Information Bulletin 13: 10.

Sebens, K. P. (2002). "Energetic constraints, size gradients, and size limits in benthic marine invertebrates." Oxford Journals 42(4): 853-861.

Sewell, M. A. (1990). "Aspects of the ecology of Stichopus mollis (Echinodermata: Holothuroidea) in north-eastern New Zealand." New Zealand Journal of Marine and Freshwater Research, 24: 97-103.

Sewell, M. A. (1991). "Measurement of size in live sea cucumbers." SPC Beche-demer Information Bulletin 3: 4-5.

Shick, J. M., J. Widdows, et al. (1988). "Calometric studies of behaviour, metabolism and energics of sessile intertidal animals." Am. Zool. 28: 161-181.

Sibuet, M. and J. M. Lawrence (1981). "Organic content and biomass of Abyssal holothuroids (Echinodermata) from the Bay of Biscay." Marine Biology 65: 143-147.

Slack, K. V. (1971). "Average dissolved oxygen measurement and water quality significance." Water Pollution Control Federation 43: 433-446.

Sloan, N. A. and B. v. Bodungen (1980). "Distribution and feeding of the sea cucumber, Isostichopus badionotus in relation to shelter and sediment criteria of the Bermuda Platform." Mar. Ecol. Prog. Ser 2: 257-264. 
Sørensen, K. B., B. Glazer, et al. ( 2007). "Spatial structure of the microbial community in sandy carbonate sediment." MARINE ECOLOGY PROGRESS SERIES Mar Ecol Prog Ser 346 61-74,.

SPC (1994). "Sea cucumbers and beche-de-mer of the tropical Pacific. A handbook for fishers Handbook No 8." Secretariat the Pacific Community. Noumea.

Stephenson, W., R. Endean, et al. (1958). "An ecological survey of the marine fauna of Low Isles, Queensland." Aust.J.Mar.Freshw.Res. 9: 261-318.

Tangai, A. and T. Sopolu (2006). Fisheries Division : Final Annual Report. Tarawa, Fisheries Division: 1-97.

Thistlewaite, B. and D. Davis, Eds. (1996). Sustainable future for Melanesia: Natural resources, population and development. Canberra, National Centra for Development studies and resources school of Pacific and Asia studies, National University of Australia.

Toral-Granda, M. V. (2005). "Requiem for the Galápagos sea cucumber fishery?" SPC Beche-de-mer Information Bulletin 21: 5-8.

Toral-Granda, V. (2006). "Convention On International Trade in endangered Species of Wild Fauna and Flora." Charles Darwin Foundation, Galapagos Islands.

Toral-Granda, V., A. Lovatelli, et al. (2008). "Sea cucumbers : A global review of fisheries and trade." FAO Fisheries Technical Paper 516.

U.S.EPA (2000). Ambient aquatic life water quality criteria for dissolved oxygen (salt-water): Cape Cod to Cape Hatteras, U.S.EPA. Washington, D.C, Office of Water, . 822.

UNDP (1999). "United Nations Environmental Programme: Pacific Islands Outlook, UNDP, Apia."

Uthicke, S. (1994). Distribution patterns and growth of two reef flat holothurians, Holothuria atra and Stichopus chlorotus. Echinoderms Through Time; Proceedings of the Eigth International Echinoderm Conference,. B. David, A. Guille, J. P. Feral and M. Roux. Dijon, AA Balkema: Rotterdam: 569-76.

Uthicke, S. (1997). "Seasonality of asexual reproduction in Holothuria (Halodeima) atra, H.(H) edulis and Stichopus chloronotus (Holothuroidea: Aspidochirotida) on the Great Barrier Reef." Mar.Biol 129: 435-441.

Uthicke, S. (1998). "Genetic structure of fissiparous populations of Holothuria (Halodeima) atra on the Great Barrier Reef." Marine Biology 132: 10.

Uthicke, S. (1999). "Population structure of Holothuria (Holodeima) atra ( Jager, 1833) and Stichopus Chloronotus (Brandt, 1833) (Holothuroidea: Aspidochirotida) and their role in nutrient recycling in coral reef ecosystems." Secretariat the Pacific Community 12: 33. 
Uthicke, S. (1999). "Sediment bioturbation and impact of feeding activity ofHolothuria (Halodeima) atra and Stichopus chloronotus, two sediment feeding holothurians, at Lizard Island, Great Barrier Reef. ." Bull. Mar. Sci. 64: $129-141$

Uthicke, S. (2000). "Ecology of two sediment-feeding Holothurians, Holothuria (Halodeima) atra (Ger,1833) and Stichopus chloronotus (Brand, 1835), on reefs near Lizard Island, Australia." Institut fur Hydrobilogie und Fischereiwissenschaft, Zeiseweg 9, Humburg 50, Germany.

Uthicke, S. (2001). "Influence of asexual reproduction on the structure and dynamics of Holothuria (Halodeima)atra and Stichopus chloronotus populations of the Great Barrier Reef." Marine Freshwater Research 52: 205-215.

Uthicke, S. ( 2004). "Overfishing of Holothurians: Lessons from the Great Barrier Reef. In: Advances in Sea Cucumber Aquaculture and Management. A. Lovateli, C. Conand, S. Purcell, S. Uthicke, J.-F. Hamel and A. Mercier, (eds.). pp. 163-171. Rome, FAO."

Vroom, P. S., C. A. Musburger, et al. (2010). "Marine biological community baselines in unimpacted tropical ecosystems: spatial and temporal analysis of reefs at Howland and Baker Islands." Biodivers. Conserv. 19: 797-812.

Widdows, J., B. L. Bayne, et al. (1979). "Physiological and bio-chemical responses of bivalve molluscs to exposure to air." Comp.Biochemic.Physio. 62A: 301-308.

Wildish, D. J. and D. D. Krishtmanson (1979). "Tidal energy and sublittoral macrobenthic animals in estuaries." J.Fish.Aquat.Sci 41: 1618-1625.

Yamanouchi, T. (1939). "Ecological and physiological studies on the holothurians in the coral reefs of Palae islands." Palao trop.Biol.Stat.Res.Studies 4: 603-635.

Yarbro, L., P. E. Carlson, et al. (2008). "Community Oxygen and Nutrient Fluxes in Seagrass Beds of Florida Bay, USA." Estuaries and Coasts 31: 877-897. 
